UNIVERSIDADE DE SÃO PAULO

INSTITUTO DE QUÍMICA

Programa de Pós-Graduação em Química

MARIANA FRANSIELE CIRIACO

\title{
Degradação de hidrocarbonetos policíclicos aromáticos em solos arenosos empregando processos oxidativos
}

Versão corrigida da Dissertação

$O$ original se encontra disponível na Secretaria de Pós graduação do IQ -USP

São Paulo

Data do Depósito na SPG:

10/09/2013 


\section{MARIANA FRANSIELE CIRIACO}

\section{Degradação de hidrocarbonetos policíclicos aromáticos em solos arenosos empregando processos oxidativos}

Dissertação apresentada ao Instituto de Química da Universidade de São Paulo para obtenção do Título de Mestre em Química

Orientador: Prof. Dr.Renato Sanches Freire

São Paulo

2013 
Ficha Catalográfica

Elaborada pela Divisão de Biblioteca e

Documentação do Conjunto das Químicas da USP.

Ciriaco, Mariana Fransiele
Degradação de hidrocarbonetos policíclicos aromáticos em
solos arenosos empregando processos oxidativos / Mariana
Fransiele Ciriaco. -- São Paulo, 2013 .
94p.
Dissertação (mestrado) - Instituto de Química da Universidade
de São Paulo. Departamento de Química Fundamental.
Orientador: Freire, Renato Sanches
1. Química ambiental 2. Hidrocarboneto policíclico : Composto
aromático I. T. II. Freire, Renato Sanches, orientador.
CDDamb 


\section{AGRADECIMENTOS}

Primeiramente a Deus por estar sempre presente em minha vida e por sempre iluminar o meu caminho.

A minha família pelo apoio, especialmente a minha mãe Selízia por sempre apoiar nas minhas decisões. Aos meus sobrinhos Júlia e Pedro Henrique que foram muitas vezes fonte de motivação.

A profa. e amiga Aurea de Souza Bazzi que me ensinou os fundamentos da Química. Agradeço por todos os conselhos, suas aulas foram fonte de inspiração para que me tornasse Química.

Ao prof e amigo João H.G. Lago e a amiga Cláudia Larini que juntamente foram responsáveis pela direção desta trajetória.

A Kerlly Pozzibon e Celize Tcanceco pela amizade e pelo apoio durante a execução deste trabalho.

Agradeço a Marilda Vianna por todo apoio, pelas oportunidades que me concedeu, como também por ter me apresentado ao Prof Renato Sanches Freire, o orientador deste trabalho.

Ao meu orientador Renato Sanches Freire, obrigada pela oportunidade, assim como também agradeço pelo apoio e pelas dicas preciosas, não só no âmbito da pesquisa, como também pessoal.

Aos companheiros de grupo e amigos: Aline Maxiline, Daniela Batistela, Larissa Ciccotti, Luciana Soeira e ao Thiago Hewer que demonstraram sempre ser parceiros. Especialmente as amigas Andressa Pilonetto e a Raquel Almeida que me deram um grande apoio na realização deste trabalho.

As técnicas de laboratório do IQ-USP Beatriz do Nascimento e Georgia Bloisi que sempre se mostraram disponíveis e dispostas a ajudar.

A todos os integrantes do Grupo de Pesquisa em Química Verde e Ambiental (GPQVA) e a direção de Pós Graduação do Instituto de Química USP.

Ao Departamento de Engenharia Química- Poli USP e ao grupo do Centro de Capacitação e Pesquisa em Meio Ambiente (CEPEMA) por todo ao apoio no desenvolvimento deste trabalho. Agradeço a Silvia Baeder, Fabrícia Rodrigues, Marcela 
Galluzzi e Miriam de Abreu por todo o apoio administrativo e técnico e especialmente ao Cláudio Oller, a Carminha e ao Paulo Firmino.

Agradeço ao pesquisador Ademir Fontana da EMBRAPA, por acreditar no meu trabalho, pela doação das amostras de solo e pelos momentos de aprendizado. Agradeço a sua aluna de iniciação científica Lucienne Silva Oliveira, aluna do curso de Engenharia Agronômica da Universidade Federal Rural do Rio de Janeiro pela realização das análises do teor de carbono das substâncias húmicas.

Ao prof.Cassius Vinicius Stevani pelo apoio e comentários pertinentes que possibilitou o enriquecimento do meu trabalho.

A Celyna Káritas, amiga "antraceno", compartilhamos muitos momentos de trabalho e pesquisa e os momentos de cansaço foram de muita cantoria.

A Lidiane Andrade pela amizade e pelas dicas "infalíveis" na realização deste trabalho.

A Daniely Souza, Jaqueline Felix e Zaíra dos Santos pela grande amizade de ontem, de hoje e sempre.

A Vânia Carla pelo apoio e incentivo durante a execução deste trabalho.

Ao Instituto Nacional de Ciência e Tecnologia do Meio Ambiente (INCT) e a Conselho Nacional de Desenvolvimento Científico e Tecnológico (CNPQ) pela bolsa concedida. 
"A natureza achará uma solução para a poluição causada pela civilização. A questão que permanece é se os seres humanos estão incluídos ou não(..)"

Mikhail Gorbatchev 


\section{RESUMO}

Ciriaco,M.F.Degradação de hidrocarbonetos policíclicos aromáticos em solos arenosos empregando processos oxidativos 2012.98p. Dissertação de Mestrado apresentada ao Instituto de Química da Universidade São Paulo, São Paulo.

Os hidrocarbonetos policíclicos aromáticos (HPA) são poluentes formados por dois ou mais anéis aromáticos que podem causar efeitos mutagênicos, carcinogênicos e teratogênicos aos seres humanos. Os HPA não são suscetíveis à degradação pela maioria dos micro-organismos devido a sua baixa solubilidade em água e a sorção destes poluentes na parte mineral e orgânica do solo. Uma forma de tratamento é o uso de processos oxidativos que podem degradar inúmeros contaminantes orgânicos e minerizá-los a gás carbônico e água. Neste trabalho foi avaliada a eficiência da degradação do isômeros fenantreno e antraceno, dois tipos de HPA, em areia padrão, utilizando-se como oxidantes o permanganato, peróxido de hidrogênio e persulfato ativado. De acordo com a matriz e o contaminante, após 24 horas de tratamento, verificou-se a degradação de 95 a $98 \%$ utilizando-se como oxidantes permanganato e de 34 a $62 \%$ utilizando-se a reação de Fenton. Foi identificada a antraquinona como produto do antraceno, independentemente do oxidante utilizado. Dentre os oxidantes, avaliou-se o persulfato ativado com ferro para a aplicação em solos arenosos contaminados com HPA. Quando se utilizou persulfato ativado com ferro em areia padrão houve a decomposição, após 24 horas de tratamento, de 60 e 95\%, de fenantreno e antraceno, respectivamente. Em solos arenosos utilizando-se o persulfato, a degradação dos contaminantes foi predominantemente inferior devido ao possível efeito de matriz. Em contrapartida praticamente não houve a decomposição das substâncias húmicas. Esta é característica favorável, pois não houve a competição da matéria orgânica com o contaminante pelo persulfato, além de não promover alterações no teor de carbono presente no solo. Palavras-chave: solo, processos oxidativos, matéria orgânica, HPA. 


\begin{abstract}
Ciriaco, M.F. Degradation of polycyclic aromatic hydrocarbons in sandy soils employing oxidative processes. Ano 2013. Número de páginas (98p.). Masters - Graduate Program in Chemistry. Instituto de Química, Universidade de São Paulo, São Paulo.

Polycyclic aromatic hydrocarbons (PAH) are pollutants formed by two or more aromatic rings that can be mutagenic, carcinogenic and teratogenic to humans. PAH do not undergo degradation by most microorganisms due to this low water solubility and adsorption in the mineral and organic soil phase. One form of treatment is the use of oxidative processes that can degrade numerous organic contaminants and mineralize them to carbon dioxide and water. In this study, it was evaluated the efficiency of phenanthrene and anthracene degradation, in standard sand soil using permanganate, hydrogen peroxide and activated persulfate as oxidants. Depending on the contaminant and the matrix, over $24 \mathrm{~h}$ of treatment, it was found the degradation 95 to $98 \%$ using permanganate and 34 to $62 \%$ using reaction Fenton. Anthraquinone was identified as product of anthracene, independent of the oxidant used. Among the oxidants, persulfate activated with iron was evaluated in the degradation of PAH in sandy soils. In standard sand, this process promoted,over 24 hours of treatment, a degradation level up to $60 \%$ phenanthrene and $95 \%$ for anthracene. In sand soils, the degradation of the contaminants was lower due to possible matrix effect. In constrast there was no decomposition of humic substances, indicating no competition between the organic matter and the PAH by persulfate, and no change in the soil carbon content.
\end{abstract}

Keywords: soil, oxidative processes, organic matter, PAH 


\section{LISTA DE ABREVIATURAS E SIGLAS}

\section{ASE Accelerated Solvent Extractor}

AF- Ácido Fúlvico

AH- Ácido Húmico

ATSDR Agency for Toxic Substances and Disease Registry

CETESB Companhia de Tecnologia e Saneamento Ambiental

CG/EM Cromatografia Gasosa acoplado a espectrometria de massa

CONAMA Conselho Nacional do Meio Ambiente

US-EPA Environmental Protection Agency

EMBRAPA Empresa Brasileira de Pesquisa Agropecuária

HPA Hidrocarboneto Policíclico Aromático

HUM- Humina

ICP AES Inductively Coupled Plasma Atomic Emission Spectroscopy

IARC International Agency for Research in Cancer-

ISCO In Situ Chemical Oxidation

ITRC Interstate Technology \& Regulatory Council

IUPAC International Union of Pure and Applied Chemistry

MEV Microscopia Eletrônica de Varredura

MOD Matéria Orgânica Dissolvida

MPE Multi Phase Extraction

POA Processo Oxidativo Avançado

PFE Pressurized Fluid Extraction

SH- Substâncias Húmicas 


\section{Sumário}

1. INTRODUÇÃ

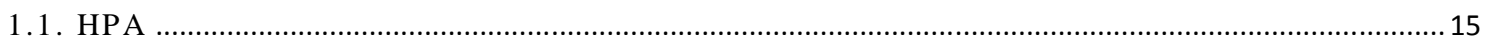

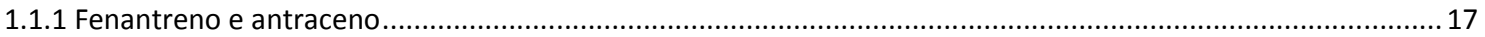

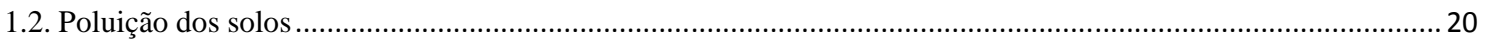

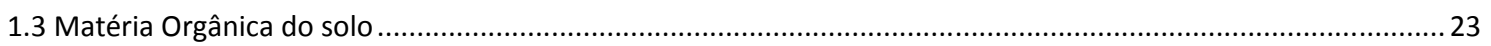

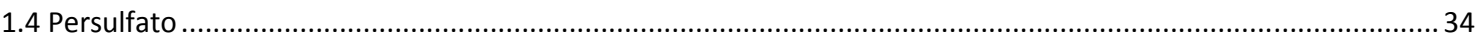

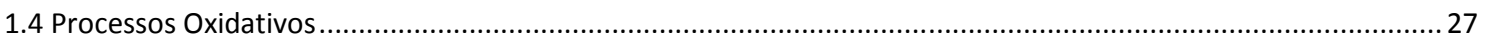

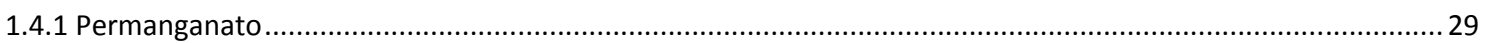

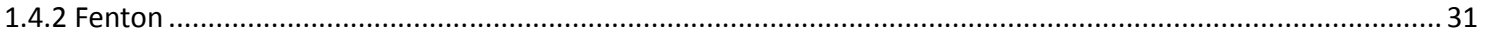

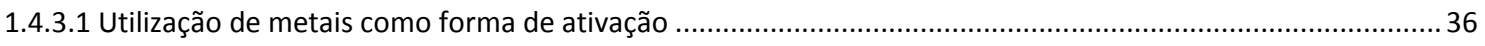

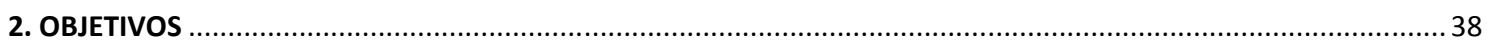

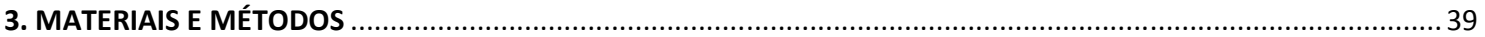

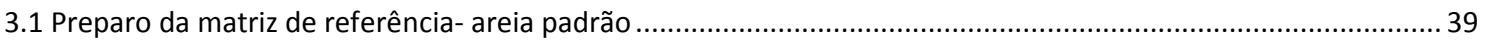

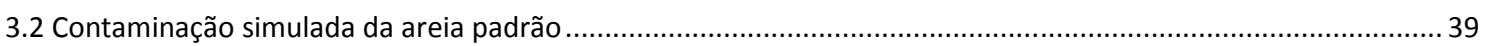

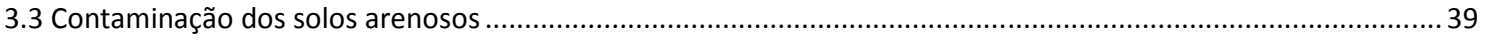

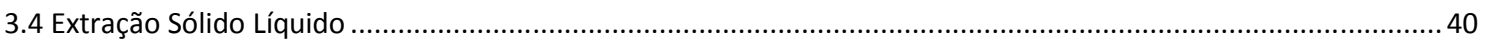

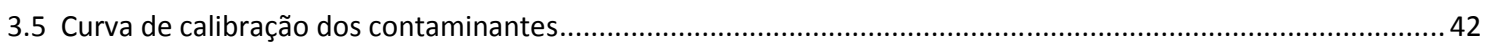

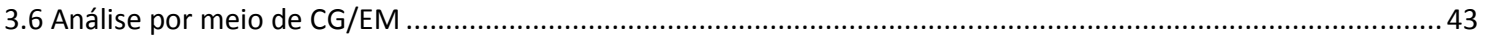

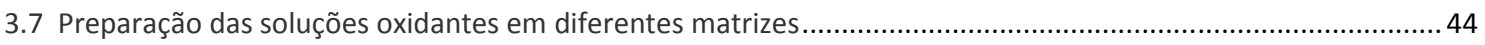

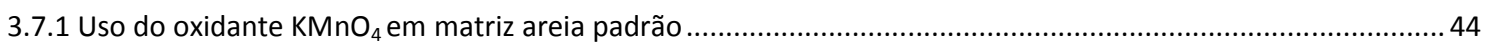

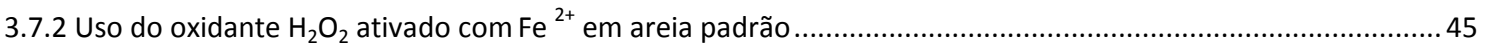

3.7.3 Uso do oxidante $\mathrm{Na}_{2} \mathrm{~S}_{2} \mathrm{O}_{8}$ ativado com $\mathrm{Fe}^{2+}$ em matriz areia padrão ....................................................... 46

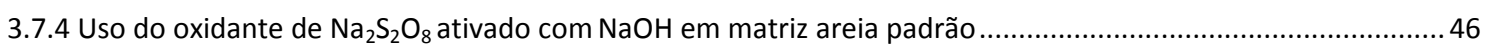

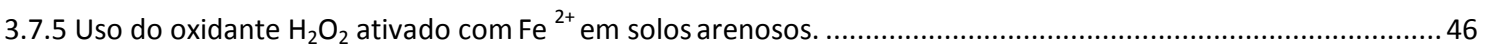

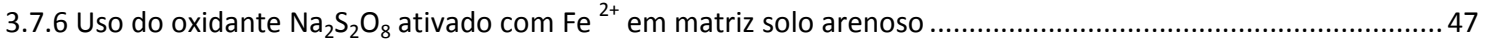

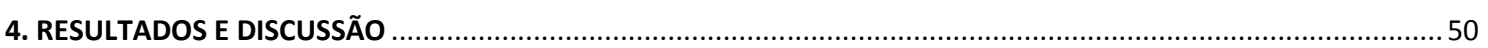

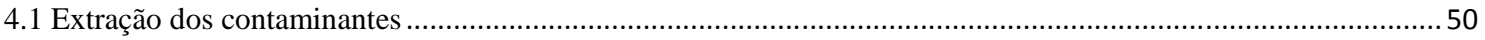

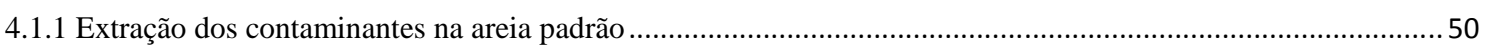

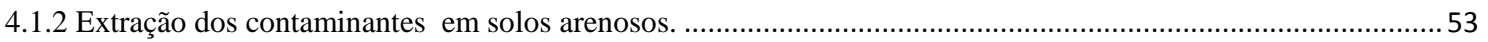

4.2 Uso do oxidante permanganato em areia padrão ….............................................................................. 57

Mariana Fransiele Ciriaco 
4.4 Avaliação do uso do oxidante persulfato

4.5. Avaliação do uso dos oxidantes utilizando a mesma matriz...........................................................................67

4.6 Identificação dos intermediários oriundos dos diferentes processos oxidativos..............................................69

4.6.1 Mecanismo de formação dos intermediários provenientes do antraceno. ................................................... 74

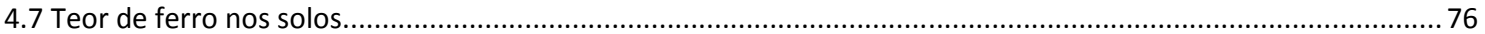

$4.8 \mathrm{O}$ uso do persulfato de sódio ativado com ferro em diferentes matrizes.......................................................77

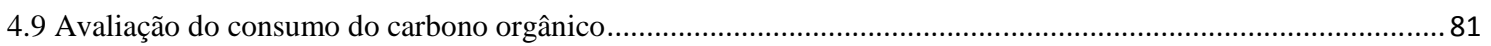

5. CONCLUSÃO

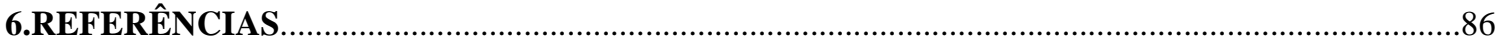




\section{INTRODUÇÃO}

Desde a Revolução Industrial, a rápida industrialização e o crescimento populacional levaram a problemas ambientais devido ao lançamento de uma infinidade de contaminantes gerados por atividades antropogênicas. Estes contaminantes, muitas vezes acabam atingindo concentrações que alteram química, física e biologicamente o meio ambiente, tornando-se, assim, poluentes. ${ }^{1}$ Durante muito tempo os produtos potencialmente poluidores foram dispostos diretamente no solo. O solo é considerado um recurso limitado e fundamental no ecossistema mundial ${ }^{1,2}$

A contaminação do solo pode afetar os aquíferos, o que pode se tornar-se um problema para as populações que fazem uso deste recurso hídrico. Essa contaminação pode ocorrer por disposição e derrame, proposital ou acidental de resíduos provenientes de atividades agrícolas, industriais, domésticas ou por deposição atmosférica. Esta contaminação altera as características naturais do solo, produzindo impactos e limitando seu uso., ${ }^{2,3}$

Dentre as possíveis fontes de contaminação em solos e águas subterrâneas, o derramamento de petróleo e derivados é um dos vários problemas que podem causar danos ao meio ambiente. O ramo petroquímico é um dos maiores causadores das contaminações, já que em toda a sua cadeia produtiva há a possibilidade de contaminação do ar, das águas superficiais e subterrâneas e dos solos por uma gama de compostos altamente poluentes, entre eles os hidrocarbonetos policíclicos aromáticos (HPA).,

A Agência de Proteção Ambiental Norte Americana (USEPA) estima que existam mais de 2,1 milhões de tanques subterrâneos de armazenamento de gasolina nos Estados Unidos da América. De acordo com a USEPA, até março de 2008 foram registrados mais de 478.000 casos de vazamentos provocando a contaminação de grandes áreas. Destes, 372.000 
estão em processo de recuperação e cerca de 107.000 sítios contaminados ainda precisam ser recuperados. $^{5}$

Na Europa ainda não foi possível quantificar a real extensão da contaminação dos solos. As estimativas apontam que o número de sítios contaminados neste continente seja cerca de 3 milhões, segundo dados de 2007 da Agência Ambiental Européia. ${ }^{6}$

Atualmente, também é desconhecido o número total de áreas contaminadas no Brasil. Entretanto, nos últimos anos vem crescendo a importância da identificação e recuperação de áreas contaminadas. A Companhia Ambiental do Estado de São Paulo (CETESB) divulgou pela primeira vez em 2002 a relação de 255 áreas contaminadas por produtos químicos. Atualmente, após mais de 10 anos, há 4.572 áreas contaminadas cadastradas sendo que 77\% são atribuídas a postos de gasolina. Segundo a CETESB, uma área contaminada pode ser definida como uma área, local ou terreno onde há comprovadamente poluição ou contaminação causada pela introdução de quaisquer substâncias ou resíduos que nela tenham sido depositados, acumulados, armazenados, enterrados ou infiltrados de forma planejada, acidental ou até mesmo natural. ${ }^{7,8}$

Para a escolha da técnica de tratamento das áreas contaminadas é levado em consideração às propriedades físico-químicas e o processo de partição dos contaminantes. Os contaminantes podem estar presentes em cinco fases: livre (imiscível em água), fase vapor, fase dissolvida, fase adsorvida e fase residual. Além disso, é preciso considerar durante o tratamento que os solos são considerados matrizes complexas, visto que há uma grande diversidade de solos encontrados em climas tropicais, como os existentes no Brasil., ${ }^{2,9}$

Dentre as 4.572 áreas contaminadas no Estado de São Paulo, mais de 2.500 estão contaminadas com solventes aromáticos e combustíveis líquidos. Assim, há o predomínio da utilização das técnicas de bombeamento e tratamento e extração multifásica no processo de descontaminação de água subterrânea, enquanto que a extração de vapores na zona não 
saturada e a remoção de solo/resíduo destacam-se como as técnicas mais utilizadas para os solos. No entanto, em crescimento percentual, as técnicas de remediação via atenuação natural e a oxidação/redução química tem se destacado nos últimos anos (Figura 1). ${ }^{7,10}$

A técnica de bombeamento e tratamento, também conhecida como pump and treat, consiste em remover as águas contaminadas, por meio de poço de extração para que seja tratada e redisposta. Já a extração multifásica conhecida como MPE, do inglês Multi Phase Extraction, possibilita a extração dos contaminantes em diferentes fases (livre, vapor e dissolvida) na matriz solo por meio da aplicação de um sistema à vácuo. As técnicas de bombeamento e tratamento e MPE se caracterizam por serem off site (remoção para um posterior tratamento).

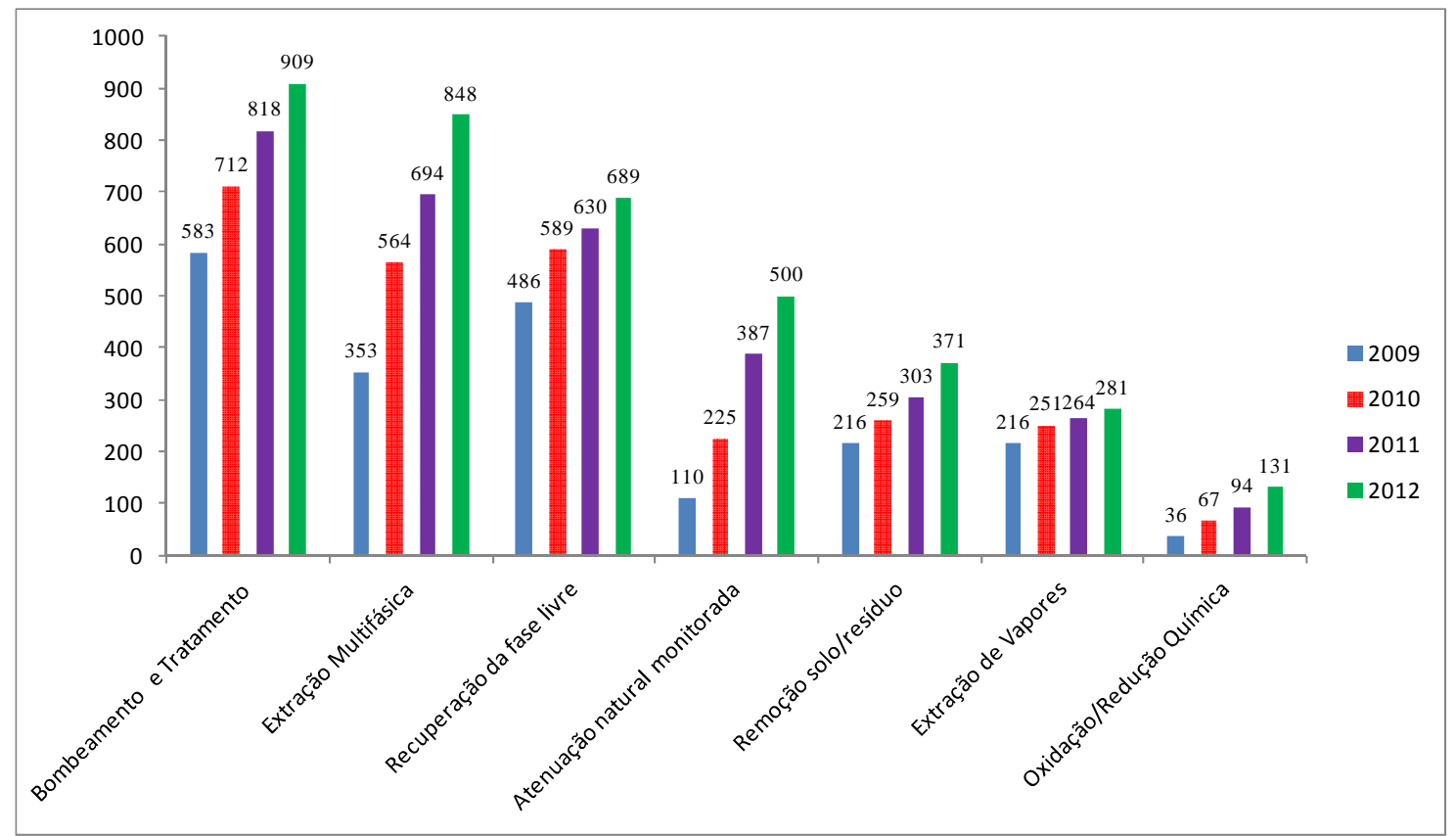

Figura 1-Histograma das técnicas de remediação implantadas no período de 2009 a 2012 divulgadas pela CETESB. ${ }^{7,8}$

Por outro lado a oxidação/redução e a atenuação natural apresentam como vantagem o tratamento in situ (tratamento no local sem remoção) e a efetiva degradação dos contaminantes em compostos menos tóxicos, podendo ser muitas vezes integradas às tradicionais técnicas de transferência de massa como bombeamento e tratamento e extração de 
vapores. O tratamento por meio da técnica de oxidação química possibilita também, diferente da maioria das técnicas, o tratamento dos contaminantes presentes no solo na fase residual (fase descontínua e não-móvel). ${ }^{3,10,11}$

Considerando-se que os HPA não são voláteis, com exceção do naftaleno, e pouco solúveis em água, frequentemente, tem-se utilizado a oxidação química para tratamento de solos contaminados com estes compostos, já que o uso das técnicas de bombeamento e tratamento e MPE não proporcionam uma efetiva extração destes contaminantes. Os processos oxidativos são eficientes na remoção de compostos tóxicos e recalcitrantes (nãobiodegradáveis) de matrizes contaminadas, pois transformam a maioria dos contaminantes orgânicos em compostos de baixa ou nenhuma toxicidade como o dióxido de carbono, água e ânions inorgânicos, por meio de reações de degradação. ${ }^{2}$

A seguir é feita uma breve discussão sobre as principais características dos poluentes HPA, a sua presença nos solos e os processos oxidativos como meio de tratamento.

\subsection{HPA}

Os HPA são considerados fontes persistentes de contaminação do solo e águas subterrâneas, correspondendo a $40 \%$ do total das áreas registradas como contaminadas no Estado de São Paulo, segundo CETESB (2012). ${ }^{3}$ Em vista da baixa reatividade da estrutura química dos HPA, devido à ressonância dos anéis aromáticos, e da baixa biodisponibilidade (baixa acessibilidade a microbiota do solo), a maioria dos micro-organismos não possui enzimas capazes de degradar os HPA constituídos com mais de três anéis aromáticos. ${ }^{12}$

De modo geral, os HPA apresentam baixa solubilidade na água e baixa pressão de vapor, sendo que ambas tendem a diminuir com o aumento da massa molecular. ${ }^{19}$ Estes compostos são normalmente encontrados como uma mistura contendo dois ou mais destes 
constituintes, com isso é preciso considerar que as solubilidades em água dos HPA em uma mistura não são as mesmas deles puros, de acordo com a Lei de Raoult. ${ }^{2,13}$

Os HPA são um grupo de mais de 100 substâncias químicas diferentes oriundos principalmente de derrames e vazamentos acidentais de hidrocarbonetos de petróleo, bem como da queima incompleta do carvão, lixo, pirólise de madeira ou outras substâncias orgânicas como o tabaco. Eles também são os principais constituintes do creosoto, cerca de 85\%. Esta substância é uma mistura complexa utilizada para preservar madeira, por esse motivo à contaminação com HPA é muitas vezes associada com a atividade de tratamento de madeira. $^{14}$

Os HPA são compostos de interesse de estudo por causa da sua toxicidade e efeitos mutagênicos, carcinogênicos e teratogênicos que podem causar nos seres vivos, além de causar danos ao meio ambiente. De acordo com a USEPA, há 16 HPA que são poluentes orgânicos prioritários, sendo considerados particularmente importantes no monitoramento ambiental. Na Figura 2 estão apresentadas as estruturas químicas destes $16 \mathrm{HPA}^{2}$

Os HPA podem ser encontrados em solos, sedimentos, água e ar. O solo é considerado um coletor de HPA provenientes da atmosfera oriundos da frota de veículos e das atividades industriais. Em países tropicais, como o Brasil, a concentração é bem variável, sendo que a proveniente do ar em solo superficial $(0-10 \mathrm{~cm})$, de áreas urbanas, atinge valores de $818 \mu \mathrm{g}$ $\mathrm{kg}^{-1}$. Já em regiões industriais da França e USA atinge valores de cerca de $3000 \mu \mathrm{g} \mathrm{kg}^{-1} \mathrm{na}$ superfície do solo. ${ }^{15,16,17,18,19}$

As concentrações de HPA geralmente são muito mais elevadas em sedimentos e solos do que as encontradas na água de superfície, pois apresentam baixa solubilidade em água e uma forte afinidade pelo carbono orgânico existente nos solos e em sedimentos. ${ }^{3}$ 
<smiles>c1ccc2ccccc2c1</smiles>

1<smiles>c1ccc2ccccc2c1</smiles>

5<smiles>C1=Cc2cccc3cccc1c23</smiles>

2<smiles>c1cc2c3c(cccc3c1)CC2</smiles>

3<smiles>c1ccc2c(c1)Cc1ccccc1-2</smiles>

4<smiles>c1ccc2cc3ccccc3cc2c1</smiles>

6<smiles>c1ccc2c(c1)-c1cccc3cccc-2c13</smiles>

7<smiles>c1cc2ccc3cccc4ccc(c1)c2c34</smiles>

8<smiles>C1=CC2=CCc3c(ccc4ccccc34)C2C=CC1</smiles><smiles>c1ccc2cc3c(cc2c1)-c1cccc2cccc-3c12</smiles>

12<smiles></smiles>

13<smiles></smiles>

14<smiles></smiles>
15<smiles></smiles>

Figura 2- Os 16 HPA classificados como poluentes prioritários: (1) naftaleno, (2) acenaftileno, (3) acenafteno, (4) fluoreno, (5) fenantreno (6) antraceno , (7) fluoranteno, (8) pireno, (9) benz(a)antraceno, (10) criseno, (11) benzo [b] fluoranteno, (12) benzo[k]fluoranteno, (13) benzo [a] pireno, (14) indeno[1,2,3 cd] pireno, (15) dibenzo [a,h] antraceno, (16) benzo[g,h,i]perileno. ${ }^{3}$

A concentração de compostos de HPA em solos pode variar de $\mu \mathrm{g} \mathrm{kg}^{-1} \mathrm{a} \mathrm{g} \mathrm{kg}^{-1}$, dependendo da proximidade e da fonte de contaminação. Por exemplo, Juhasz e Naidu (2000) em uma revisão de literatura, relataram uma concentração de HPA de $5863 \mathrm{mg} \mathrm{kg}^{-1}$ em um local de produção de creosoto, $18.704 \mathrm{mg} \mathrm{kg}^{-1}$ em um local de preservação de madeira, 821 $\mathrm{mg} \mathrm{kg}^{-1}$ em uma petroquímica, e $451 \mathrm{mg} \mathrm{kg}^{-1} \mathrm{em}$ uma fábrica de gás. ${ }^{20}$

\subsubsection{Fenantreno e antraceno}

Os isômeros fenantreno e antraceno constituídos de três anéis aromáticos são alvos de estudos, pois estão entre os que apresentam maior solubilidade em água dentre os 16 HPA com exceção do naftaleno. Apesar de apresentarem a mesma massa molecular, o antraceno é 
18 vezes menos solúvel em água que o fenantreno devido à estrutura molecular. A solubilidade do fenantreno é $1,18 \mathrm{mg} \mathrm{L}^{-1}$ enquanto do antraceno é $0,075 \mathrm{mg} \mathrm{L}^{-1}$. A hidrofobicidade dos compostos é identificada pela baixa solubilidade em água e pelos altos valores do coeficiente de partição octanol-água $\left(\mathrm{K}_{\mathrm{ow}}\right)$. Quanto maior a massa molecular dos HPA, maior a hidrofobicidade, menor a pressão de vapor, portanto os compostos tendem a ser recalcitrantes. As propriedades físico-químicas do fenantreno e antraceno estão descritas na Tabela $1 .^{21}$

Tabela 1 Propriedades físico químicas dos contaminantes fenantreno e antraceno. ${ }^{21}$

\begin{tabular}{ccccccc}
\hline Estrutura & Massa & Log & Solubilidade & Pressão de & Constante da Lei & Ponto de \\
Molecular & Molar & $\mathrm{K}_{\mathrm{ow}}$ & $20^{\circ} \mathrm{C}$ & Vapor & de Henry & Ebulição \\
& $\left(\mathrm{g} \mathrm{mol}^{-1}\right)$ & & $\left(\mathrm{mg} \mathrm{L}^{-1}\right)$ & $20^{\circ} \mathrm{C}$ & $20^{\circ} \mathrm{C}$ & ${ }^{\circ} \mathrm{C}$ \\
& & & & & & $\left(\mathrm{mmHg}^{-1}\right)$
\end{tabular}

$178,23 \quad 4,45 \quad 1,18 \quad 2,01 \times 10^{-4} \quad 3,98 \times 10^{-5} \quad 340$

Antraceno

$178,23 \quad 4,46 \quad 7,510^{-2} \quad 1,08 \times 10^{-5} \quad 3,38 \times 10^{-5} \quad 342$

Embora a degradação de HPA por muitos micro-organismos já tenha sido demonstrada em vários estudos, estes compostos apresentam grande persistência no ambiente. A efetiva biorremediação é influenciada por fatores ambientais e microbiológicos. Entre eles o tipo de solo, porcentagem de matéria orgânica, tempo de contaminação, toxicidade do sedimento, temperatura, $\mathrm{pH}$, concentração e as propriedades físico químicas dos HPA. Com isso o tempo de meia vida biológica dos HPA pode variar de dias a anos, segundo estudos da 
literatura. ${ }^{22,23}$ Os processos oxidativos podem ser mais eficientes na remoção destes poluentes, pois degradam os compostos recalcitrantes muito mais rapidamente, principalmente para os compostos com mais de três anéis aromáticos que são menos biodisponíveis. ${ }^{23,24}$

Segundo a CETESB e a Resolução n $420 / 2009$ do CONAMA (Conselho Nacional do Meio Ambiente), se a concentração do contaminante indicar riscos diretos ou indiretos para a saúde humana e para o ambiente, é necessária fazer uma intervenção. ${ }^{25,26}$

No caso do fenantreno, torna-se necessário uma intervenção, quando o solo apresentar concentrações iguais ou superiores a $15 \mathrm{mg} \mathrm{kg}^{-1}$ em solos agrícolas, de $40 \mathrm{mg} \mathrm{kg}^{-1} \mathrm{em}$ solos residenciais e de $95 \mathrm{mg} \mathrm{kg}^{-1}$ em industriais. Em relação às águas subterrâneas, o valor de intervenção é de $140 \mu \mathrm{g} \mathrm{L}{ }^{-1}{ }^{25}$

Para o antraceno, foram somente determinados os valores de prevenção, ou seja, à concentração do contaminante acima da qual podem ocorrer alterações prejudiciais à qualidade do solo e da água subterrânea, sendo este igual a $0,039 \mathrm{mg} \mathrm{kg}^{-1}$. Os HPA com maior número de anéis aromáticos apresentam geralmente menores valores de intervenção e prevenção como os apresentados na Tabela $2 .^{25}$ 
Tabela 2 Valores orientadores da concentração de HPA em solo e água subterrânea. ${ }^{\mathbf{2 5 , 2 6}}$

\begin{tabular}{|c|c|c|c|c|c|c|}
\hline \multirow{4}{*}{ Substância } & \multirow{4}{*}{$\begin{array}{c}\text { Solubilidade } \\
\text { em água b } \\
\left(\mathrm{mg} \mathrm{L}^{-1}\right)\end{array}$} & \multicolumn{5}{|c|}{ Solo (mg kg-1 de peso seco) } \\
\hline & & \multirow{3}{*}{ Prevenção } & \multicolumn{3}{|c|}{ Intervenção } & \multirow{3}{*}{ Intervenção } \\
\hline & & & \multicolumn{3}{|l|}{ Agrícola } & \\
\hline & & & APMAx & Residencial & Industrial & \\
\hline Antraceno & 0,075 & 0,039 & - & - & - & - \\
\hline Benzo (a) antraceno & 0,014 & 0,025 & 9 & 20 & 65 & 1,75 \\
\hline Benzo(k) fluoranteno & 0,014 & 0,38 & - & - & - & - \\
\hline Benzo $(\mathrm{g}, \mathrm{h}, \mathrm{i})$ perileno & 0,00026 & 0,57 & - & - & - & - \\
\hline Benzo (a) pireno & 0,0038 & 0,052 & 0,4 & 1,5 & 3,5 & 0,7 \\
\hline Criseno & 0,0060 & 8,1 & - & - & - & - \\
\hline Dibenzo $(\mathrm{a}, \mathrm{h})$ antraceno & 0,0025 & 0,08 & 0,15 & 0,6 & 1,3 & 0,18 \\
\hline Fenantreno & 1,18 & 3,3 & 15 & 40 & 95 & 140 \\
\hline Indeno $(1,2,3-\mathrm{c}, \mathrm{d})$ pireno & 0,00053 & 0,031 & 2 & 25 & 130 & 0,17 \\
\hline Naftaleno & 31 & 0,12 & 30 & 60 & 90 & 140 \\
\hline
\end{tabular}

\subsection{Poluição dos solos}

O solo é um material constituído por partículas sólidas e pelo espaço entre elas, que pode estar preenchido por água ou ar, sendo que a proporção desses componentes pode variar de um solo para outro e, até mesmo, dentro do mesmo solo, de horizonte para horizonte. Os componentes do solo incluem aproximadamente $45 \%$ em volume de partículas minerais, 30 a $35 \%$ de água, 15 a $20 \%$ do ar e $5 \%$ de matéria orgânica. ${ }^{27}$ 
Os solos desempenham um papel fundamental no destino, transporte e comportamento de muitos contaminantes, principalmente os hidrofóbicos. Sua granulometria interfere na adsorção dos contaminantes assim como na disponibilidade para tratamento. Por isso o solo é classificado quanto à granulometria, de acordo com a porcentagem em massa que corresponde a cada fração: areia $(2$ a $0,06 \mathrm{~mm})$, silte $(0,06$ a $0,002 \mathrm{~mm})$ e argila (menor que $0,002 \mathrm{~mm}) .^{28}$

Por meio da análise granulométrica determina-se a textura dos solos de maneira que o grupamento textural é definido como a reunião de uma ou mais classes de textura (Figura 3), sendo os seguintes grupamentos texturais existentes:

- $\quad$ Textura arenosa - que compreende as classes texturais areia e areia franca;

- $\quad$ Textura média - que compreende classes texturais ou parte delas, cuja composição granulométrica é menos de $35 \%$ de argila e mais de $15 \%$ de areia, excluídas as classes texturais areia e areia franca;

- Textura argilosa - que compreende classes texturais ou parte delas, sendo sua composição granulométrica de $35 \%$ a $60 \%$ de argila;

- $\quad$ Textura muito argilosa - que compreende a classe textural com mais de $60 \%$ de argila.

- $\quad$ Textura siltosa - que compreende parte de classes texturais que tenham menos de $35 \%$ de argila e menos de $15 \%$ de areia em sua composição.

A classificação da textura é importante, pois por meio dela tem-se o entendimento das propriedades físicas e químicas do solo. ${ }^{29}$ 


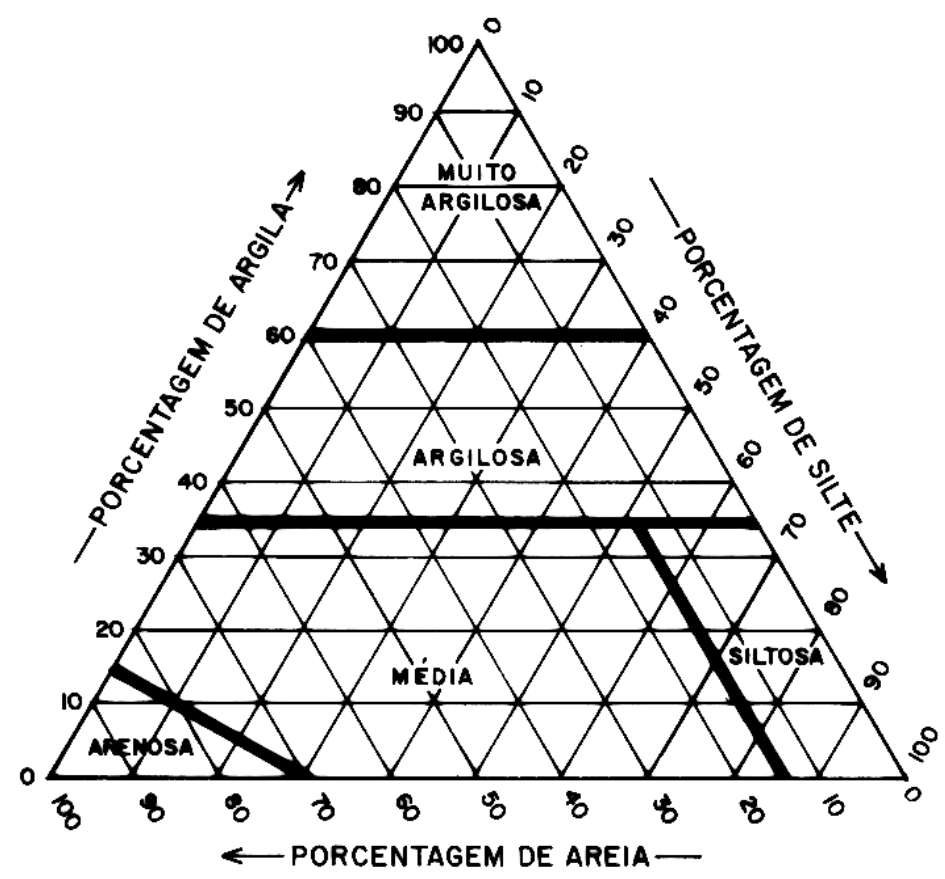

Figura 3- Esquema do triângulo de grupamento textural dos solos. ${ }^{29}$

De acordo com a classificação brasileira de solos publicada pela Empresa Brasileira de Pesquisa Agropecuária (EMBRAPA), o solo é estudado através do seu perfil, ou seja, em um corte vertical, de até $200 \mathrm{~cm}$ de profundidade ou até a rocha quando ela está acima de 2,0 m. Desta maneira o perfil de solo expõe os diferentes horizontes e propriedades (atributos) que o classificam em 13 ordens. As que são predominantes em solos no Brasil são os latossolos e argilossolos que correspondem, a cerca de $58 \%$ do total. Os solos da ordem dos latossolos apresentam textura argilosa com baixo teor de silte em relação à argila e textura uniforme ao longo do perfil. Já os solos da ordem dos argilossolos apresentam textura variável, mas com predomínio de textura média na superfície e argilosa em subsuperfície. ${ }^{25} \mathrm{Com}$ isso, torna-se laborioso um estudo para avaliar o perfil e o tratamento dos contaminantes em solos brasileiros, pois a distribuição dos HPA é afetada pelo perfil, granulometria e tamanho dos poros do solo, assim como pela estrutura química da matéria orgânica. ${ }^{30}$ 


\subsection{Matéria orgânica do solo}

Dentre os diversos componentes presentes no solo, a matéria orgânica desempenha papel primordial em sua qualidade. Sua quantificação é normalmente feita a partir do conteúdo de carbono orgânico, utilizando-se um fator 1,724 para quantificar o teor de matéria orgânica. Este valor significa que a massa de carbono orgânico presente no solo, corresponde a $58 \%$ da massa total de matéria orgânica do solo (Equação 1). No entanto tem-se diagnosticado fatores maiores que 1,724 em solos brasileiros, possivelmente devido ao alto grau de oxidação da material orgânica em condições de clima tropical. Devido a essas diferenciações para quantificar a matéria orgânica, seria adequado para um estudo comparativo avaliar os valores de teor de carbono orgânico. ${ }^{31,32}$

$$
\mathrm{MO} \%=100 / 58 \times \mathrm{C} \%=1,724 \times \mathrm{C} \% \quad \text { (Equação 1) }
$$

$\mathrm{MO}$ = matéria orgânica

$\mathrm{C} \%=$ teor de carbono

A estrutura química da matéria orgânica é determinada principalmente pela matriz do solo inorgânico, clima e os precursores de plantas. Também é preciso destacar que sua composição varia de acordo com a localização e profundidade do solo, assim como se altera devido às diferentes texturas (areia, silte e argila). A matéria orgânica existente em solos, turfas, sedimentos e águas naturais apresenta-se como um sistema complexo de várias substâncias de diversas naturezas e em transformação contínua, sob a ação de fatores físicos, químicos e biológicos. $^{33,34}$

O material originado de todas essas transformações pode ser dividido em dois grandes grupos. O primeiro, denominado genericamente de substâncias não húmicas, é constituído por aminoácidos, proteínas, polissacarídeos, ácidos graxos e outros compostos orgânicos de características físicas e químicas bem definidas. O segundo denominado de substâncias húmicas (SH) que são misturas complexas e heterogêneas de materiais polidispersos 
formados por reações químicas e bioquímicas durante a decomposição e transformação de plantas e restos microbianos (um processo chamado de humificação). A lignina da planta e seus produtos de transformação, bem como polissacarídeos, proteínas, lipídios e ácidos nucléicos são componentes importantes que participam neste processo. Este grupo apresentase como uma mistura amorfa de moléculas polidispersas com elevadas massas moleculares e grupos funcionais distintos, sendo responsáveis por inúmeros processos naturais. As SH são compostos em decomposição que se originam de acordo as propriedades do solo, constituindo de 85 a 90\% da reserva total de carbono orgânico do solo. Sabe-se que a composição química das $\mathrm{SH}$ presentes nos solos varia muito com a região, tipo de solo e clima, o que dificulta a determinação da estrutura dessas moléculas. ${ }^{33,35}$

Baseando-se nas solubilidades das SH em meio aquosos em função do pH, as SH são usualmente classificadas em :

- Ácidos fúlvicos (AF): fração solúvel em meio alcalino e em meio ácido diluído.

-Ácidos húmicos (AH): fração solúvel em meio alcalino, quimicamente complexos, amorfos, formados por polímeros de compostos aromáticos e alifáticos e de grande capacidade de troca catiônica. Estes combinam-se com elementos metálicos formando os humatos, que podem precipitar ou permanecer em dispersão coloidal. ${ }^{35}$

- Humina (HUM): fração insolúvel em meio alcalino ou em meio ácido diluído que possui reduzida capacidade de reação e apresenta coloração preta. ${ }^{33,35}$

Embora haja diferença entre as SH de diferentes fontes, algumas propriedades gerais consideram suas origens similares, assim na Tabela 3 estão descritas as propriedades químicas das substâncias húmicas.

As SH possuem flexibilidade estrutural e têm a capacidade de mudar a conformação molecular de acordo com as mudanças de pH, força iônica e das ligações dos grupamentos funcionais. 
Tabela 3 Algumas propriedades químicas comuns às substâncias húmicas. ${ }^{36}$

\begin{tabular}{cccc}
\hline & AF & AH & HUM $^{\text {a }}$ \\
Massa molecular $(\mu)$ & $640-5000$ & $10.000-100.000$ & $>100.000$ \\
\hline C & $\%$ & $51-62$ & $>62$ \\
O & $42-47$ & $31-36$ & $>30$ \\
N & $45-50$ & $3-6$ & $>5$
\end{tabular}

a - Valores da fração humina são aproximados, dada a dificuldade em se eliminar a fase mineral para análise elementar.

Os AH e AF são solúveis em meio alcalino devido à presença de grupos carboxílicos e fenólicos que hidrolisam, e a sua solubilidade, deve-se também a força de repulsão eletrostática intramolecular entre os íons que facilita a hidratação.

Como descrito na Tabela 3, os AH em relação aos AF, se caracterizam-se por terem uma maior massa molar, maior conteúdo de carbono e menor conteúdo de oxigênio. Portanto este apresenta menor solubilidade e mobilidade. Conforme pode ser observada a estrutura molecular proposta por Schulten e Schnitzer (1993) na Figura 4, o AH contém cavidades de diferentes tamanhos no interior da macromolécula. Estes permitem que os compostos orgânicos, como os poluentes orgânicos HPA, liguem-se aos $\mathrm{AH}^{36}$ Em relação aos $\mathrm{AF}$, estes são solúveis em toda a faixa de $\mathrm{pH}$ e sua massa molecular é relativamente baixo. Eles combinam-se com óxidos de $\mathrm{Fe}$ e Al, argilas e compostos orgânicos. Possuem propriedades redutoras e formam complexos estáveis com $\mathrm{Fe}, \mathrm{Cu}, \mathrm{Ca}$ e $\mathrm{Mg}$. Na Figura 5 é ilustrada a imagem do AF por meio da técnica de microscopia eletrônica de varredura (MEV). 


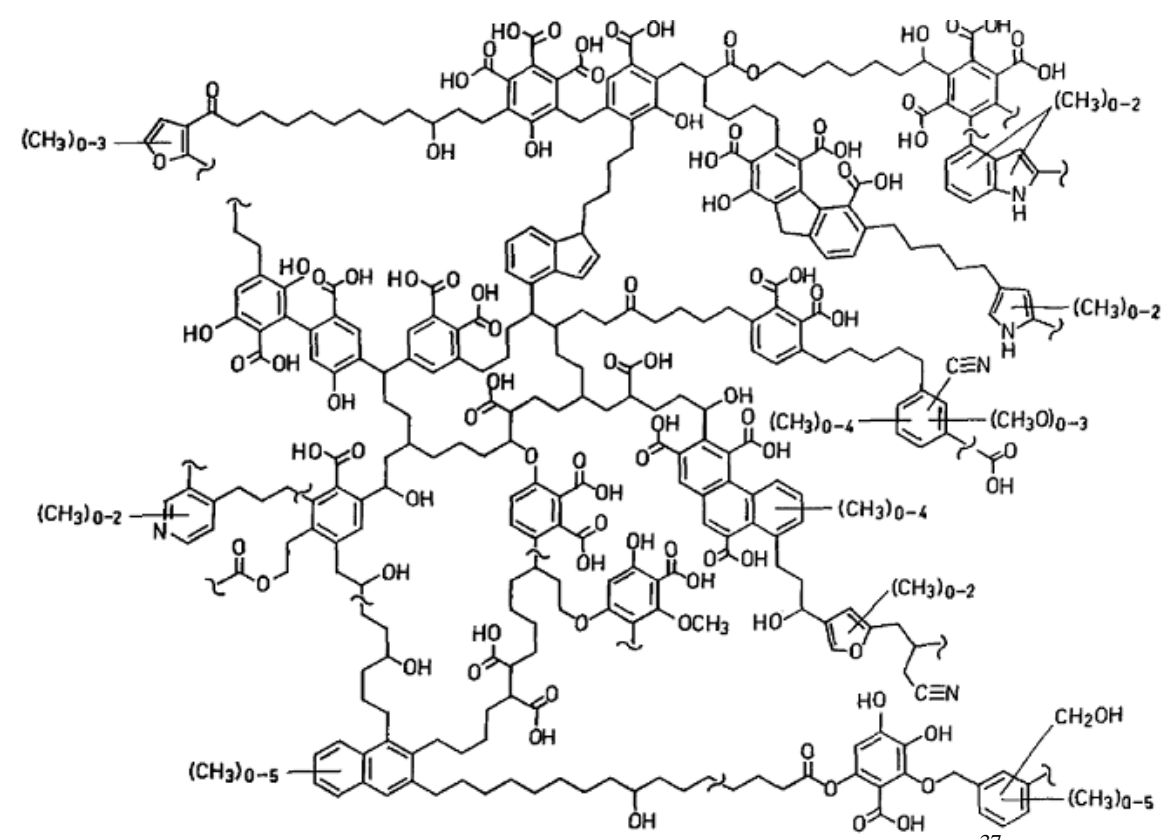

Figura 4-Representação esquemática de um possível fragmento do ácido húmico. ${ }^{37}$

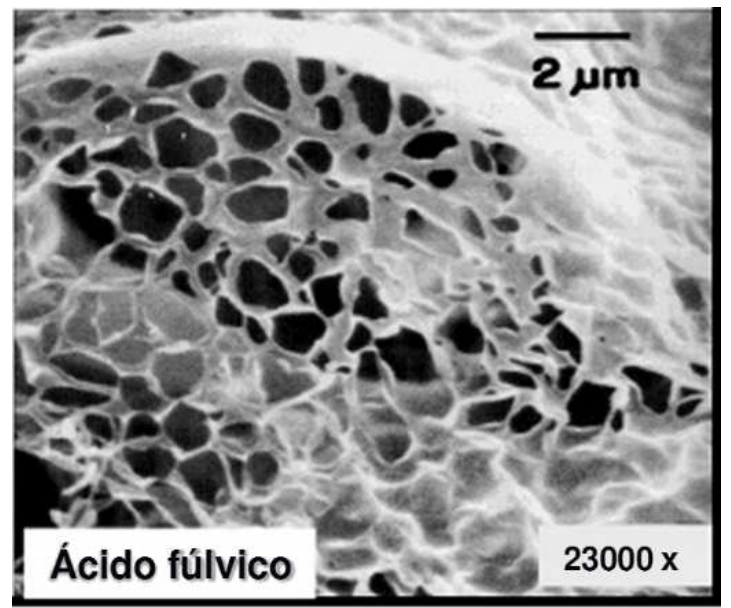

Figura 5-Imagem do ácido fúlvico obtido por meio de microscopia eletrônica de varredura (MEV). ${ }^{38}$

Estudos demonstraram que a matéria orgânica dissolvida (MOD) aumenta a mobilidade dos HPA, visto que aumenta a solubilidade dos compostos não-polares em água que agem como transportadores dos contaminantes. Neste caso a distribuição da matéria orgânica entre a MOD, AF, AH e HUM pode gerar uma competição entre a lixiviação e a retenção dos contaminantes no solo. ${ }^{34,39}$

A interação das SH com compostos hidrofóbicos, entre eles os HPA, pode afetar não só a fertilidade do solo e a comunidade microbiana deste, mas também a biodisponibilidade e 
a persistência ambiental dos HPA. Muitos estudos têm demonstrado que a heterogeneidade da matéria orgânica do solo afeta na sorção dos poluentes orgânicos, assim como sua mobilidade, isso se deve à interação do contaminante hidrofóbico com a matéria orgânica em termos de polaridade, tamanho e configuração molecular. Por outro lado o decréscimo da matéria orgânica do solo pode reduzir a capacidade de sorção do solo dos compostos orgânicos hidrofóbicos como os HPA, o que ocasionaria a lixiviação dos contaminantes. , $^{3,30,40}$

É importante considerar que a taxa de degradação dos contaminantes pode ser facilmente afetada pela presença de espécies competidoras, como a presença de matéria orgânica ou espécies minerais redutoras., ${ }^{3,41}$

\subsection{Processos Oxidativos}

Os contaminantes HPA podem ser recalcitrantes nos sítios de contaminação sendo necessário um processo de tratamento que garanta sua remoção eficiente. ${ }^{42,43}$ Os processos de tratamento para poluentes recalcitrantes, entre eles os HPA, são diversos, destacando-se aqueles denominados como processos oxidativos e "Processos Oxidativos Avançados" (POA). Estes são considerados eficientes no que diz a respeito à degradação de compostos tóxicos e recalcitrantes visto que promovem a oxidação de poluentes químicos no ar, água e solo.

Conforme discutido anteriormente, os processos oxidativos destacam-se por não transferir de fase os contaminantes, mas mineralizá-los. Por outro lado, os oxidantes não são seletivos, podendo reagir com a matéria orgânica e os constituintes inorgânicos presentes no solo. ${ }^{42,43,44}$ Os POA consistem na geração de radicais a partir de oxidantes como o peróxido de hidrogênio e persulfato. Eles atuam em uma gama de compostos orgânicos como nos contaminantes e matéria orgânica presente no solo, pois são altamente reativos. ${ }^{3,14,45}$ 
Para avaliar a eficiência do tratamento de solos contaminados por meio de processos oxidativos é importante avaliar a presença da matéria orgânica que pode gerar uma possível competição com os contaminantes em relação aos radicais. Com isso a eficiência do tratamento por meio dos processos oxidativos pode ser comprometida, já que há a possibilidade dos radicais serem consumidos entre as substâncias húmicas de diferentes fontes ao invés de reagir com os contaminantes. ${ }^{37,46}$

Alguns parâmetros são determinantes na remediação de solos por meio das reações de processos oxidativos tais como: $\mathrm{pH}$ do solo, temperatura, os tipos de contaminantes, a proporção molar entre a concentração do oxidante e do contaminante e a presença de matéria orgânica.

Outros fatores precisam ser avaliados para se determinar a eficiência da degradação dos contaminantes pelos oxidantes. Para isso é preciso considerar a profundidade vertical de coleta do solo contaminado, tempo, fonte de contaminação, bem como a porcentagem presente de cada um dos HPA. Este último parâmetro é importante porque quanto o maior número de anéis, os compostos são menos solúveis em água e, portanto, mais persistentes. Em um estudo feito por Jonsson e colaboradores (2007) verificaram que a concentração dos contaminantes HPA está relacionada com a profundidade do solo e fonte de contaminação, assim como a eficiência da degradação dos contaminantes pode ser influenciado pelo tempo de contaminação. Eles avaliaram que em um mesmo solo havia $1800 \mathrm{mg} \mathrm{kg}^{-1}$ e $3400 \mathrm{mg} \mathrm{kg}^{-1}$ de HPA quando a profundidade de amostragem era de $(2-18 \mathrm{~cm})$ e $(0-10 \mathrm{~cm})$, respectivamente. Ao avaliar fontes diferentes de contaminação dos HPA em solos, a degradação destes em solos oriundos de uma indústria de preservação de madeira e de uma refinaria de gás foi de $43 \%$ e $22 \%$, respectivamente, após 24 horas de tratamento utilizando as mesmas condições das reações de Fenton. A degradação dos contaminantes depende não só da textura do solo, mas também da presença de sobrenadante. ${ }^{47}$ 
Além desses parâmetros, a escolha do oxidante depende de sua reatividade em relação ao contaminante e de sua estabilidade em relação à matriz nos quais se encontra. ${ }^{46}$ Também é importante avaliar a presença de interferentes durante o uso do oxidante. Neste caso, os íons carbonatos $\left(\mathrm{CO}_{3}{ }^{2-}\right)$ e cloretos $\left(\mathrm{Cl}^{-}\right)$atuam como sequestradores de radicais entre eles os radicais hidroxila $\left(\mathrm{OH}^{*}\right)$ e sulfatos $\left(\mathrm{SO}^{*}{ }^{*}\right)$. Comprometendo a cinética e as reações de oxidação nos processos oxidativos., , $^{33,47}$

Dentre os principais oxidantes utilizados para a remediação de solos e águas subterrâneas estão o permanganato de potássio $\left(\mathrm{KMnO}_{4}\right)$, o peróxido de hidrogênio $\left(\mathrm{H}_{2} \mathrm{O}_{2}\right)$ e o persulfato de sódio $\left(\mathrm{Na}_{2} \mathrm{~S}_{2} \mathrm{O}_{8}\right){ }^{3,43}$

As propriedades e o uso destes oxidantes em solos serão descritos nos próximos tópicos.

\subsubsection{Permanganato}

$\mathrm{O}$ íon permanganato $\left(\mathrm{MnO}_{4}{ }^{-}\right)$é um agente oxidante com potencial de redução padrão de 1,7 V. É efetivo para remediação de muitos hidrocarbonetos de petróleo e amplamente aplicado no processo de remediação em solos nos últimos anos. Outras características relevantes são: a solubilidade em água que atinge valores de até $60 \mathrm{~g} \mathrm{~L}^{-1}(6 \%)$, é altamente estável em águas subterrâneas e tem a capacidade de oxidar orgânicos a uma ampla faixa de pH. Em relação ao custo-benefício, é a substância mais acessível e econômica entre os oxidantes, e disponível em forma sólida, o que facilita o transporte e manuseio. $3,43,46$

A oxidação por meio da ação do íon $\mathrm{MnO}_{4}{ }^{-}$é altamente efetiva para compostos que contém dupla ligação carbono-carbono presentes em alcenos (hidrocarbonetos insaturados) e em anéis aromáticos (Figura 6). Por ser estável, pode permanecer por meses no solo facilitando a interação com os contaminantes. ${ }^{17,48}$ 

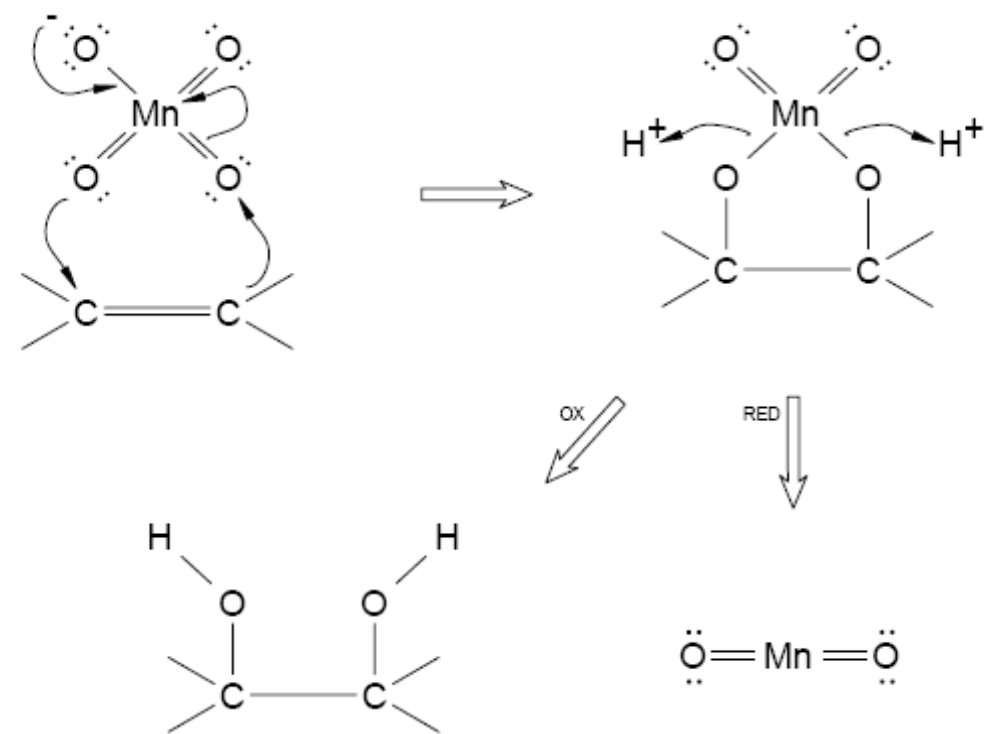

Figura 6-O íon permanganato atuando como oxidante em alcenos. ${ }^{49}$

Embora o aumento da concentração de permanganato tende a aumentar a taxa de oxidação de contaminantes, uma concentração em excesso de permanganato pode ser contraprodutiva. Isto porque a taxa de redução de permanganato também aumentará, possivelmente devido a decomposição do permanganato por $\mathrm{MnO}_{2}$ sólidos.

Assim, o acúmulo de $\mathrm{MnO}_{2}$ gerado durante o processo pode interferir na transferência de massa, com consequente acúmulo desta espécie nos poros, resultando na redução da permeabilidade e, portanto limitando o fluxo subterrâneo. Embora o $\mathrm{MnO}_{2}$ seja insolúvel em água, o íon $\mathrm{Mn}^{+4}$ pode ser reduzido a $\mathrm{Mn}^{+2}$ em meio ácido $(\mathrm{pH}<2)$ ou condições redutoras. ${ }^{50}$ Por outro lado a solução de $\mathrm{MnO}_{4}{ }^{-}$de 2 a $6 \%$ é mais densa que a água, facilitando o transporte vertical deste oxidante no solo. Desta forma, facilita-se a distribuição e o transporte entre os poros, além de favorecer o contato entre o contaminante e o oxidante. ${ }^{43}$

Jonsson e colaboradores (2007), avaliaram a degradação de contaminantes presentes em dois solos, sendo um com a presença do fenantreno e pireno como espécies a serem degradadas, enquanto o outro continha uma mistura de HPA de uma refinaria refinaria sendo utilizados o íon $\mathrm{MnO}_{4}{ }^{-}$como oxidante. Em ambos os solos, houve a degradação de cerca de 
$66 \%$ dos contaminantes sendo que a duração do tratamento foi de 72 e 144 horas. ${ }^{47}$ Por outro lado, em um outro estudo realizado por Brown e colaboradores (2003), a quantidade restante de fenantreno e antraceno em um solo foi de 56 e $53 \%$ respectivamente, utilizando-se uma solução de $\mathrm{KMnO}_{4}$ de $0,16 \mathrm{~mol} \mathrm{~L}^{-1}$ sob 30 minutos de agitação. ${ }^{51}$

Já em um sedimento contaminado com HPA, Ferrarese e colaboradores (2008) obtiveram uma degradação de até $96 \%$ dos HPA, porém com uma concentração de 0,5 a 1 mol L ${ }^{-1}$ de $\mathrm{KMnO}_{4}$. No entanto, restou cerca de 15 e $35 \%$ de carbono orgânico total (COT) em relação ao início do tratamento, respectivamente. ${ }^{52}$

Estes e outros trabalhos demonstram que fatores como concentração do contaminante e do oxidante, sistema de agitação e tempo de reação podem interferir na porcentagem de degradação quando se utiliza o permanganato como oxidante.

\subsubsection{Fenton}

Um dos POA mais conhecidos é a reação de Fenton. A reação de Fenton consiste na decomposição do peróxido de hidrogênio na presença de metais, como íons ferrosos $\left(\mathrm{Fe}^{2+}\right)$ gerando radicais e tem demonstrado ser bastante eficiente na oxidação de compostos orgânicos tóxicos e não biodegradáveis.

$\mathrm{O}$ pH impacta na solubilidade dos íons de ferro e na reatividade junto ao peróxido de hidrogênio, assim como no radical formado na degradação do contaminante alvo. ${ }^{53} \mathrm{Em} \mathrm{pH}$, acima de 4, há a formação de óxidos e hidróxidos de ferros, o que tornam os íons de ferro não disponíveis para a geração do radical.

As reações radicalares geradas durante a reação de Fenton, as quais ocorrem simultaneamente, são reações em cadeia, onde os produtos de reação fornecem produtos para outra reação (Figura 7). Há radicais provenientes do peróxido de hidrogênio que podem desempenhar diferentes papéis na degradação de contaminantes orgânicos (Reação 1-4) 


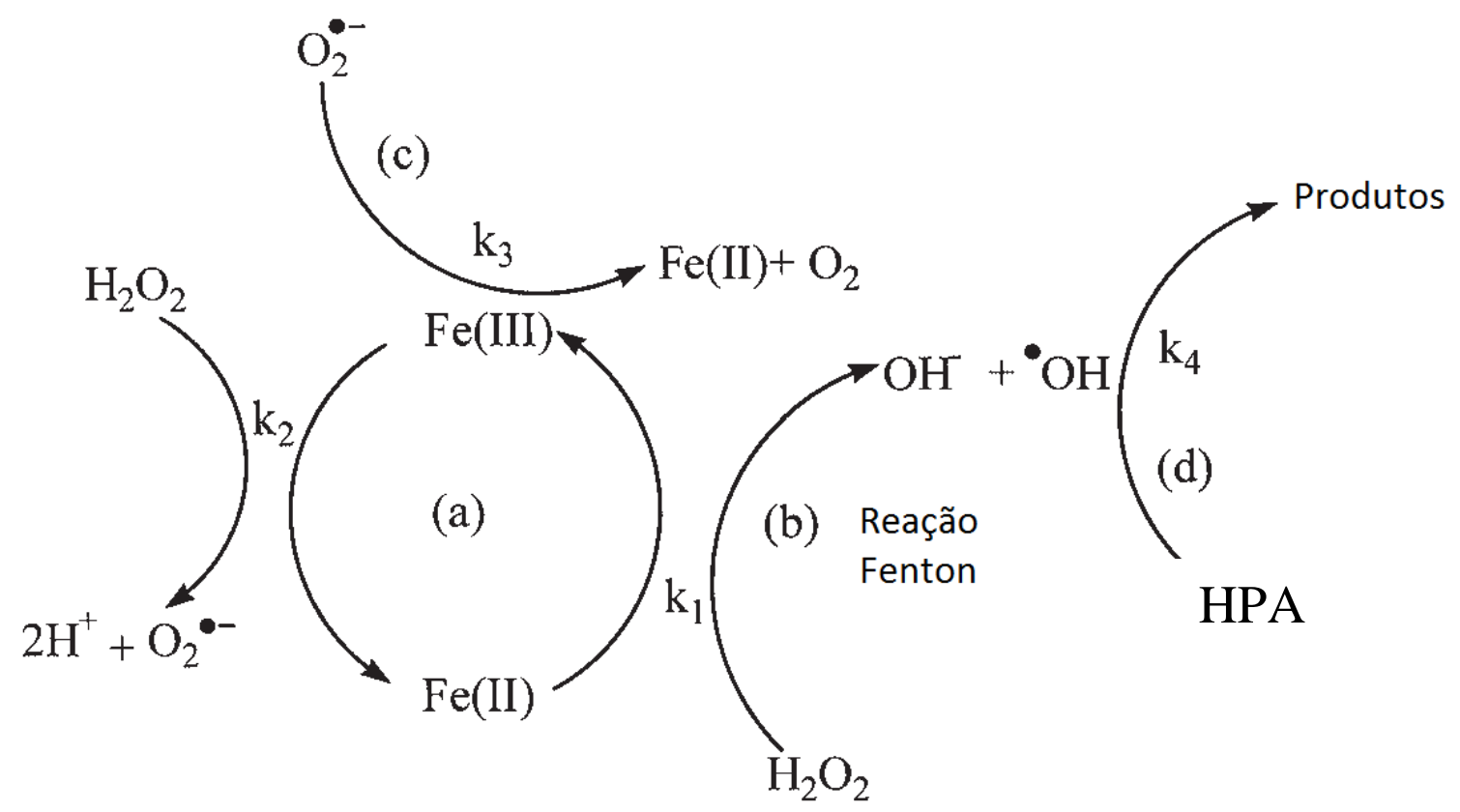

Figura 7- Mecanismo de decomposição dos HPA via Fenton ${ }^{54}$ : (a) ciclo do ferro entre os estados de oxidação II e III; (b) formação do radical hidroxila via reação Fenton; (c) redução do Fe (III) por radicais superóxido; (d) reações entre HPA e o radical hidroxila.

O radical hidroxila $(\cdot \mathrm{OH})$ é um forte oxidante não-seletivo, reage com uma ampla variedade de compostos orgânicos e inorgânicos. Outros importantes radicais estão envolvindos na oxidação dos contaminantes incluindo o radical hidroperoxila $\left(\mathrm{HO}_{2}{ }^{\circ}\right)$, o ânion radical superóxido $\left(\mathrm{O}_{2}{ }^{-}\right)$e ânion hidroperóxido $\left(\mathrm{HO}_{2}^{-}\right)$. Entre estes radicais gerados pelo peróxido de hidrogênio, o radical hidroxila tem o maior potencial de redução $(2,8 \mathrm{~V})$ e é o radical predominante em condições ácidas. ${ }^{55}$

$$
\begin{aligned}
& \mathrm{Fe}^{2+}+\mathrm{H}_{2} \mathrm{O}_{2} \rightarrow \mathrm{Fe}^{3+}+\mathrm{OH}^{-}+{ }^{\cdot} \mathrm{OH} \text { (Reação 1) } \\
& \cdot \mathrm{OH}+\mathrm{H}_{2} \mathrm{O}_{2} \rightarrow \mathrm{HO}_{2} \cdot+\mathrm{H}_{2} \mathrm{O} \text { (Reação 2) } \\
& \mathrm{HO}_{2}{ }^{\cdot} \leftrightarrow \mathrm{O}_{2}{ }^{\cdot-}+\mathrm{H}^{+} \text {pKa 4,8 (Reação 3) } \\
& \mathrm{HO}_{2}{ }^{-}+\mathrm{O}_{2}{ }^{\cdot-} \rightarrow \mathrm{HO}_{2}^{-}+\mathrm{O}_{2}(\text { Reação } 4)
\end{aligned}
$$


Em elevadas concentrações de peróxido de hidrogênio $\left(\mathrm{H}_{2} \mathrm{O}_{2}\right)$ no meio reacional, pode haver reação do peróxido de hidrogênio com o radical hidroxila, formando o radical hidroperoxila $\left(\mathrm{HO}_{2}\right)$ (Reação 3). Com isso a eficiência da reação é reduzida pois o radical hidroperoxila apresenta menor potencial de redução $(1,5 \mathrm{~V})$ em relação ao radical hidroxila. Altas concentrações de $\mathrm{Fe}^{2+}$ tem efeito similar sob a eficiência das reações de Fenton quando em concentrações elevadas, pois estes íons podem reagir com os radicais hidroxilas formados comprometendo a degradação dos contaminantes (Reação 5).

$$
\cdot \mathrm{OH}+\mathrm{Fe}^{2+} \rightarrow \mathrm{Fe}^{3+}+\mathrm{OH}^{-}(\text {Reação } 5)
$$

Os radicais são reativos com o próprio peróxido de hidrogênio e também com espécies como carbonatos, bicarbonatos e cloretos e outros íons inorgânicos presentes no solo que podem afetar a eficiência da degradação dos HPA. ${ }^{53}$

A uniformidade e eficiência nos tratamentos baseados nos processo de Fenton em solos contaminados com HPA são afetadas pela heterogeneidade da matriz do solo, decorrente da variação do carbono total orgânico (COT), material oxidável, porosidade da matriz e idade do solo. Além disso, estudos anteriores têm demonstrado que mesmo adicionando oxidante em excesso a mineralização pode não ser completa, pois fatores como efeito da matriz solo, o tempo de reação e a quantidade de ferro pode comprometer a eficiência da degradação. Por exemplo, Sun e colaboradores (2008) verificaram que a degradação de pireno em três solos com diferentes texturas variou de 65 a $89 \%$ utilizando os processos de Fenton, tendo como concentração de contaminante inicial de $40 \mathrm{mg} \mathrm{kg}^{-1}{ }^{56} \mathrm{Em}$ outro estudo realizado por Flotron e colaboradores (2005) verificaram uma remoção de 8 a 98\% dos HPA (4 a 5 anéis aromáticos) em diferentes matrizes (solo, sedimento e lodo) nativas. ${ }^{57}$ Ferrarese e colaboradores (2008) estudaram a utilização de sedimento nativo 
contaminado com a 16 HPA prioritários e obtiveram a degradação de $70-98 \%$ dos contaminantes utilizando as reações de Fenton. ${ }^{52}$

\subsubsection{Persulfato}

$\mathrm{O}$ persulfato $\left(\mathrm{S}_{2} \mathrm{O}_{8}{ }^{-2}\right)$ tem sido estudado como um oxidante alternativo para tratamentos de contaminantes em solos e águas subterrâneas. Há três sais comercialmente disponível de persulfato, entre eles sódio, potássio e amônio. Destes, o persulfato de sódio é muito mais solúvel em água que o de potássio e o de amônio é o menos estável.

O persulfato apresenta similaridade com o peróxido de hidrogênio, pois ambos os oxidantes ao serem ativados geram radicais que tem uma reatividade não específica que permite atacar uma variedade de contaminantes orgânicos.

Os radicais sulfato $\left(\mathrm{SO}_{4}{ }^{-*}\right)$, tal qual o radical hidroxila $(\cdot \mathrm{OH})$ são altamente reativos para compostos orgânicos e apresentam mecanismo de reação semelhantes. O radical sulfato $\left(\mathrm{SO}_{4}{ }^{-}\right)$e hidroxila $(\cdot \mathrm{OH})$ são fortes oxidantes que degradam os contaminantes orgânicos. ${ }^{58,59,60}$ No entanto, o persulfato é mais estável que o peróxido de hidrogênio assim como também seu radical intermediário sulfato $\left(\mathrm{SO}_{4}{ }^{-{ }^{-}}\right)$é mais estável que o radical ${ }^{\circ} \mathrm{OH}$. Isso possivelmente deve-se ao fato que o radical sulfato apresenta maior número de estruturas possíveis de ressonância o que ocasiona maior estabilidade ao radical sulfato em relação ao radical hidroxila (Figura 8). O peróxido de hidrogênio é também facilmente decomposto na presença de luz e de certas enzimas. Com isso o persulfato pode ser transportado por distâncias maiores pelos poros dos solos, o que favorece maior tempo de contato entre o próprio oxidante e o contaminante. Apesar do potencial padrão de redução do radical sulfato $(2,5 \mathrm{~V})$ ser similar ao potencial do radical hidroxila $(2,8 \mathrm{~V})$, a demanda de oxidante para o consumo da matéria orgânica natural presente nos solos é menor para o oxidante persulfato que para o peróxido de 
hidrogênio, o que acarreta melhor desempenho do persulfato em solos que apresentam maior quantidade de matéria orgânica. ${ }^{3,43,44,61}$ Em relação ao permanganato, o persulfato não é tão reativo com a matéria orgânica presente no solo. ${ }^{62}$

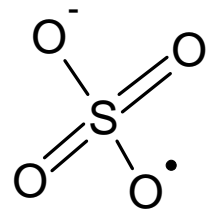

Figura 8 - Estrutura molecular do radical sulfato.

Koltoff e Miller (1951), mensuraram a taxa de decomposição do $\mathrm{K}_{2} \mathrm{~S}_{2} \mathrm{O}_{8}$ (persulfato de potássio) em água a temperatura de $50^{\circ} \mathrm{C}$, em diferentes valores de $\mathrm{pH}$. Verificaram que em meio ácido o tempo de meia vida do oxidante é menor que em meio neutro. Em $\mathrm{pH} 1$, o tempo de meia vida é de 20 horas enquanto em pH 7 tempo de meia vida de é 132 horas. Considerando que a decomposição do persulfato é de primeira ordem, o tempo de meia vida é independente da concentração inicial do oxidante no sistema. ${ }^{63}$

Os radicais sulfatos apresentam maior reatividade perante os poluentes do que o ânion persulfato. ${ }^{64,65}$ A taxa de reação do íon persulfato são de 1.000 a 100.000 mais lenta que o radical sulfato, sendo então necessário gerá-los. ${ }^{66,67}$

Assim, para gerar os radicais sulfato é preciso ativar o ânion persulfato, e essa ativação pode ser por meio de aquecimento (Reação 6), da radiação UV (Reação 7), e do uso de metais de transição (Reação 8) e da alteração do pH (Reação 9). Quando o persulfato é ativado por aquecimento, utiliza-se sistemas com temperaturas entre $40-99^{\circ} \mathrm{C}$ tendo como vantagem a formação somente de radicais sulfatos proveniente do persulfato como produto. No entanto não é aplicável para a degradação de compostos semi-voláteis e voláteis, como o fenantreno e antraceno. ${ }^{58,61,63,68}$ 


$$
\begin{aligned}
& \mathrm{S}_{2} \mathrm{O}_{8}{ }^{2-} \stackrel{\text { aquecimento }}{\longrightarrow} 2 \mathrm{SO}_{4}{ }^{-*} \text { (Reação 6) } \\
& \mathrm{S}_{2} \mathrm{O}_{8}{ }^{2-} \stackrel{\mathrm{hv}}{\longrightarrow} 2 \mathrm{SO}_{4}^{0^{-}} \text {(Reação 7) } \\
& \mathrm{S}_{2} \mathrm{O}_{8}{ }^{2-}+\mathrm{M}^{\mathrm{n}+} \longrightarrow \mathrm{SO}_{4}^{--}+\mathrm{SO}_{4}^{2-}+\mathrm{M}^{\mathrm{n}+1} \quad(\text { Reação } 8) \\
& \mathrm{S}_{2} \mathrm{O}_{8}{ }^{2-}+2 \mathrm{H}_{2} \mathrm{O} \stackrel{\text { OH- }}{\longrightarrow} \mathrm{SO}_{4}^{-^{-}}+3 \mathrm{SO}_{4}^{2-}+\mathrm{O}_{2}{ }^{--}+4 \mathrm{H}^{+} \text {(Reação 9) }
\end{aligned}
$$

\subsubsection{Utilização de metais como forma de ativação}

O uso de metal de transição é o método de ativação mais comum para persulfato. $\mathrm{O}$ persulfato ativado por metais de transição oferece vantagens como acelerar a reação à temperatura ambiente. $\mathrm{O}$ metal mais utilizado é o ferro por não ser potencialmente tóxico e muitas vezes estar presente no próprio solo. ${ }^{69}$

O mecanismo envolve a transferência de um elétron, proveniente do íon ferroso, resultando na formação de um radical sulfato e um ânion sulfato assim como um íon férrico como produtos (Reação 10). ${ }^{69,70}$

$$
\mathrm{S}_{2} \mathrm{O}_{8}{ }^{2-}+\mathrm{Fe}^{2+} \stackrel{\text { em pH 2 3 }}{\longrightarrow} \mathrm{SO}_{4}^{{ }^{--}}+\mathrm{SO}_{4}{ }^{2-}+\mathrm{Fe}^{3+} \text { (Reação 10) }
$$

A adição em excesso de $\mathrm{Fe}^{2+}$, pode resultar em uma reação rápida com o próprio radical $\mathrm{SO}_{4}{ }^{-}$, destruindo o radical. Este comportamento pode ser caracterizado como a competição do $\mathrm{SO}_{4}{ }^{--}$entre o contaminante alvo e o excesso de $\mathrm{Fe}^{2+}$ o que ocasiona uma baixa eficiência de degradação do contaminante alvo. ${ }^{71}$ Embora o persulfato possa ser gerado por íons de ferro, este também pode atuar como sequestrantes de radical sulfato (Reação 11).

$$
\mathrm{SO}_{4}{ }^{--}+\mathrm{Fe}^{2+} \longrightarrow \mathrm{Fe}^{3+}+\mathrm{SO}_{4}{ }^{2-} \text { (Reação 11) }
$$


Há poucos estudos no tratamento de HPA usando persulfato ativado com $\mathrm{Fe}^{2+} \cdot 3,72 \mathrm{~A}$ degradação de HPA por persulfato ativado tem sido descrito na literatura, no entanto há pouca informação específica disponível, como o mecanismo de destruição dos contaminantes e quais são os intermediários que podem ser formados. ${ }^{61,65}$

Usman e colaboradores (2012) avaliaram o perfil do oxidante persulfato em solo na presença de ferro solúvel, verificou-se que houve a degradação de somente $15 \%$ após uma semana de tratamento. Em outro estudo, Ferrarese e colaboradores (2008) utilizando também o ferro como ativante, observaram a degradação de 81 a $91 \%$ dos HPA. ${ }^{52,73}$ Ambos eram solos nativos contaminados, porém com dosagem e concentração de oxidantes diferentes. 


\section{OBJETIVOS}

O principal objetivo deste trabalho foi avaliar a eficiência da degradação de HPA presentes em solos arenosos contaminados com diferentes oxidantes, bem como verificar a influência da matéria orgânica presente no solo, no processo de degradação dos contaminantes.

Como metas específicas, foi realizado um estudo comparativo entre os oxidantes peróxido de hidrogênio, persulfato de sódio e permanganato de potássio em diferentes matrizes. Foi avaliado também, se parte do carbono orgânico proveniente da matéria orgânica é consumida pelo oxidante persulfato, pois isso pode retardar o processo de mineralização, assim como alterar as características originais do solo. Além disso, identificou-se a possível formação de intermediários provenientes dos contaminantes formados durante o processo de degradação com os diferentes oxidantes. 


\section{MATERIAIS E MÉTODOS}

\subsection{Preparo da matriz de referência areia padrão}

Foi utilizada a areia para filtro de piscina (Jacuzzi) como matriz padrão para avaliar eficiência dos diferentes oxidantes. Esta areia apresentava granulometria de $0,5 \mathrm{~mm}$ de diâmetro e porosidade de $26 \%$. Antes de realizar os experimentos, a areia foi lavada com etanol e água deionizada e depois seca em estufa a $100{ }^{\circ} \mathrm{C}$ por $24 \mathrm{~h}$, para garantir a ausência de matéria orgânica.

\subsection{Contaminação simulada da areia padrão}

Os contaminantes, fenantreno (98\% de pureza-Sigma Aldrich) e antraceno (97\% de pureza Sigma Aldrich), foram dissolvidos em diclorometano (VETEC), separadamente, resultando em concentração final de $40 \mathrm{~g} \mathrm{~L}^{-1}$ para fenantreno e $10 \mathrm{~g} \mathrm{~L}^{-1}$ para antraceno. Adicionou-se na areia controle pré-lavada, de acordo com item 3.1, diferentes volumes, com a seringa gás tight, das soluções de fenantreno e antraceno, de tal modo que a concentração final dos contaminantes em relação a areia fosse de $200 \mathrm{mg}$ de fenantreno e $25 \mathrm{mg}$ de antraceno para cada $\mathrm{kg}$ de solo seco. O sistema foi homogeneizado na areia utilizando um bastão de vidro. A areia contaminada foi acondicionada em um frasco revestido por papel alumínio e armazenado em geladeira, para não haver perda da concentração dos contaminantes, pois o fenantreno e antraceno, são compostos semi-voláteis. A extração dos contaminantes e a adição de oxidante foram feitas somente após 24 h da contaminação da areia padrão.

\subsection{Contaminação simulada dos solos arenosos}


As amostras deformadas de solos arenosos pertencentes a ordem do espodossolos e subordem humilúvicos foram gentilmente cedidas por FONTANA e colaboradores (2010), os quais também realizaram a caracterização física e química destes solos (Tabela 4). ${ }^{74} \mathrm{As}$ amostras de solo foram secas em temperatura ambiente, posteriormente destorroadas e passadas por peneira de 2,0 $\mathrm{mm}$ de diâmetro de malha, obtendo-se assim a terra fina seca.

As amostras de solos arenosos foram contaminadas da mesma maneira que a areia padrão (item 3.2) e assim como na areia padrão, a extração dos contaminantes e a adição de oxidante foram realizadas após 24 horas do procedimento de contaminação.

Tabela 4 Características Físico- químicas dos solos arenosos. ${ }^{74}$

\begin{tabular}{|c|c|c|c|c|c|c|c|c|c|}
\hline & Local & $\begin{array}{l}\text { Profundidade } \\
\qquad(\mathrm{cm})\end{array}$ & $\begin{array}{l}\text { C org } \\
\left(\mathrm{g} \mathrm{kg}^{-1}\right)\end{array}$ & $C-\mathbf{F A F}^{\mathbf{b}}$ & $\begin{array}{l}\text { C-FAH } \\
\left(\mathrm{g} \mathrm{kg}^{-1}\right)\end{array}$ & C-HUM ${ }^{d}$ & Areia & $\begin{array}{c}\text { Silte } \\
\left(\mathrm{g} \mathrm{kg}^{-1}\right)\end{array}$ & Argila \\
\hline Solo A & $\begin{array}{c}\text { Linhares } \\
\text { ES Bh1 }\end{array}$ & $15-50$ & 27,2 & 3,7 & 4,8 & 7,8 & 860 & 20 & 120 \\
\hline Solo B & $\begin{array}{l}\text { Linhares } \\
\text { ES Bh2 }\end{array}$ & $50-80$ & 16,0 & 4,5 & 4,4 & 3,9 & 908 & 3 & 89 \\
\hline Solo C & $\begin{array}{l}\text { Rio das } \\
\text { Ostras } \\
\text { RJ Bh }\end{array}$ & $40-65$ & 31,2 & 1,2 & 18,5 & 2,8 & 915 & 0 & 85 \\
\hline
\end{tabular}

\subsection{Extração Sólido Líquido}

Para a extração dos contaminantes foi usado o Extrator Acelerado por Solventes, (ASE-Accelerated Solvent Extractor), modelo 300 da Dionex Corporation, baseado no método 3545 da EPA. ${ }^{75}$ A técnica também é conhecida como Extração por Fluído Pressurizado, conhecida como PFE( Pressurized Fluid Extraction), ilustrada na Figura 9. 


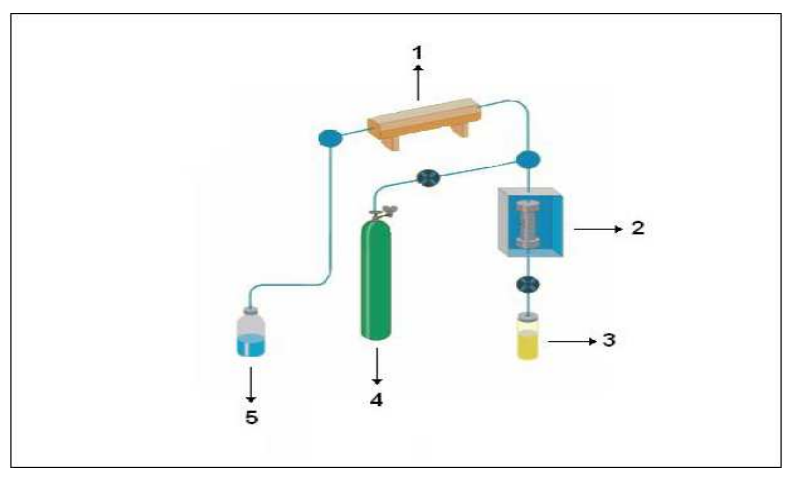

Figura 9- Ilustração das extração via ASE. $^{84}$ 1.Bomba, 2. Célula de extração (66 ml), 3. Frasco de coleta, 4. Cilindro de gás (nitrogênio), 5. Solvente (solução de 1:1 hexano:acetona).

Foram retirados quantitativamente $15 \mathrm{~g}$ de areia contaminadas dos frascos $\mathrm{e}$ transferidos para as células de extração $(66 \mathrm{~mL})$ que continha um micro filtro de fibra de vidro (33 mm FMAIA). Foram adicionandos $20 \mathrm{~g}$ de sulfato de sódio $\left(\mathrm{Na}_{2} \mathrm{SO}_{4}\right), 50 \mathrm{~g}$ de areia como material inerte e $10 \mu \mathrm{L}$ de surrogate fluorbifenil (Sigma Aldrich 47581U).

A extração foi feita com uma mistura de solventes hexano /acetona (1:1 v/v; VETEC) a $100{ }^{\circ} \mathrm{C}$. A célula foi preenchida com o solvente de extração (hexano:acetona) e foi mantida por 5 minutos em equilíbrio térmico com a válvula estática aberta. Depois a válvula era fechada e a célula foi mantida aquecida sob pressão por 15 minutos. Após este processo a válvula foi aberta e foram coletados o extrato e o solvente no frasco coletor. Foi realizado a descarga de $60 \%(40 \mathrm{~mL})$ correspondente ao volume da célula $(66 \mathrm{~mL})$ com o solvente de extração e 120 segundos de purga com o gás nitrogênio. O processo de extração foi efetuado a pressão de 1500 psi, o que corresponde a cerca de 100 atm.

Para as amostras de areia e solo controle que estavam em uma solução saturada de água, obteve-se o extrato no frasco de coleta do ASE com duas fases: orgânica (contaminante, hexano e acetona) e aquosa (água e acetona). A fase orgânica normalmente correspondia a cerca de $90 \%$ do total. A solução foi colocada em um funil de separação, onde a fase aquosa era coletada pela parte inferior e descartada, sendo analisada somente a fase orgânica. A fase 
orgânica foi transferida e concentrada em um concentrador de amostra modelo Rapid Vap da LabConco a $60{ }^{\circ} \mathrm{C}$, utilizando o nitrogênio como gás de arraste e à uma velocidade $70 \%$ de rotação $(350 \mathrm{rpm})$. O extrato foi levado para um balão volumétrico de $10 \mathrm{~mL}$ e o volume completado utilizando o solvente de extração. Para as amostras de solos arenosos, o extrato foi filtrado em filtro milipore $(0,45 \mathrm{~mm})$ para a retirada do material particulado, e transferido para vials de 1,5 $\mathrm{mL}$, para posterior análise em um cromatógrafo gasoso acoplado a espectrômetro de massa (CG/EM). As análises foram realizadas em duplicatas.

\subsection{Curvas de calibração dos contaminantes}

Para as curvas de calibração, foram preparadas soluções estoque de fenantreno, antraceno e antraquinona solubilizados em diclorometano com concentrações de 25.000, 1.000 e $1.000 \mathrm{mg} \mathrm{L}^{-1}$ respectivamente. Foram pipetadas as alíquotas, a partir das soluções estoque, de cada um dos contaminantes no mesmo balão com seringa de gás tight, de acordo com a Tabela 5.

TABELA 5 Dados empregados para a preparação da curva de calibração na quantificação de fenantreno, antraceno e atraquinona.

\begin{tabular}{ccccccc}
\hline $\begin{array}{c}\text { balão } \\
\text { de } 10 \mathrm{ml}\end{array}$ & $\begin{array}{c}\text { Alíquota } \\
\mu \mathrm{L}\end{array}$ & $\begin{array}{c}\text { Conc. F } \\
\left(\mathrm{mg} \mathrm{L}^{-1}\right)\end{array}$ & $\begin{array}{c}\text { Alíquota } \\
\mu \mathrm{L}\end{array}$ & $\begin{array}{c}\text { Conc. A } \\
\left(\mathrm{mg} \mathrm{L}^{-1}\right)\end{array}$ & $\begin{array}{c}\text { Alíquota } \\
\mu \mathrm{L}\end{array}$ & $\begin{array}{c}\text { Conc. Q } \\
\left(\mathrm{mg} \mathrm{L}^{-1}\right)\end{array}$ \\
\hline 1 & 4 & 10 & 10 & 1 & 10 & 1 \\
2 & 20 & 50 & 50 & 5 & 25 & 2,5 \\
3 & 40 & 100 & 100 & 10 & 50 & 5 \\
4 & 80 & 200 & 200 & 20 & 100 & 10 \\
5 & 120 & 300 & 300 & 30 & 200 & 20 \\
6 & 140 & 350 & 400 & 40 & 300 & 30 \\
\hline Conc.F=concentração de fenantreno; Conc.A=concentração de antraceno e Conc.Q=concentração de antraquinona.
\end{tabular}

Para compreensão da Tabela 5, por exemplo, no balão 1 foram adicionados $4 \mu \mathrm{L}$ de fenantreno, $10 \mu \mathrm{L}$ de antraceno , $10 \mu \mathrm{L}$ de antraquinona e o volume foi completado com o solvente de extração. As amostras foram analisadas posteriormente no CG/EM. 


\subsection{Análise por meio de CG/EM}

As análises foram feitas em um cromatógrafo gasoso acoplado a um espectrômetro de massas do fabricante Shimadzu (modelo QP 2010 Plus). O detector seletivo de massas foi operado no modo de ionização por impacto eletrônico, com energia de ionização de $70 \mathrm{eV}$ com um analisador de massa tipo quadrupolo linear. Foi utilizada a coluna capilar DB5MS (30 m de comprimento, $0,25 \mathrm{~mm}$ de diâmetro interno e $0,25 \mu \mathrm{m}$ de espessura do filme). A injeção foi de $1 \mu \mathrm{L}$ de amostra no modo splitless, nas seguintes condições cromatográficas: injetor a $250{ }^{\circ} \mathrm{C}$, interface a $280{ }^{\circ} \mathrm{C}$, fonte de íons a $300{ }^{\circ} \mathrm{C}$ e a temperatura da coluna de acordo com a programação a seguir $100{ }^{\circ} \mathrm{C}(1 \mathrm{~min})$; depois $10^{\circ} \mathrm{C} \min ^{-1}$ até $200^{\circ} \mathrm{C}(1 \mathrm{~min})$; a seguir $10^{\circ} \mathrm{C} \min ^{-1}$ até $250{ }^{\circ} \mathrm{C}$ (15 min). Utilizou-se hélio como gás de arraste, com fluxo constante de $1,5 \mathrm{~mL} \mathrm{~min}^{-1}$. Foi feita uma varredura no modo scan de 40 a $350 \mu$. Os parâmetros foram baseados no método 8270 da EPA. ${ }^{76}$ A quantificação foi feita por meio da curva de calibração preparada como descrito no item 3.5. O procedimento analítico empregado em todo processo de contaminação dos solos até a quantificação dos poluentes está representado na Figura 10. 


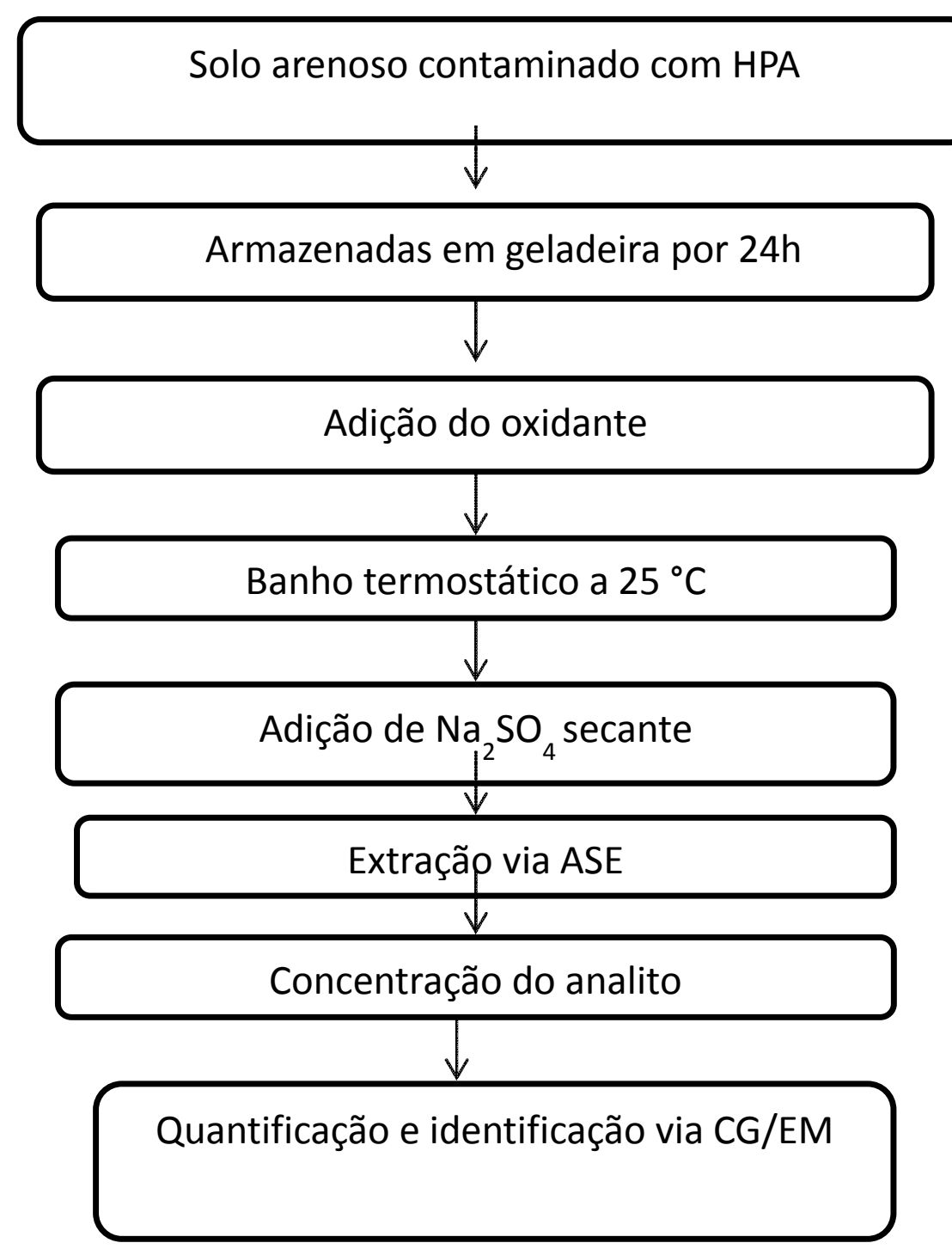

Figura 10- Procedimento de contaminação, remediação, identificação e quantificação dos contaminantes presentes no solo.

\subsection{Preparação das soluções oxidantes em diferentes matrizes}

O preparo das soluções oxidantes aplicadas nas diferentes matrizes está descrita abaixo, assim como na Tabela 6 consta resumidamente as proporções molares aplicadas para o uso dos diferentes oxidantes.

\subsubsection{Uso do oxidante $\mathrm{KMnO}_{4} \mathrm{em}$ matriz areia padrão}


Para os ensaios utilizando areia padrão como matriz tendo como oxidante permanganato foi primeiramente preparada uma solução de permanganato de potássio com concentração de aproximadamente $16 \mathrm{~g} \mathrm{~L}^{-1}$, agitada por no mínimo 1 hora, para se certificar da completa dissolução do permanganato, foi aquecida a $60^{\circ} \mathrm{C}$ por $30 \mathrm{~min}$. As soluções foram deixadas em repouso por $24 \mathrm{~h}$ e posteriormente padronizadas de acordo com o método teste padrão 4500 para determinação de $\mathrm{KMnO}_{4}{ }^{77}$ Para o tratamento foram pesados $15 \mathrm{~g}$ da areia padrão contaminada conforme o item 4.2, e colocada em um frasco com volume de 40 $\mathrm{mL}$, ao qual foi adicionado um volume de $4 \mathrm{~mL}$ da solução do oxidante $\mathrm{KMnO}_{4}$ de tal forma que garantisse a saturação e não houvesse sobrenadante, além de manter a proporção estequiométrica de 1:22 (contaminante:oxidante). Os frascos foram vedados, revestidos com papel alumínio e colocados em banho termostático à $25^{\circ} \mathrm{C}$.

\subsubsection{Uso do oxidante $\mathrm{H}_{2} \mathrm{O}_{2}$ ativado com $\mathrm{Fe}^{2+}$ em areia padrão}

Para o ensaio do Fenton, foram pesados $0,53 \mathrm{~g}$ de $\mathrm{FeSO}_{4} \cdot 7 \mathrm{H}_{2} \mathrm{O}$ (VETEC) em um balão volumétrico de $50 \mathrm{~mL}$, avolumou-se com água deionizada e acertou-se o pH em cerca de 2 3 com uma solução de ácido sulfúrico 10\%. Foram retiradas uma alíquota de $4 \mathrm{~mL}$ da solução de ferro e $127,8 \mu \mathrm{L}$ de uma solução de $\mathrm{H}_{2} \mathrm{O}_{2}$ com concentração de 11,8 mol L $\mathrm{L}^{-1}$ (Synth lote 134143 ) e transferidas para um frasco que continha 15 g de areia padrão. Após 12 horas foram transferidos mais $127,8 \mu \mathrm{L}$ de uma solução de $\mathrm{H}_{2} \mathrm{O}_{2}$. Assim tanto nos ensaios com areia padrão quanto nos ensaios com solos arenosos foi mantida a proporção em número de mols de 1:160: 8 entre contaminante: oxidante: $\mathrm{Fe}^{2+}$. Os frascos foram vedados, revestidos com papel alumínio e colocados em banho termostático à $25^{\circ} \mathrm{C}$. O procedimento analítico está representado na Figura 10. 


\subsubsection{Uso do oxidante $\mathrm{Na}_{2} \mathrm{~S}_{2} \mathrm{O}_{8}$ ativado com $\mathrm{Fe}^{2+}$ em matriz areia padrão}

Para os ensaios que se utilizou o oxidante $\mathrm{Na}_{2} \mathrm{~S}_{2} \mathrm{O}_{8}$ ativado com $\mathrm{Fe}^{2+}$ tendo a areia padrão como matriz, utilizou-se a proporção molar 1:33 (contaminante: oxidante) para a qual foram pesados $4 \mathrm{~g}$ de $\mathrm{Na}_{2} \mathrm{~S}_{2} \mathrm{O}_{8}$ (VETEC) em um balão volumétrico de $50 \mathrm{~mL}$ e completado com água deionizada. Para preparar a solução de $\mathrm{Fe}^{2+}$, foram pesados $1,06 \mathrm{~g}$ de $\mathrm{FeSO}_{4} \cdot 7 \mathrm{H}_{2} \mathrm{O}$ (VETEC) em um balão volumétrico de $50 \mathrm{~mL}$ e acertou-se o pH em cerca de 2 3 com uma solução de ácido sulfúrico 10\%. Foram retiradas alíquotas de $2 \mathrm{~mL}$ de cada uma das soluções (oxidante e ferro) e transferidas para um frasco que continha $15 \mathrm{~g}$ da areia padrão contaminada de acordo com o item 4.2. Os frascos foram vedados, revestidos com papel alumínio e colocados em banho termostático à $25^{\circ} \mathrm{C}$.

Foi também utilizada a proporção molar de 1:100 (contaminante:oxidante) para qual foram pesados $11,20 \mathrm{~g}$ de $\mathrm{Na}_{2} \mathrm{~S}_{2} \mathrm{O}_{8}$ (VETEC) transferidos para um balão volumétrico de $50 \mathrm{~mL}$, completando com água deionizada. Assim, a concentração de $\mathrm{Fe}^{2+}$ e a proporção 1:33 (contaminante: oxidante) foram mantidas.

\subsubsection{Uso do oxidante de $\mathrm{Na}_{2} \mathrm{~S}_{2} \mathrm{O}_{8}$ ativado com $\mathrm{NaOH}$ em matriz areia padrão}

Foi pesado $4 \mathrm{~g}$ de $\mathrm{Na}_{2} \mathrm{~S}_{2} \mathrm{O}_{8}$ (VETEC) em um balão volumétrico de $50 \mathrm{~mL}$ e completou-se com água deionizada.Para preparar uma solução de $\mathrm{NaOH}$ (VETEC) foram pesados 1,06 g e avolumado para um balão de $100 \mathrm{~mL}$. Foram retiradas alíquotas de $2 \mathrm{~mL}$ de cada uma das soluções e transferidas para o frasco que já continha a areia contaminada, como nos experimentos anteriores.

\subsubsection{Uso do oxidante $\mathrm{H}_{2} \mathrm{O}_{2}$ ativado com $\mathrm{Fe}^{2+}$ em solos arenosos}


Para os ensaios do solo padrão, foram pesados 0,265 g de $\mathrm{FeSO}_{4} \cdot 7 \mathrm{H}_{2} \mathrm{O}$ (VETEC) em um balão volumétrico de $50 \mathrm{~mL}$, avolumou-se com água deionizada e ajustou-se o $\mathrm{pH}$ em cerca de 2 3 com uma solução de ácido sulfúrico 10\%. Foram retiradas alíquotas de $8 \mathrm{~mL}$ da solução de ferro e $127,8 \mu \mathrm{L}$ de uma solução de $\mathrm{H}_{2} \mathrm{O}_{2}$ com concentração de 11,8 mol L $\mathrm{L}^{-1}$ (Synth lote 134143). As alíquotas foram transferidas para um frasco que continha $15 \mathrm{~g}$ de areia padrão. Após 12 horas foram adicionados mais 127,8 $\mu \mathrm{L}$ de uma solução de $\mathrm{H}_{2} \mathrm{O}_{2}$. Para realizar um estudo comparativo entre a areia padrão e o solo arenoso para que ambos mantivessem saturados e com a mesma quantidade de mol de oxidante e ferro no sistema, foi necessário dobrar o volume de solução aquosa para $8 \mathrm{~mL}$. No entanto manteve-se a proporção em número de mols de 1:160:8 entre contaminante:oxidante: $\mathrm{Fe}^{2+}$ tanto na areia padrão quanto no solo arenoso. Os frascos foram vedados, revestidos com papel alumínio e colocados em banho termostático à $25^{\circ} \mathrm{C}$. O procedimento analítico está representado na Figura 10.

\subsubsection{Uso do oxidante $\mathrm{Na}_{2} \mathrm{~S}_{2} \mathrm{O}_{8}$ ativado com $\mathrm{Fe}^{2+}$ em matriz solo arenoso}

Para os ensaios com os solos arenosos (Tabela 6), foram pesados 5,50 g de $\mathrm{Na}_{2} \mathrm{~S}_{2} \mathrm{O}_{8}$ (VETEC) em um balão volumétrico de $50 \mathrm{~mL}$, avolumado com água destilada. Em outro balão volumétrico de $50 \mathrm{~mL}$ foi adicionado $0,53 \mathrm{~g}$ de $\mathrm{FeSO}_{4} .7 \mathrm{H}_{2} \mathrm{O}$ (VETEC), avolumou-se com água destilada e acertou o pH em cerca de 2 3 com uma solução de ácido sulfúrico 10\%. Foram retiradas alíquotas de $4 \mathrm{~mL}$ da solução de ferro e $4 \mathrm{~mL}$ da solução do oxidante $\left(\mathrm{Na}_{2} \mathrm{~S}_{2} \mathrm{O}_{8}\right)$ e transferidas para um frasco que continha $15 \mathrm{~g}$ de solo arenoso. Os solos arenosos apresentavam maior porosidade em relação a areia padrão, mesmo apresentando o predomínio percentual de areia em sua composição. Com isso para realizar um estudo comparativo com a areia padrão dobrou-se o volume de solução aquosa para $8 \mathrm{~mL}$ para que ambos mantivessem saturados e com a mesma quantidade de mol de oxidante e ferro no sistema. Assim tanto nos ensaios com areia padrão quantos nos solos arenosos manteve-se a proporção em número 
de mols de 1:100:8 entre contaminante:oxidante: $\mathrm{Fe}^{2+} . \mathrm{O}$ procedimento analítico adotado são os mesmos representados na Figura 10.

\subsection{Quantificação do teor de carbono orgânico presente nos solos arenosos}

A quantificação de carbono orgânico total (C-org) do solo foi obtido após oxidação do carbono orgânico com dicromato de potássio $\left(\mathrm{K}_{2} \mathrm{Cr}_{2} \mathrm{O}_{7}\right)$ em meio ácido $\left(\mathrm{H}_{2} \mathrm{SO}_{4}\right)$, onde o excesso de dicromato foi titulado com sulfato ferroso amoniacal $\left(\mathrm{Fe}\left(\mathrm{NH}_{4}\right)_{2}\left(\mathrm{SO}_{4}\right)_{2} \cdot 6 \mathrm{H}_{2} \mathrm{O}\right)$. A matéria orgânica do solo foi fracionada nas frações húmicas: ácidos fúlvicos, ácidos húmicos e humina, baseando nas solubilidades diferenciais destas frações em solução de $\mathrm{NaOH}$ e de acordo com o pH da solução. Foram seguidas as normas da Sociedade Internacional de Substância Húmicas em proposta modificada por Benites e colaboradores (2003). O carbono de cada fração foi obtido após oxidação do carbono orgânico com dicrormato de potássio $\left(\mathrm{K}_{2} \mathrm{Cr}_{2} \mathrm{O}_{7}\right)$ em meio ácido $\left(\mathrm{H}_{2} \mathrm{SO}_{4}\right)$, onde o excesso de dicromato foi titutaldo com sulfato ferroso amoniacal $\mathrm{Fe}\left(\mathrm{NH}_{4}\right)_{2}\left(\mathrm{SO}_{4}\right)_{2} \cdot 6 \mathrm{H}_{2} \mathrm{O}$. Ambas as quantificações foram efetuadas na Universidade Federal Rural do Rio de Janeiro. ${ }^{78,79,80}$ 
Tabela 6 Uso dos diferentes oxidantes aplicados em diferentes matrizes.

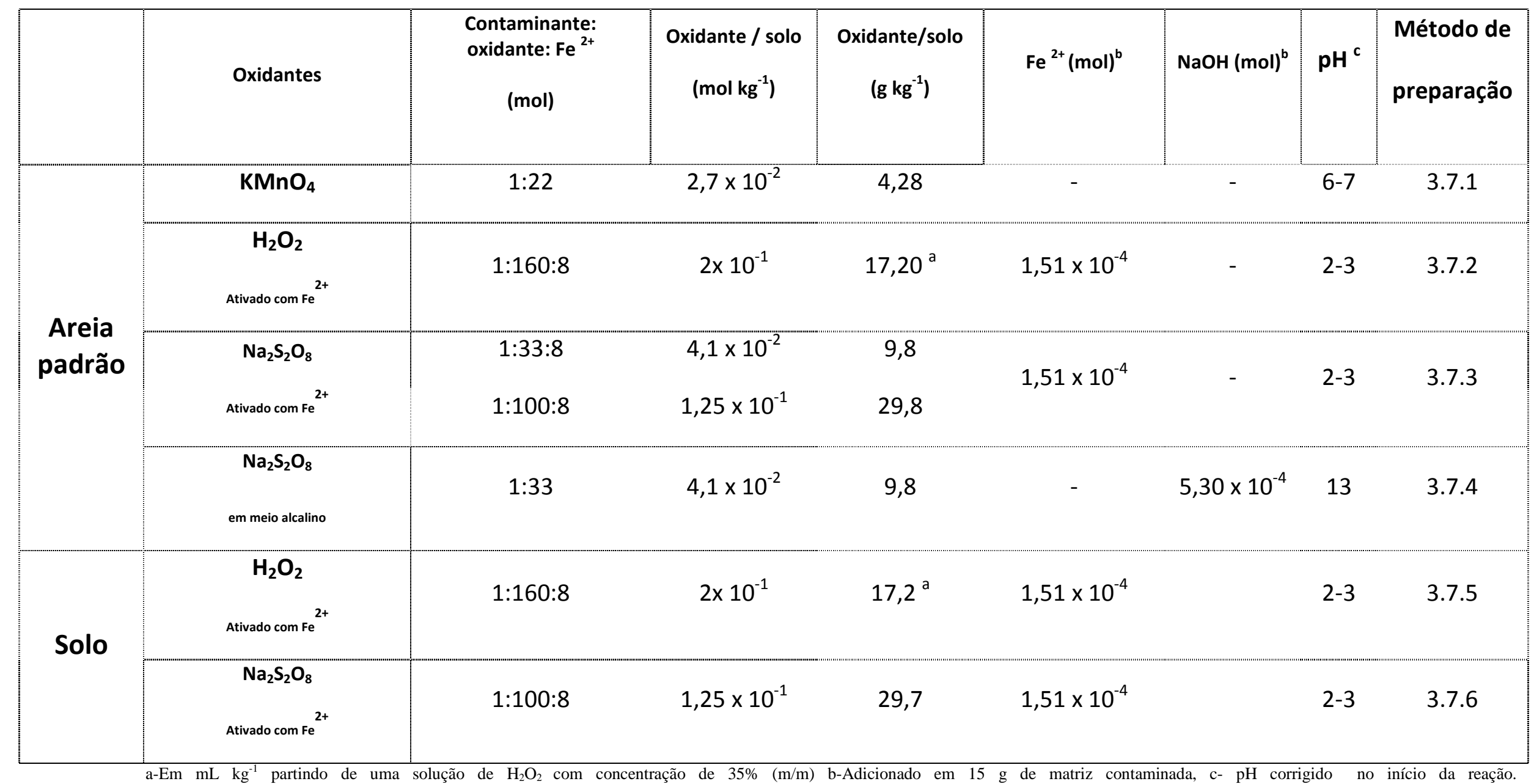




\section{RESULTADOS E DISCUSSÃO}

Uma das etapas do presente trabalho envolveu o desenvolvimento da metodologia de extração e de identificação dos contaminantes para avaliar a eficiência de cada um dos oxidantes. Foi utilizado, inicialmente como matriz, a areia padrão para avaliar a eficiência de degradação e formação de intermediários originados dos contaminantes. Após esta etapa, foram aplicados os oxidantes em solos arenosos na presença de diferentes teores de matéria orgânica.Nos tratamentos oxidativos, foi avaliado também o consumo de carbono orgânico nos solos arenosos proveniente da matéria orgânica. Tanto a areia padrão quanto os solos arenosos foram impregnados com fenantreno e antraceno em laboratório como descritos nos itens 3.1 e 3.2. Todos os experimentos foram realizados em duplicata. Os valores de concentração dos contaminantes escolhidos para este estudo eram valores que estão acima dos valores orientadores para solo determinados pela CETESB, o que permitiu simular a possibilidade de tratamento destes solos por meio de uso de diferentes oxidantes. ${ }^{26} \mathrm{O}$ limite de quantificação para esta metodologia adotada para os compostos fenantreno, antraceno e antraquinona foram de 6,67, 0,66 e $1,67 \mathrm{mg} \mathrm{kg}^{-1}$, respectivamente.

\subsection{Extração dos contaminantes em diferentes matrizes}

Foi avaliado a eficiência da extração dos contaminantes fenantreno e antraceno tanto na matriz areia padrão quanto na matrizes solo A, B e C.

\subsubsection{Extração dos contaminantes na areia padrão}

Para avaliar o índice de recuperação dos contaminantes na areia padrão no processo de extração, foi realizada a extração tanto em "areia seca" (sem umidade) quanto na areia padrão saturada de água, nomeada de areia controle. Ambas as matrizes foram contaminadas com 
fenantreno e antraceno. Avaliou-se o perfil de recuperação dos contaminantes tanto na areia padrão quanto nas amostras de solos arenosos utilizados neste presente trabalho.

No processo de extração no $A S E$, houve perda na recuperação dos contaminantes presentes na areia controle em relação aos presentes na areia seca. Houve a perda de cerca de $20 \%$ dos contaminantes durante o processo de extração, possivelmente essa perda não esteja ocorrendo por partição do contaminante para fase aquosa. $\mathrm{O}$ antraceno apesar de ser 120 vezes menos solúvel em água em relação ao fenantreno, considerando a solubilidade efetiva, apresentou o mesmo perfil de recuperação do fenantreno quando se avaliou a mesma matriz (Tabela 7). A recuperação dos contaminantes não está diretamente relacionada com a solubilidade dos contaminantes.

Tabela 7- Extração dos contaminantes no ASE.

\begin{tabular}{ccccc}
\hline Amostra & $\begin{array}{c}\text { Conc. Fenantreno } \\
\left(\mathbf{m g ~ k g} \mathbf{~ k}^{-1}\right)\end{array}$ & $\mathbf{C V}^{\mathbf{a}}$ & $\begin{array}{c}\text { Conc. Antraceno } \\
\left(\mathbf{m g ~ k g}^{\mathbf{- 1}}\right)\end{array}$ & $\mathbf{C V}^{\mathbf{a}}$ \\
\hline Areia controle & 155,5 & 10,1 & 17,7 & 1,8 \\
Areia seca & 200,3 & 9,2 & 23,2 & 1,4 \\
\hline a- & CV - coeficiente de variação &
\end{tabular}

A presença de umidade no solo estudado influenciou na eficiência da extração do contaminante com o solvente de extração. Foram obtidos cerca de $80 \%$ de recuperação para ambos os contaminantes na areia controle em relação a areia seca, mesmo apresentando solubilidades em água tão distintas.

Sabe-se que fatores como temperatura, umidade, polaridade do solvente, tipo de solo e presença de matéria orgânica podem influenciar na extração dos HPA do solo. ${ }^{81}$ Assim cada matriz, poderia apresentar distintos valores de recuperação dos contaminantes, ainda que fosse adotado o mesmo método de extração.

Não foi possível secar as amostras antes e após o processo de oxidação, tendo em vista que a recuperação dos contaminantes poderia ser menor, pois os contaminantes 
fenantreno e antraceno presentes na matriz são considerados semi-voláteis. Além disso, eram desconhecidas as propriedades físico-químicas dos possíveis compostos formados a partir dos contaminantes, após o uso dos oxidantes. Estudos constataram perdas significativas do analito quando amostras de solos contaminados com HPA foram secas em temperaturas superiores a $40{ }^{\circ} \mathrm{C}$, motivo pelo qual foi utilizado sulfato de sódio como secante. ${ }^{82} \mathrm{O}$ sulfato de sódio $\left(\mathrm{Na}_{2} \mathrm{SO}_{4}\right)$ foi adicionado como secante e também para cessar as reações de oxidação química, já que estas reações preferencialmente ocorrem em meio aquoso.

A solubilidade do fenantreno e o antraceno em água eram de $1,18 \mathrm{mg} \mathrm{L}^{-1}$ e $7,5 \times 10^{-2}$ $\mathrm{mg} \mathrm{L}^{-1}$, respectivamente. ${ }^{21}$ A concentração inicial do fenantreno e antraceno nos solos eram de $200 \mathrm{mg} \mathrm{kg}^{-1}$ e $25 \mathrm{mg} \mathrm{kg}^{-1}$ respectivamente. De acordo com a Lei de Raoult, a solubilidade é proporcional a sua fração molar, assim a solubilidade efetiva, nas condições experimentais avaliadas era de $1,05 \mathrm{mg} \mathrm{L}^{-1}$ e $8,25 \times 10^{-3} \mathrm{mg} \mathrm{L}^{-1}$ do fenantreno e antraceno respectivamente. Nestas misturas binárias, houve um decréscimo de dez vezes na solubilidade do antraceno em relação as soluções puras . A lixiviação da maioria dos HPA é geralmente muito baixa devido à hidrofobicidade dos contaminantes e também por se tratar de uma mistura de HPA, há o decaimento da solubilidade de cada um dos contaminantes. ENELL e colaboradores (2004) constataram que somente $0,3 \%$ do total de HPA foram lixiviados para o meio aquoso, após um período de 1600 h sob condições de saturação. ${ }^{83}$ Em outro estudo realizado por Ferrarese e colaboradores (2008) em um sedimento contaminado com uma concentração de 2816 mg $\mathrm{kg}^{-1}$ de diferentes HPA, observou-se um deslocamento dos HPA inferior a $1 \%$ para água. ${ }^{52}$ Esta é uma das características que levam os HPA a se acumular mais em sedimentos e solos do que particionarem para a água.

Essa perda na recuperação dos contaminantes devido a presença de água foi constatada também por Richter e colaboradores (2000) na extração de hidrocarbonetos de petróleo utilizando os mesmos solventes. Eles verificaram, neste mesmo estudo, que a recuperação em 
solos secos é de cerca de $100 \%$. No entanto em solos saturados de água, constataram que era necessário que o solvente fosse uma mistura de solvente polar e apolar, como por exemplo, hexano:acetona (1:1), para que se tivesse a recuperação dos contaminantes na faixa de $80 \%$,

como no presente trabalho. ${ }^{84,85}$ A extração é dificultada, pois a água presente nos poros do solo entra em contato previamente com os contaminantes, com isso protege os contaminantes hidrofóbicos de entrar em contato com o solvente de extração hexano (não-polar), mesmo tratando de uma mistura (hexano:acetona-1:1). Richter e colaboradores (2000) constataram também que houve a recuperação de menos de $20 \%$ dos contaminantes, com o uso de $100 \%$ de hexano como solvente para a extração de contaminantes de solo úmido.

A partir disso, foi possível avaliar a degradação dos contaminantes, pois foram mantidas as mesmas condições de extração dos solos antes e após a degradação, mas considerando a perda de $20 \%$ dos contaminantes durante o procedimento de extração.

Poderia ter sido adotada o Soxhlet como técnica de extração que tem eficiência de extração semelhante ao ASE quando se considera a matriz seca. Porém é necessário um maior tempo de extração e o uso de um maior volume de solvente para a extração destes mesmos contaminantes. Outra técnica que também poderia ser utilizada seria a extração por ultrassom, apesar de utilizar menor tempo de extração (3-5 minutos), a eficiência de extração é geralmente menor do que quando se utiliza via Soxhlet. ${ }^{86,87}$

\subsubsection{Extração dos contaminantes em solos arenosos}

Neste estudo, foi priorizado a avaliação da decomposição dos contaminantes na presença da matéria orgânica do solo arenoso utilizando processos oxidativos e não a adsorção dos contaminantes causados pelo perfil do solo e tempo de contaminação que poderia ser ocasionada em matrizes argilosas. Isso dificultaria avaliar se houve a degradação ou se houve a adsorção dos contaminantes na matriz. Por isso foram escolhidos para este 
presente estudo, amostras de solos da ordem do espodossolos e subordem humilúvicos, pois estes apresentam uma textura arenosa ao longo do perfil e um acúmulo de matéria orgânica. Os solos classificados como arenosos possuem teores de areia superiores a 70\% e o de argila inferior a $15 \%$.

Foi avaliada a eficiência de extração dos contaminantes em solos arenosos, utilizando as mesmas condições para a matriz areia e a controle. As características físico-químicas destes solos estão descritas na Tabela 4. Tanto a matriz areia padrão quanto a matriz solo apresentaram recuperação quase integral dos contaminantes quando secos (Figura 11 e 12), com exceção do solo $\mathrm{C}$, para o qual houve uma perda de cerca de $25 \%$ na recuperação dos contaminantes em solo seco tanto para o fenantreno quanto para o antraceno. $\mathrm{O}$ solo $\mathrm{C}$ tinha maior quantidade de carbono orgânico proveniente do ácido húmico em relação aos outros solos. O tipo de revestimento húmico, também influência na adsorção dos compostos orgânicos hidrofóbicos, como os HPA. Quanto maior o teor de carbono aromático oriundos do ácido húmico, maior a adsorção dos contaminantes na matriz, o que poderia ter dificultado no processo de extração. ${ }^{88}$

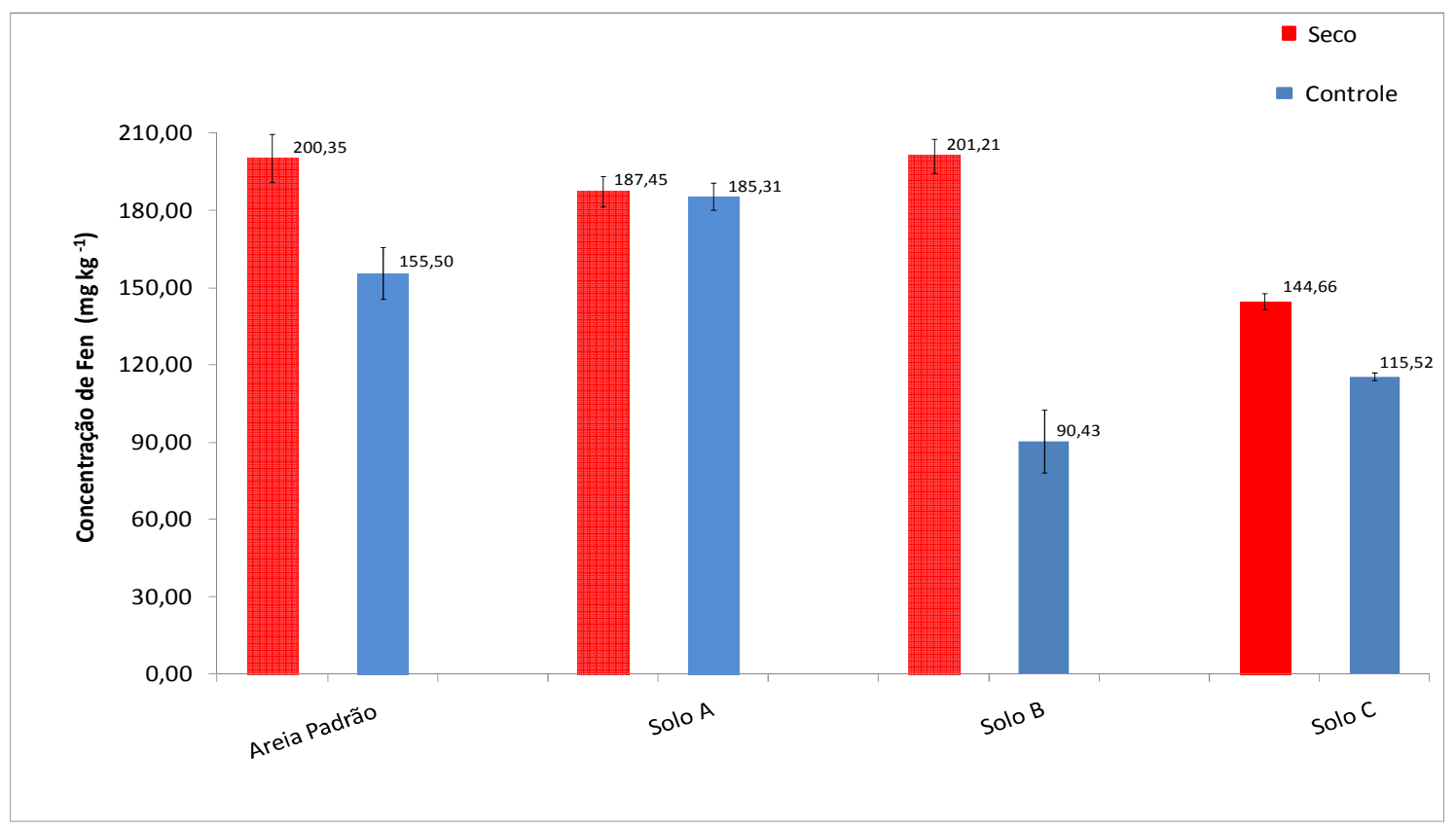

Figura 11 - Avaliação da recuperação do contaminante fenantreno presentes na areia padrão e nos solos A,B e C inicialmente contaminados com $200 \mathrm{mg} \mathrm{kg}^{-1}$ comprando a matriz seca com o seu controle. 
Os solos arenosos A, B e C apresentaram o mesmo percentual de recuperação dos contaminantes fenantreno (Figura 11) e antraceno (Figura 12) quando comparadas com a mesma matriz, considerando o solo controle em relação ao solo seco. No entanto, ocorreu uma variação significativa na recuperação dos contaminantes entre os diferentes solos, isso pode ser justificado pelos solos arenosos apresentarem diferentes porosidades e permeabilidades devido aos diferentes teores de substâncias húmicas e a presença de argila em sua composição. Esta variação também pode ter sido ocasionada devido à presença de água, como ocorreu nas amostras de areia e solo controle, que dificultou o contato entre o contaminante e o solvente no momento da extração.

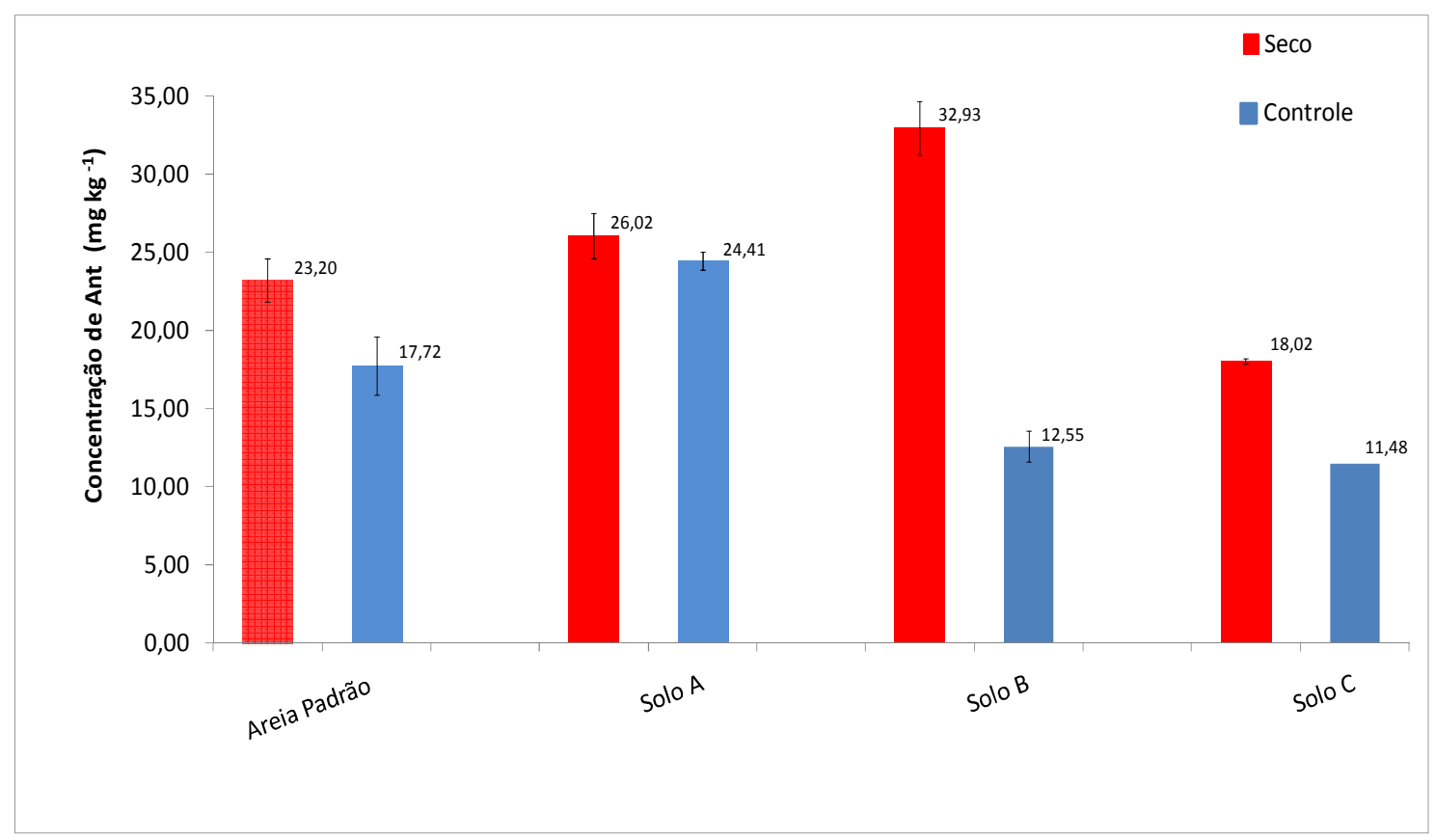

Figura 12- Avaliação da recuperação do contaminante antraceno presentes na areia padrão e nos solos A,B e C inicialmente contaminados com $25 \mathrm{mg} \mathrm{kg}^{-1}$ comprando a matriz seca com o seu controle.

Como houve variação na recuperação dos contaminantes de acordo com a matriz, adotou-se como concentração inicial (Co) nos processos de tratamento, os valores de concentrações dos contaminantes obtidos na areia e nos solos controle em $\mathrm{mg} \mathrm{kg-}{ }^{1}$.

Foi possível também, avaliar a partição dos contaminantes entre água e solo, ao estimar os valores de Kd (coeficiente de partição entre a concentração do fenantreno e 
antraceno sorvido ao solo e presentes na água) a partir do valor do Koc (coeficiente de adsorção dos compostos orgânicos) e foc ( fração de carbono orgânico) presente em cada uma das matrizes (solos A,B e C). Com exceção da areia padrão que não continha a presença matéria orgânica (foc=0), (Equação 2).

$$
\mathrm{Kd}=\mathrm{Koc} \cdot \text { foc (Equação 2) }
$$

Com a obtenção dos valores de Kd estimou-se a partição dos contaminantes em mg L ${ }^{-1}$ (C) para o meio aquoso (Equação 3), considerando que a concentração dos contaminantes (fenantreno e antraceno) eram de $225 \mathrm{mg} \mathrm{kg-}^{1}$ (fenantreno e antraceno) em cada uma das diferentes matrizes (Tabela 8).

$$
\mathrm{Kd}=\mathrm{S}\left(\mathrm{mg} \mathrm{kg}^{-1}\right) / \mathrm{C}\left(\mathrm{mg} \mathrm{L}^{-1}\right)(\text { Equação 3) }
$$

TABELA 8- Coeficiente de sorção (Kd e Koc) para cada uma das matrizes (solos A, B e C) contaminadas com $225 \mathrm{mg} \mathrm{kg}^{-1}$ (fenantreno +antraceno).

\begin{tabular}{ccccc}
\hline Matriz & $\begin{array}{c}\mathbf{l o g} \mathbf{K o c}^{\mathbf{a}} \\
\mathbf{L ~ k g}^{-1}\end{array}$ & $\mathbf{f o c}^{\mathbf{b}}$ & $\begin{array}{c}\mathbf{K d}^{\mathbf{c}} \\
\mathbf{L ~ k g}^{-1}\end{array}$ & $\begin{array}{c}\mathbf{C}^{\mathbf{d}} \\
\mathrm{mg} \mathrm{L}^{-1}\end{array}$ \\
\hline Areia controle & 4,06 & 0 & 0 & - \\
Solo A controle & 4,06 & 0,0272 & 312,3 & 0,72 \\
Solo B controle & 4,06 & 0,0160 & 183,7 & 1,22 \\
Solo C controle & 4,06 & 0,0312 & 358,2 & 0,62 \\
\hline
\end{tabular}

a-Valor estimado de acordo com Karickloff (1981) para ambos os contaminantes (fenantreno e antraceno) ${ }^{89}$;bFração de carbono orgânico presente na matriz,c-Coeficiente de partição solo/ água, d-Concentração dos contaminantes (fenantreno + antraceno) em água , considerando a concentração de $225 \mathrm{mg} \mathrm{kg-}{ }^{1}$.

Quanto maior o valor de Kd maior a tendência dos contaminantes fenantreno e antraceno ficarem adsorvidos nas matrizes, $\log$ o o solo $\mathrm{C}$ foi o que apresentou maior sorção dos contaminantes. Verificou-se que o solo B foi o que apresentou maior transferência para a fase aquosa, particionando cerca de $1,22 \mathrm{mg} \mathrm{L}^{-1}$, no entanto não foi possível determinar quantitativamente a concentração de cada um dos compostos separadamente dissolvidos na fase aquosa. 


\subsection{Uso do oxidante permanganato em areia padrão}

Foi realizada a degradação dos contaminantes na areia padrão utilizando o oxidante permanganato de potássio $\left(\mathrm{KMnO}_{4}\right)$, de acordo com estequiometria da Reação 12. Utilizou-se a proporção estequiométrica de 1:22 que corresponde à relação molar entre os contaminantes (fenantreno e antraceno) e o oxidante (permanganato de potássio) para uma mineralização completa dos contaminantes.

$$
\mathrm{C}_{14} \mathrm{H}_{10}+22 \mathrm{MnO}_{4}^{-}+6 \mathrm{H}_{2} \mathrm{O} \rightarrow 14 \mathrm{CO}_{2}+22 \mathrm{MnO}_{2}+22 \mathrm{OH}^{-}+(\text {Reação } 12)
$$

De acordo com o ITRC (2005), são necessários 14,7g do íon $\mathrm{MnO}_{4}{ }^{-}$para mineralizar cada grama do contaminante fenantreno. A mesma razão foi empregada na oxidação da mistura de fenantreno e antraceno, mantendo-se a proporção em mols do íon $\mathrm{MnO}_{4}{ }^{-} \mathrm{em}$ relação ao composto $\mathrm{C}_{14} \mathrm{H}_{10}$ que é 1:22 (contaminante:oxidante): ${ }^{3}$

A remediação com o oxidante $\mathrm{KMnO}_{4}$ foi realizada de acordo com a descrição no item 3.7.1 e posteriormente analisada de acordo com a descrição dos itens 3.4, 3.5 e 4.6.

Verificou-se que após 24 h de tratamento havia degradado 95\% e $98 \%$ do fenantreno e antraceno, respectivamente, em relação a concentração inicial dos contaminantes na areia controle (C/Co) em mg kg-1 (Figura 13), sendo que após somente 8 horas de tratamento, cerca de $85 \%$ de ambos os contaminantes já haviam sido degradados. O perfil cinética da degradação dos contaminantes apresentam um perfil de pseudo primeira ordem, pois há um excesso na concentração do oxidante permanganato em relação à concentração do contaminante. O Kobs do fenantreno e do antraceno foram de 0,2356 $\mathrm{s}^{-1}$ e $0,3595 \mathrm{~s}^{-1}$ respectivamente considerando 8 horas de tratamento. O tempo de meia vida da decomposição do antraceno foi de 1,9 horas enquanto do fenantreno foi de 2,9, o que comprova que após 8 de tratamento a reação praticamente já havia cessado. 


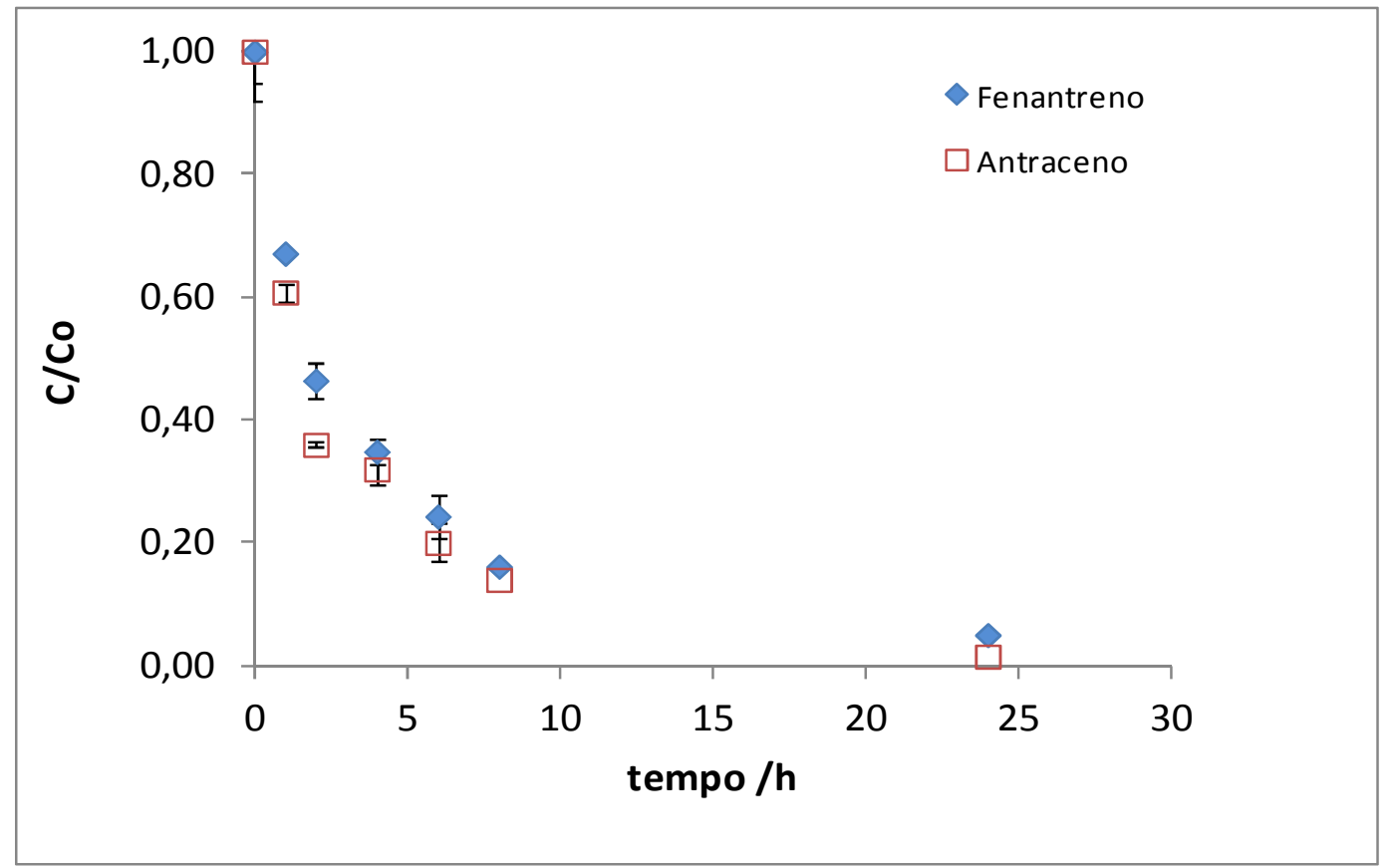
padrão.

Figura 13- Variação da concentração do fenantreno e do antraceno em função do tempo de tratamento, utilizando o $\mathrm{KMnO}_{4}$ como oxidante na proporção (1:22- contaminante:oxidante) em matriz areia

É possível avaliar que a velocidade de degradação decai após 8 horas de tratamento, possivelmente pela formação do óxido de manganês $\mathrm{MnO}_{2}$ que diminui a porosidade da areia, o que pode ter dificultado a interação entre os poluentes adsorvidos nas partículas da areia e o oxidante. Apesar de o fenantreno ser termodinamicamente mais estável em relação ao antraceno devido à ligação entre os átomos $\mathrm{H}_{4}-\mathrm{H}_{5}$ na região de compartilhamento (bay region), isso não interferiu na velocidade da reação, visto que ambos os contaminantes apresentaram perfis semelhantes de degradação. ${ }^{90}$

Em estudo realizado por Sierguey e colaboradores (2008), utilizando permanganato como oxidante $\left(0,1 \mathrm{~g} \mathrm{~L}^{-1}\right)$ em solo arenoso contaminado com $700 \mathrm{mg} \mathrm{kg}^{-1}$ de fenantreno sob agitação mecânica foi degradado $96 \%$ do fenantreno, após 36 horas de tratamento. Neste mesmo estudo, utilizando o mesmo oxidante, mas com concentração de $0,65 \mathrm{~g} \mathrm{~L}^{-1}$ e aplicando em solo arenoso contaminado com uma mistura de 14 HPA com concentração de 3.264 mg $\mathrm{kg}^{-1}$ presente no solo, a degradação foi de cerca de $65 \%$, após 6 dias de tratamento. Essa 
variação na eficiência da degradação pode estar relacionada com a concentração dos contaminantes, a de matéria orgânica e tempo de tratamento. ${ }^{45}$

Neste presente trabalho, o tratamento foi realizado sem agitação mecânica, em menor tempo de tratamento e sem a presença de sobrenadante, por outro lado a quantidade de contaminante era menor no solo, mas mesmo assim foi utilizado a concentração do oxidante 150 vezes maior em relação ao estudo anterior. No entanto resultou em valores semelhantes de degradação em relação ao estudo realizado por Sierguey (2008). Em ambos os estudos não foram avaliados se houve a mineralização total dos contaminantes, pois a reação cessa antes com a formação do óxido de manganês. ${ }^{46}$ Por outro lado, Ferrarese e colaboradores (2008), ao utilizar permanganato como oxidante em um solo contaminado com HPA, obtiveram a degradação de 91 a $96 \%$ dos contaminantes, porém ainda restou, cerca de 15 a $35 \%$ do carbono presente no solo inicialmente, antes da adição do oxidante. Com isso é possível afirmar que a mineralização pode não ser completa.

O permanganato tem impacto na disponibilidade dos nutrientes às plantas nos solos, pois o óxido de manganês $\left(\mathrm{MnO}_{2}\right)$, produto da reação de oxidação, provoca o decréscimo da permeabilidade do solo, consequentemente, isso tem impacto negativo na fertilidade do solo. Por outro lado, o uso do oxidante diminuiu a toxicidade e a concentração dos contaminantes presentes no solo o que torna o seu uso favorável em solos contaminados com baixo teor de matéria orgânica. ${ }^{3,48}$

\subsection{Uso do oxidante peróxido de hidrogênio com ferro (Fenton) em diferentes}

\section{matrizes}

Dos POA, o processo de Fenton é o mais consolidado. Com isso, foi avaliado a eficiência da degradação do fenantreno e antraceno utilizando o peróxido de hidrogênio como oxidante, ativado com ferro em diferentes matrizes. A razão estequiométrica para a 
mineralização completa (Reação 13) seria de 1:33 (contaminante: oxidante), no entanto, neste presente estudo utilizou-se a razão molar maior que a razão estequiométrica entre contaminante:oxidante: $\mathrm{Fe}^{2+}$ de 1:160:8. Estes valores foram adotados, pois o tempo de meia vida do radical hidroxila é curto. ${ }^{91}$

$$
1 \mathrm{C}_{14} \mathrm{H}_{10}+33 \mathrm{H}_{2} \mathrm{O}_{2} \underset{\mathrm{pH} 2 \sim 3}{\stackrel{\mathrm{Fe}^{2+}}{\longrightarrow}} 14 \mathrm{CO}_{2}+38 \mathrm{H}_{2} \mathrm{O} \text { (Reação 13) }
$$

Foram realizados os ensaios em duas diferentes matrizes, pois o radical hidroxila não é seletivo, logo pode degradar uma gama de poluentes como também espécies não poluentes. Isso pode resultar no decréscimo da degradação dos contaminantes dependo da matriz.

Verificou-se que houve degradação de $20 \%$ do fenantreno em relação a concentração C/Co, após 12 horas de tratamento, utilizando a areia padrão. Após 24 horas de tratamento, na mesma matriz, havia degradado $34 \%$ do fenantreno e $33 \%$ do antraceno em relação a concentração inicial da areia controle. No entanto no solo A, houve a degradação de $49 \%$ do fenantreno e 66\% do antraceno, após 24 horas, conforme Figura 14.

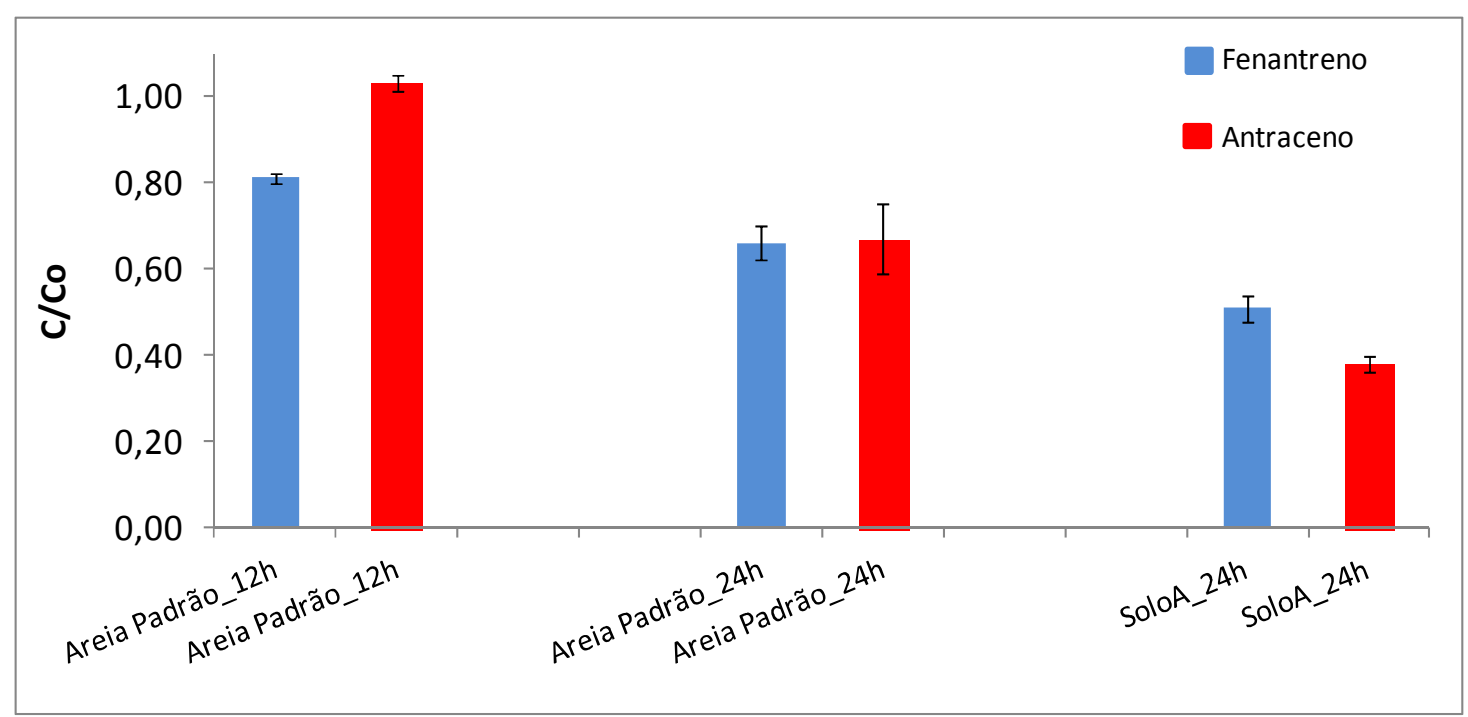

Figura 14 - Variação da concentração do fenantreno e do antraceno em função do tempo de tratamento, utilizando $\mathrm{o}_{2} \mathrm{O}_{2}$ como oxidante ativado com $\mathrm{Fe}^{2+}$, em pH 2-3, na proporção (1:160:8- contaminante:oxidante: Ferro). 
Mesmo que adicionando-se igual quantidade de oxidante em ambas as matrizes, a areia controle apresentou o dobro na concentração molar de oxidante e ferro em relação ao solo A, pois ambas as matrizes foram mantidas em condições saturadas. Isso pode ter facilitado a degradação dos contaminantes no solo A, já que o solo A era mais poroso que a areia padrão devido a presença de matéria orgânica e argila em sua composição, o que aumentava a superfície de contato entre oxidante, ferro e contaminante ocasionando uma maior decomposição dos contaminantes. Um estudo similar realizado por Sun e colaboradores (2008) verificou-se a degradação de 65,4 a 88,9\% do pireno após 30 minutos, sendo que o tratamento destes solos foi feito utilizando $2 \mathrm{~g}$ de solo contaminando em $10 \mathrm{~mL}$ de solução $\left(0,2\right.$ mol L $\left.\mathrm{L}^{-1} \mathrm{H}_{2} \mathrm{O}_{2}+0,02 \mathrm{~mol} \mathrm{~L}^{-1} \mathrm{Fe}^{2+}\right)$ e sob agitação mecânica. A agitação mecânica e a diluição favoreceram o contato entre o contaminante presente na matriz, o ferro e o peróxido de hidrogênio, o que pode ter resultado em maior eficiência de degradação quando comparado com os resultados do presente trabalho. ${ }^{56}$

Por outro lado, o presente trabalho contrasta com os resultados de Lindsey e colaboradores (2000) que relataram um decréscimo na taxa de degradação de compostos aromáticos por reações de Fenton $(\mathrm{pH} 2,5)$ na presença de ácidos fúlvicos e húmicos que foram adicionados ao sistema. Segundo os autores, isso deve-se a uma separação espacial entre os locais de ligação do ferro, situado nas regiões hidrofílicas, e os contaminantes, ligados nas regiões hidrofóbicas das substâncias húmicas. Em outro estudo mais recente realizado por Georgi e colaboradores (2007) utilizando as reações de Fenton como oxidante ( $\mathrm{pH}$ 5), houve a degradação de fluoreno na presença de ácido húmico de $80 \%$ enquanto na sua ausência menos de $10 \%$. É preciso considerar que nestes estudos relatados, os ácidos húmicos e fúlvicos foram adicionados em sistemas aquosos na ausência da matriz solo. ${ }^{92}$ No entanto, não é possível afirmar que a presença dos ácidos húmicos e fúlvicos possam facilitar ou inibir a oxidação de poluentes hidrofóbicos por reações de Fenton. Para compreender, 
seria preciso um estudo de diferentes fontes de ácidos húmicos e fúlvicos presentes no solo, para avaliar se a composição hidrofílica e hidrofóbica das estruturas das substâncias húmicas podem interferir nas reações de Fenton. ${ }^{93}$

Havia no solo A a presença de $1.230 \mathrm{mg} \mathrm{kg}^{-1}$ de ferro total (Tabela 7), que a princípio poderia justificar a melhor eficiência na decomposição dos contaminantes em relação a areia padrão. No entanto um outro estudo realizado por Jonsson e colaboradores (2007) constatou que a remoção de HPA, presente em um solo com $18 \mathrm{~g} \mathrm{~kg}^{-1}$ de óxidos de ferro, foi $50 \%$ inferior quando comparada com a remoção do contaminante, após a adição de sais de ferro utilizando os reagentes de Fenton. ${ }^{47} \mathrm{O}$ ferro presente no solo pode não estar totalmente disponível para a interação com o peróxido de hidrogênio para a formação dos radicais hidroxilas e /ou o excesso de ferro interage com os radicais formados comprometendo a degradação dos contaminantes.

Estudos anteriores realizads por Watts e colaboradores (2002) mostram que, sob condições de alta concentrações do oxidante peróxido de hidrogênio $\left(15 \mathrm{~mol} \mathrm{~L}^{-1}\right)$ e com o solo contendo $33.500 \mathrm{mg} \mathrm{kg}^{-1}$ de ferro cristalino, obteve-se $85 \%$ de mineralização do contaminante benzo[a]pireno. Altas concentrações de peróxido de hidrogênio podem aumentar a dessorção e dissolução dos contaminantes presentes na fase não aquosa, o que facilitaria a degradação, porém o oxidante pode ser consumido pela matéria orgânica presente no solo. ${ }^{94}$

A uniformidade e a eficiência nos tratamentos com Fenton em solos contaminados com HPA são afetados pela heterogeneidade da matriz do solo, decorrentes da variação da matéria orgânica, da porosidade da matriz e idade do solo, assim como da concentração dos oxidantes e dos compostos inorgânicos presentes no solo. ${ }^{57,95}$

\subsection{Avaliação do uso do oxidante persulfato}


Foram avaliadas duas formas de ativação do persulfato, utilizando o meio alcalino e ferro como ativantes na areia padrão como matriz. Tomando como base a razão estequiométrica de 1:33 (contaminante:oxidante) (Reações 14 e 15).

$$
\begin{aligned}
& \mathrm{C}_{14} \mathrm{H}_{10}+33 \mathrm{~S}_{2} \mathrm{O}_{8}{ }^{2-}+28 \mathrm{H}_{2} \mathrm{O} \rightarrow 14 \mathrm{CO}_{2}+66 \mathrm{HSO}_{4}^{-} \text {em pH 2-3 (Reação 14) } \\
& \mathrm{C}_{14} \mathrm{H}_{10}+33 \mathrm{~S}_{2} \mathrm{O}_{8}{ }^{2-}+\mathrm{OH}^{-} \rightarrow 14 \mathrm{CO}_{2}+66 \mathrm{HSO}_{4}{ }^{-}+33 \mathrm{SO}_{4}{ }^{2-}+5 \mathrm{H}_{2} \mathrm{O} \text { em pH>10 }
\end{aligned}
$$

(Reação 15)

Após 24 horas de tratamento, houve a decomposição de $47 \%$ do fenantreno e $95 \%$ do antraceno com o ferro como ativante em pH 2-3. Já em condições alcalinas $(\mathrm{pH}>10)$ houve a decomposição de 30 e $87 \%$ do fenantreno e antraceno, respectivamente (Figura 15).Verificouse neste presente trabalho que a degradação foi mais efetiva utilizando o sulfato de ferro II como ativante em condições ácidas ( $\mathrm{pH}$ 2-3) quando comparado ao uso do hidróxido de sódio em $\mathrm{pH}>10$. Estudos realizados com persulfato ativado em meio alcalino aquoso sugerem que o radical hidroxila é a espécie oxidante predominante no sistema, justificando menor decomposição dos contaminantes em sistema alcalinos em relação ao sistema ativado com ferro em condições ácidas, pois o radical hidroxila é menos estável que radical sulfato. ${ }^{96} \mathrm{Com}$ isso, a degradação dos contaminantes em condições alcalinas não é tão efetiva, pois o tempo de meia vida do radical hidroxila é menor que o radical sulfato, o qual este predomina em meio ácido, favorecendo o uso do persulfato em condições ácidas. ${ }^{51}$ Verificou-se degradação similar do fenantreno tanto utilizando os reagentes de Fenton como oxidante quanto o persulfato ativado em meio alcalino, que nessas condições possivelmente predomina a presença dos mesmos radicais hidroxilas. 


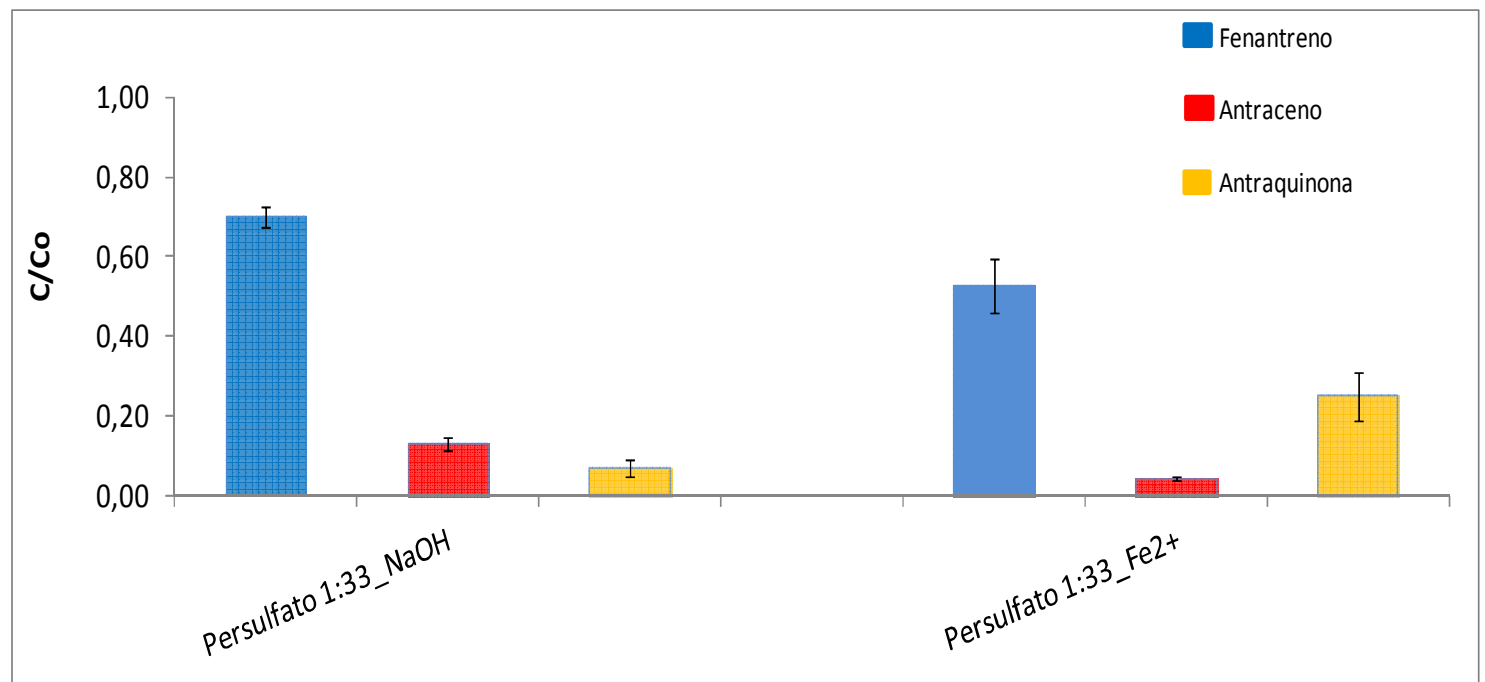

Figura 15-Variação da concentração do fenantreno e do antraceno após 24 horas de tratamento, utilizando como oxidante persulfato ativado com $\mathrm{Fe}^{2+} \mathrm{em}$ pH 2-3 e em condições alcalinas ( $\left.\mathrm{pH}>10\right)$.

A formação do intermediário antraquinona foi mais abundante com o uso de persulfato ativado com ferro em meio ácido do que em meio alcalino, após 24 horas de tratamento, pois a formação da antraquinona é diretamente proprocional a decomposição do antraceno. Após avaliar que o persulfato ativado com ferro tinha um melhor desempenho, foi avaliado o aumento da proporção molar entre contaminante e oxidante provocaria um aumento significativo na decomposição do contaminante, já que a proporção de 1:33 (contaminante:oxidante) corresponderia a mineralização total a carbono e água considerando a estequiometria da reação. Desta forma, foi realizado um experimento utilizando proporção de 1:100 (contaminante:oxidante). Com base nos resultados, foi possível avaliar que a proporção de 1:100 (contaminante:oxidante) apresentou desempenho semelhante em relação a proporção de 1:33 (contaminante:oxidante) tanto em relação a decomposição dos contaminantes quanto na formação do subproduto, tendo $55 \%$ do fenantreno e $94 \%$ do antraceno degradados (Figura 16). 


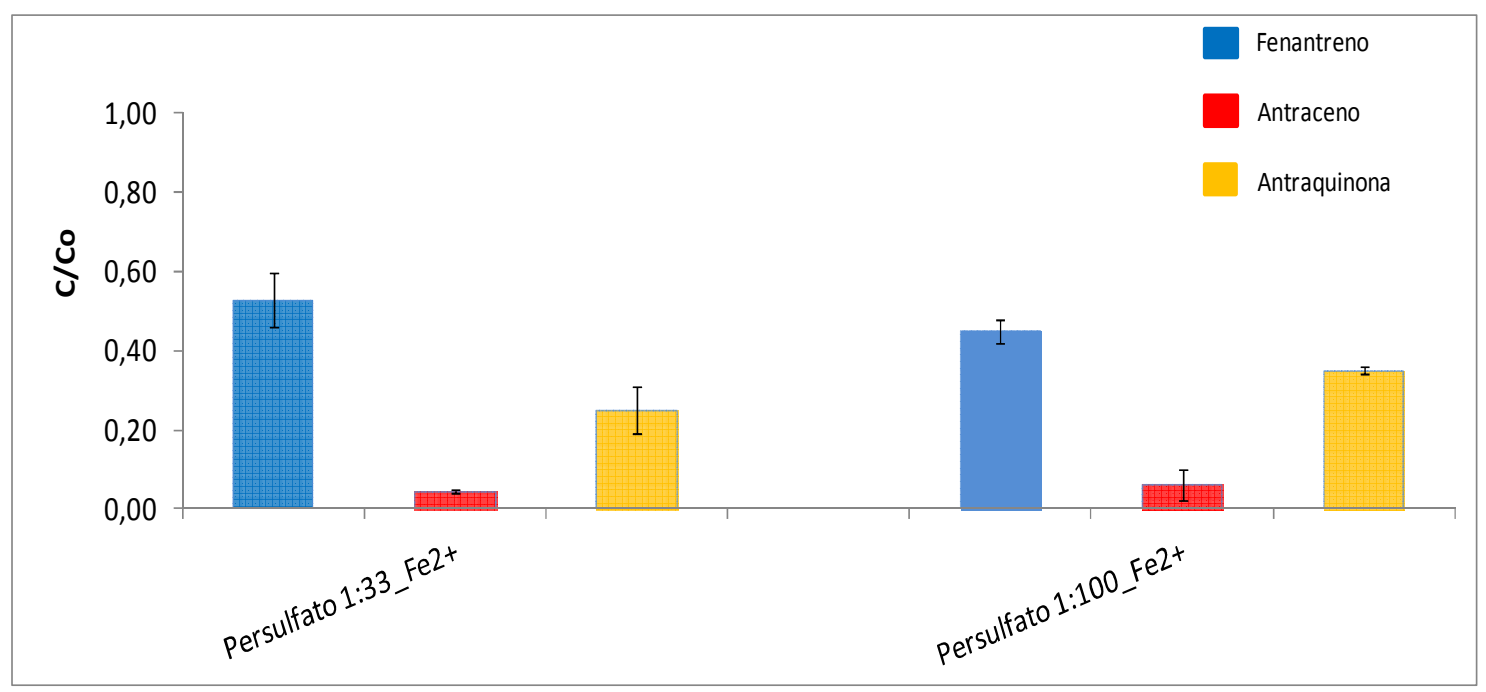

Figura 16- Variação da concentração do fenantreno e do antraceno após 24 horas de tratamento, utilizando persulfato ativado com ferro como oxidante na proporções molar de 1:33:8 e 1:100:8 entre contaminante: oxidante: $\mathrm{Fe}^{2+}$.

Para se avaliar a eficiência dos oxidantes em solos utilizou-se a maior proporção molar entre contaminante e oxidante (1:100), pois nos solos há a presença de matéria orgânica e minerais que podem competir com os contaminantes pelo radical sulfato e comprometer na eficiência da degradação.

Forsey (2004) em seus estudos também observou que ao aumentar a razão entre pcreosol: persulfato de 1:10 para 1:33, mas mantendo a concentração de ferro, não se provoca mudanças significativas na oxidação do p-creosol, entretanto, observou-se a degradação de cerca de $80 \%$ do creosol após 4 horas de tratamento. ${ }^{97}$

Foi avaliado também o perfil de decomposição do persulfato em areia padrão utilizando como oxidante o $\mathrm{Na}_{2} \mathrm{~S}_{2} \mathrm{O}_{8}$ ativado com $\mathrm{Fe}^{2+}$ em meio ácido. Foi avaliado com proporção estequiométrica de 1:100:8 entre contaminante: $\mathrm{Na}_{2} \mathrm{~S}_{2} \mathrm{O}_{8}: \mathrm{Fe}^{2+}$. O tratamento com $\mathrm{Na}_{2} \mathrm{~S}_{2} \mathrm{O}$ foi realizada de acordo com a descrição no item 3.7.3 e posteriormente analisada de acordo com a descrição dos itens 3.4, 3.5 e 3.6.

Ao avaliar o perfil de decomposição dos contaminantes fenantreno e antraceno (Figura 17), verificou-se que após 24 horas de tratamento a reação já havia cessado a confirmação se deu após o acompanhamento por 100 horas de tratamento, sem que houvesse 
variação na concentração dos contaminantes. Em relação à concentração inicial, após 48 horas de tratamento, havia $38 \%$ e $5 \%$ do fenantreno e antraceno respectivamente. A decomposição do fenantreno foi mais efetiva utilizando o permanganato como oxidante do que persulfato, já que o persulfato é menos reativo que o permanganato. Em relação ao antraceno, a velocidade de decomposição utilizando persulfato como oxidante, foi maior que utilizando o permanganato. No entanto a concentração residual final foi praticamente igual para ambos os oxidantes. Foi avaliado o perfil cinético e observou-se que a reação apresentou um perfil cinético de pseudo primeira ordem como no tratamento com o permanganato, devido ao excesso de oxidante. Não foi possível identificar a ordem da reação na decomposição do atraceno através do perfil cinético da curva. O Kobs do fenantreno foi de 0,0185 , sendo que o tempo de meia vida do fenantreno foi de 37 horas. Verificou-se que a decomposição do fenantreno é cerca de 12 vezes mais lenta em relação ao uso do permanganato como oxidante.

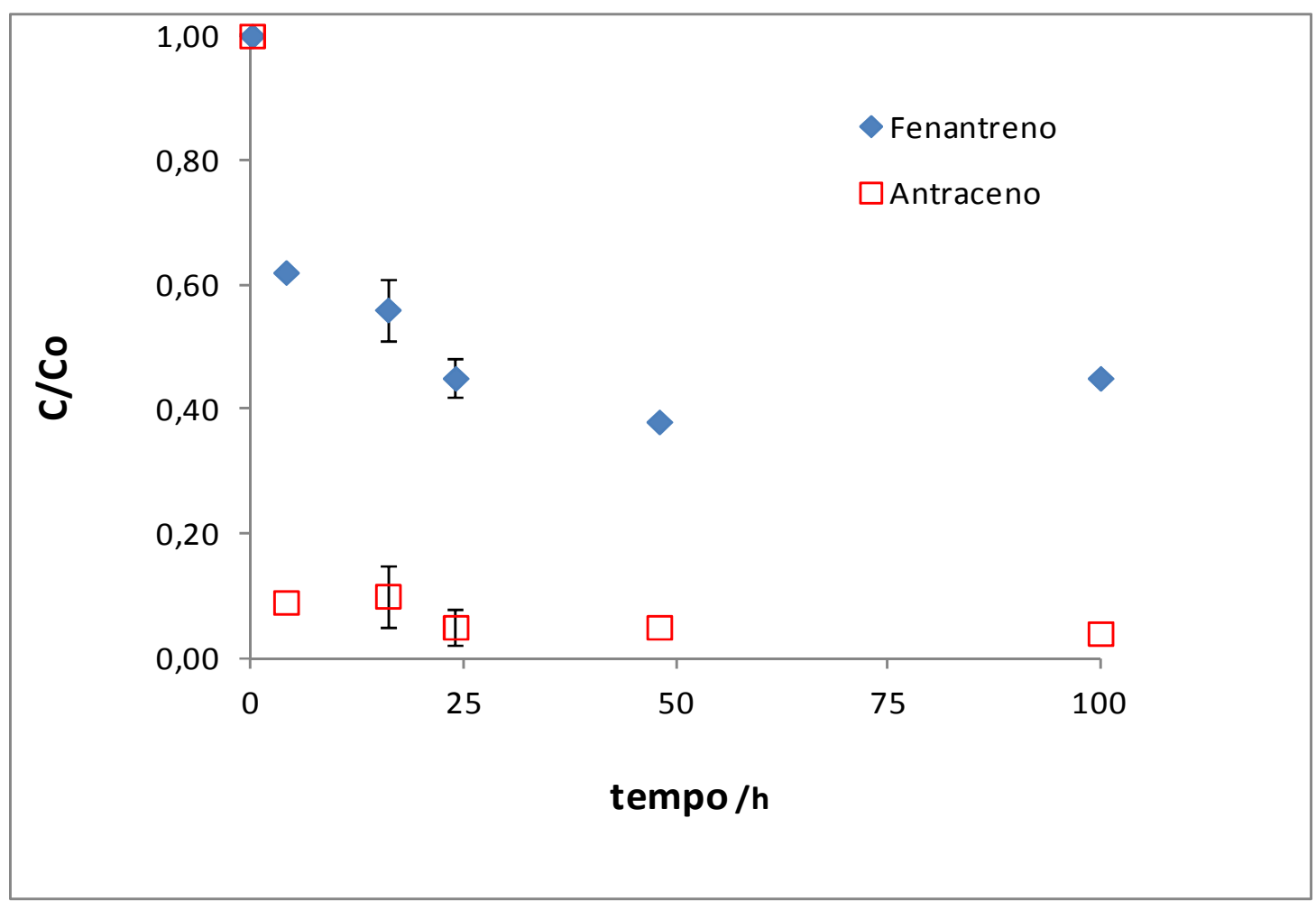

Figura 17- Variação da concentração do fenantreno e do antraceno em função do tempo de tratamento, utilizando o persulfato ativado com ferro como oxidante na proporção 1:100:8 (contaminante:oxidante: ferro) presentes na matriz areia padrão. 


\subsection{Avaliação do uso dos diferentes oxidantes utilizando a mesma matriz}

Foi avaliado o uso de diferentes oxidantes tendo como matriz a areia padrão com a mesma concentração de contaminante HPA após 24 horas de tratamento. Como oxidantes foram utilizados o peróxido de hidrogênio, o persulfato ativado e o permanganato. Os resultados indicam que o oxidante permanganato e persulfato ativado com ferro são mais eficientes na degradação dos HPA do que o peróxido de hidrogênio (reação Fenton) na matriz areia (Figura 18). Embora o potencial de redução do radical hidroxila (2,8 V), seja maior do que o radical sulfato $(2,5 \mathrm{~V})$ e do que íon permanganato $(1,7 \mathrm{~V})$, este oxidante não permanece por um longo período de tempo no solo, devido à facilidade de decomposição do peróxido de hidrogênio e a reatividade do radical hidroxila. Para obter um melhor desempenho no uso do oxidante peróxido de hidrogênio ativado com ferro na decomposição dos contaminantes é necessário que a adição do peróxido seja gradativa, pois o radical hidroxila tem tempo de meia vida curto em relação ao radical sulfato. No entanto é preciso considerar que a formação do radical sulfato não é predominante quando o persulfato é ativado em condições alcalinas. 


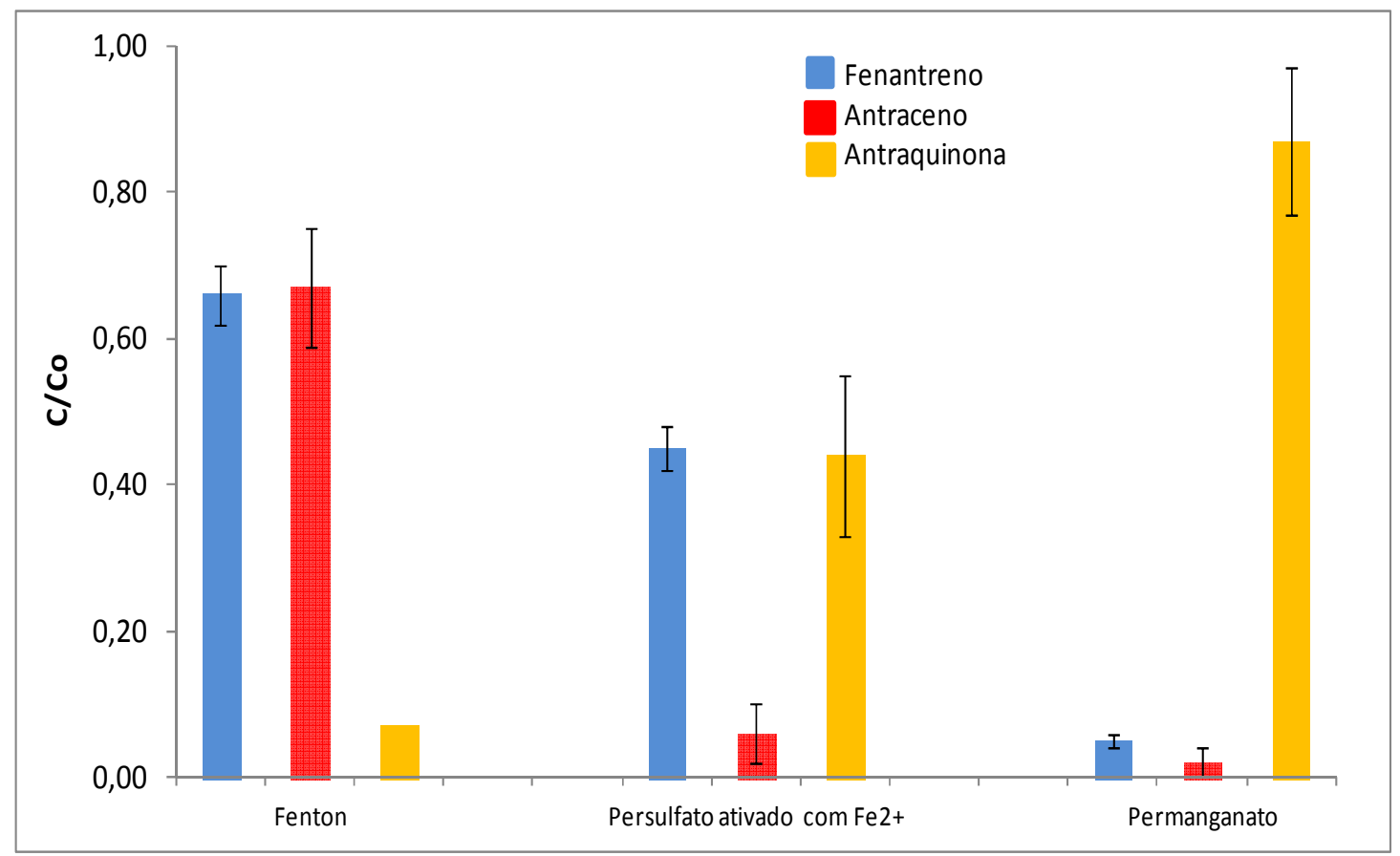

Figura 18- Avaliação da degradação do fenantreno e antraceno, após 24 horas de tratamento, presentes na areia padrão, utilizando os oxidantes da reação de Fenton, persulfato ativado com ferro e permanganato, nas proporções molares entre contaminante: oxidante:ferro (1:160:8, 1:100:8 e 1:22, respectivamente).

Por outro lado, o oxidante permanganato e persulfato são mais persistentes em relação ao oxidante peróxido de hidrogênio, o que resultou em maior degradação dos contaminantes. O permanganato é mais efetivo na degradação do fenantreno e antraceno após 24 horas de tratamento, tendo degradado 95 e $98 \%$, respectivamente. Já o persulfato ativado com ferro em pH 2-3, degradou 55 e 94\% dos mesmos contaminantes (Figura 18).

Foi escolhido o oxidante persulfato ativado com ferro na proporção 1:100 (contaminante: oxidante) para a aplicação em diferentes matrizes de solos arenosos, pois estudos anteriores demonstraram que ocorrem uma competição entre o contaminante e o ácido húmico da matéria orgânica presente no solo pelo oxidante permanganato. ${ }^{48,98}$ Além disso, o oxidante persulfato apresenta vantagens em relação ao permanganato por ser um oxidante incolor, menos prejudicial aos micro-organismos in situ e devido a sua alta solubilidade (40\% $\mathrm{m} / \mathrm{m}$ ) em água, o que facilita o seu deslocamento em longos raios de fonte de contaminação. 
Observa-se que a formação da antraquinona como produto, após o uso de oxidantes nos processos de tratamento, foi diretamente proporcional à decomposição dos contaminantes.

\subsection{Identificação dos intermediários oriundos dos diferentes processos oxidativos}

Um problema que pode ocorrer durante a oxidação dos contaminantes HPA em solo é a mineralização incompleta e a consequente produção de intermediários decorrentes da degradação. Há poucos estudos que identificaram os possíveis intermediários formados, provenientes dos HPA,em processo oxidativos. $52,57,99$

Neste presente trabalho foi possível identificar e quantificar a formação da antraquinona a partir da decomposição do antraceno tanto utilizando permanganato, como persulfato ativado e reações de Fenton como oxidantes, tendo a areia padrão como matriz. Sua identificação foi constatada por meio de uso de padrão para avaliar o tempo de retenção e do espectrômetro de massa para avaliar as proporções dos fragmentos de massa/carga. No solo A foi possível identificar a formação da antraquinona por meio das reações de Fenton, após 24 horas de tratamento (Figura 19). 


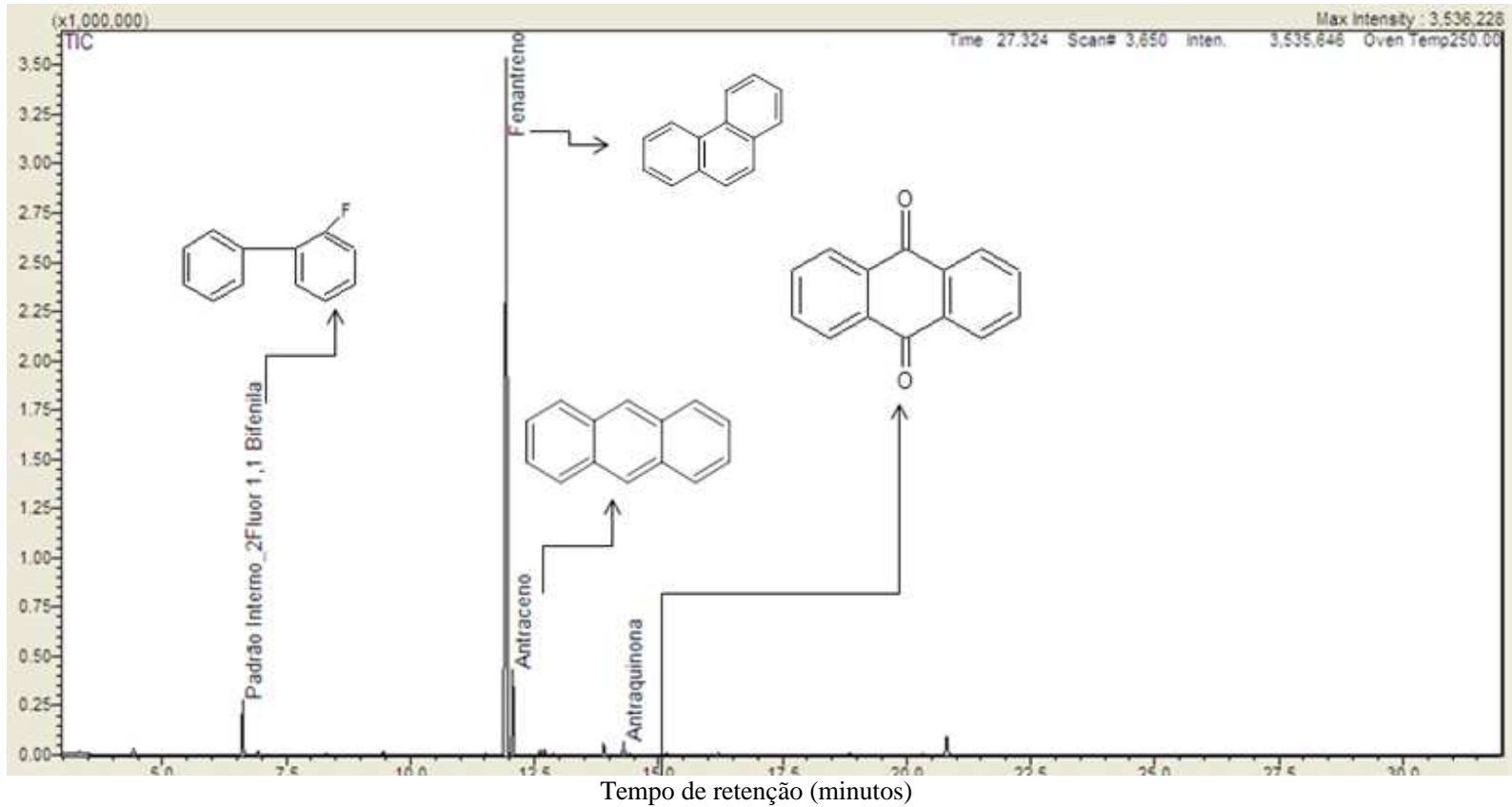

Figura 19 - Cromatograma dos contaminantes fenantreno, antraceno residual e da formação antraquinona presentes no solo A, após 24 horas de tratamento utilizando reagente de Fenton na proporção de $1: 160$ (contaminante:oxidante).

Ao utilizar o permanganato como oxidante, após 24 horas de tratamento, verificou-se que a concentração de antraquinona correspondeu a $87 \%$ da concentração inicial de antraceno (Co) e restaram $2 \%$ da concentração inicial do antraceno. Observou-se que a variação na concentração do antraceno é inversamente proporcional a formação da antraquinona Apesar da degradação do antraceno atingir $98 \%$ após 24 horas de tratamento, constatou-se que não houve a mineralização completa do antraceno dentre deste período. Foi considerado como concentração inicial (Co), a concentração do antraceno em $\mathrm{mg} \mathrm{Kg}^{-1}$ presente na matriz antes da oxidação (Figura 20). 


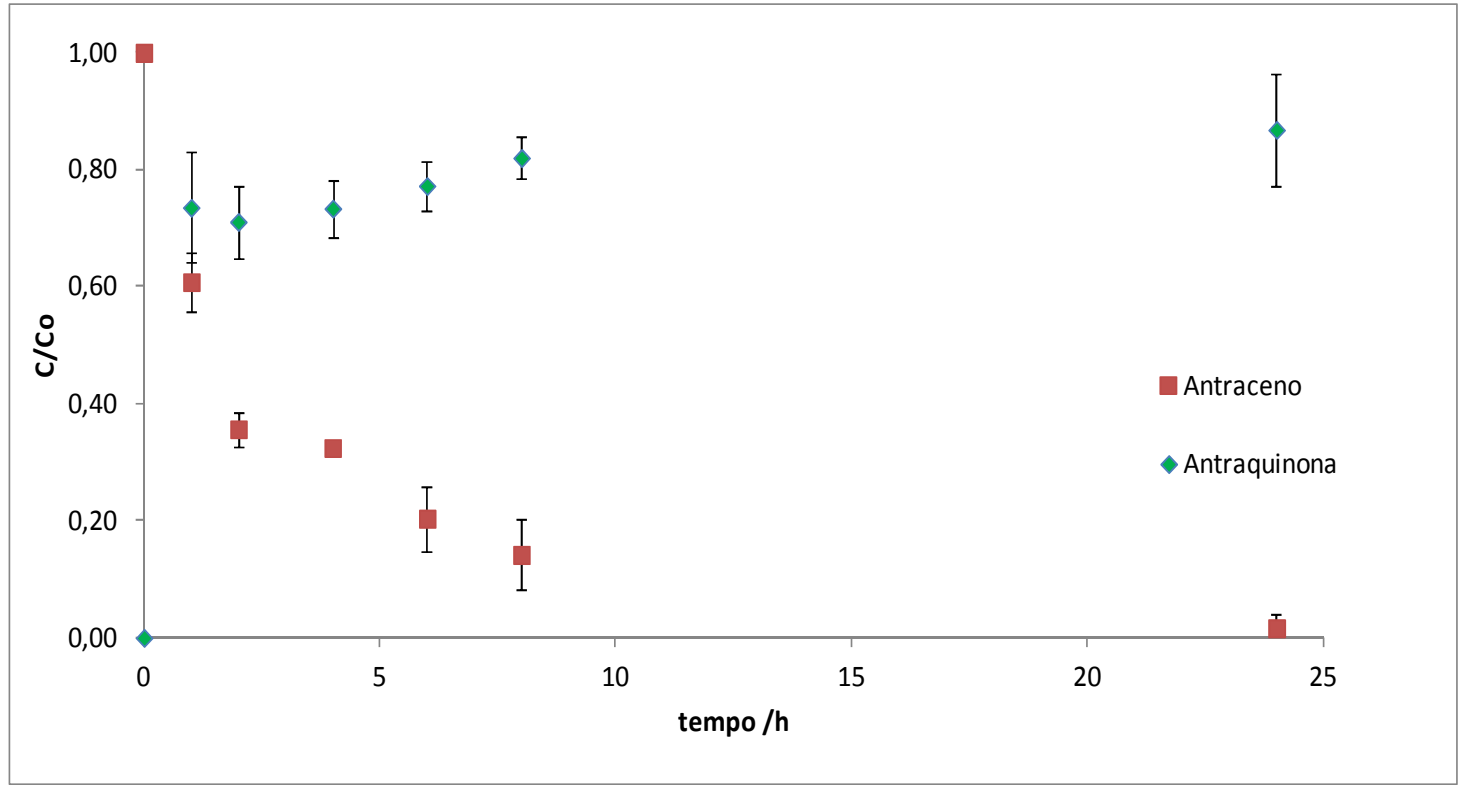

Figura 20- Formação da antraquinona, a partir da decomposição do antraceno, utilizado permanganato como oxidante na proporção (1:22 contaminante:oxidante) em matriz areia padrão, durante 24 horas de tratamento.

Nos experimentos utilizando o persulfato ativado com ferro como oxidante (Figura 21) verificou-se que a decomposição do antraceno após 4 horas de tratamento já havia praticamente cessado; restando após 24 horas de tratamento somente 5\% da concentração inicial de antraceno. No entanto a concentração da antraquinona manteve-se em $37 \%$ em relação à concentração inicial do antraceno. A degradação da antraquinona pode ter cessado, pois a taxa de reação do radical sulfato (eletrofílico) decresce na presença do substituinte carbonila ligado ao anel aromático central que compõe a antraquinona. ${ }^{45,100}$ A concentração residual do antraceno foi semelhante utilizando tanto o oxidante permanganato quanto persulfato ativado com ferro. No entanto, a concentração percentual da antraquinona; utilizando persulfato como oxidante, correspondeu a praticamente metade da concentração da antraquinona quando se utilizou o permanganato como oxidante no mesmo período de tempo. 


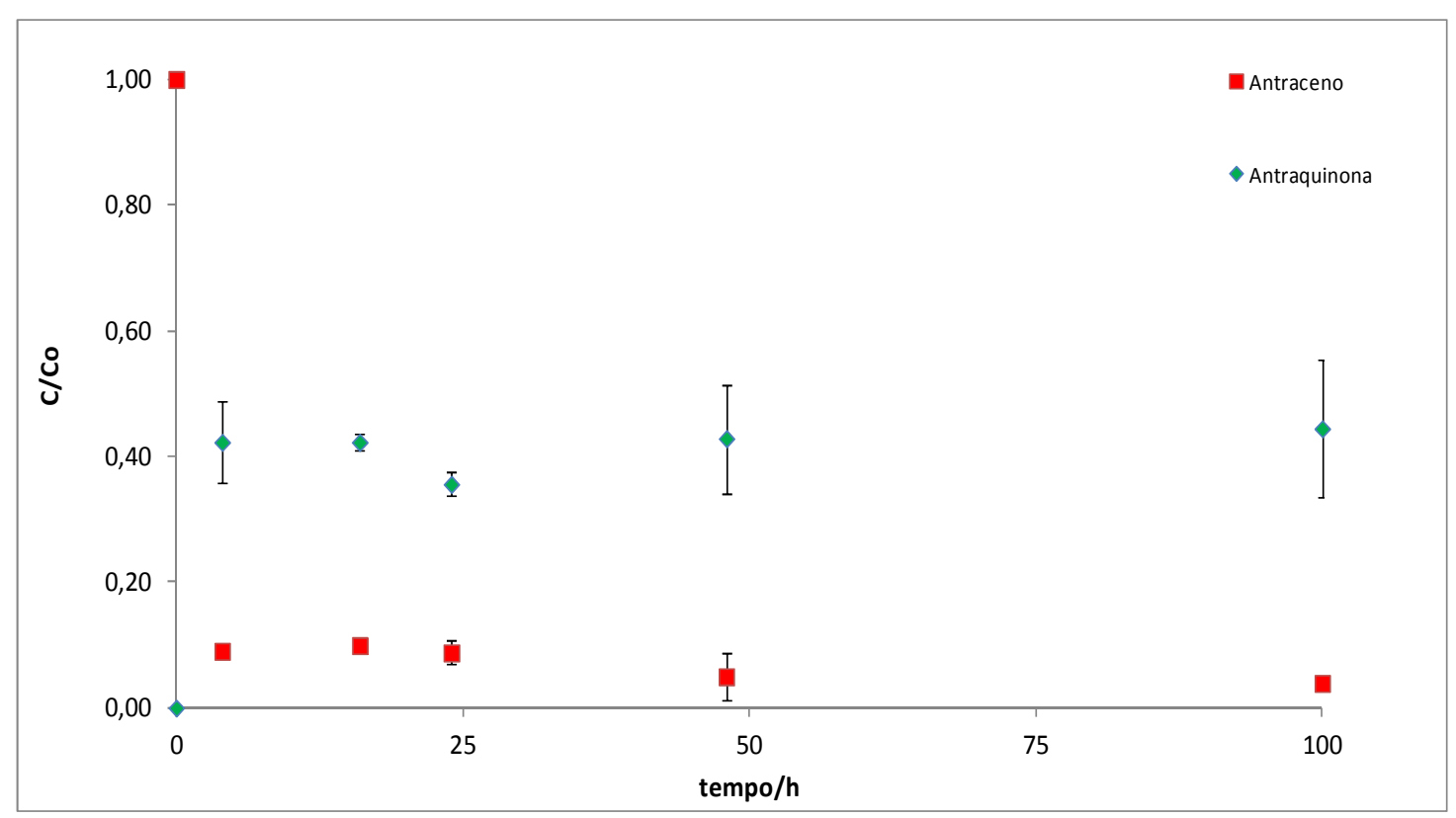

Figura 21- Formação da antraquinona, a partir da decomposição do antraceno, utilizado o persulfato ativado com ferro como oxidante na proporção de 1:100 (contaminante:oxidante) em matriz areia padrão, durante 100 horas de tratamento.

Mesmo a antraquinona sendo um intermediário de degradação do antraceno, ele é considerado menos estável em relação ao antraceno, devido à quebra da aromaticidade, sendo então menos persistentes ao meio ambiente. Estudo anterior realizado por Lee e colaboradores (1998) demonstraram que a antraquinona é mais biodegradável que o antraceno, pois após 30 dias houve a degradação de $90 \%$ da antraquinona e somente $30 \%$ do antraceno no mesmo período. Em um outro estudo similar realizado por Lee e Hosomi (2001), verificou que os micro-organismos aeróbicos e anaeróbicos presentes no sedimento degradaram $98 \%$ do benzo[a]antraceno-7,12diona enquanto somente $12 \%$ do benzo[a]antraceno foi degradado. $\mathrm{O}$ benzo[a]antraceno-7,12diona é originado a partir do benzo[a] antraceno, após uma processo de tratamento por reações de Fenton. Os intermediários oxigenados de HPA, gerados após o uso de processos oxidativos, são mais facilmente degradados por micro-organismos e menos tóxicos. ${ }^{101,102}$ Logo, o uso de processos oxidativos antes da aplicação de um processo de biorremediação pode torná-lo viável. 
Além de ter sido identificada a formação do intermediário antraquinona independente do oxidante utilizado, neste presente estudo, também foi identificada a formação de intermediários provenientes do antraceno. Após 24 horas de tratamento, utilizando o permanganato como oxidante, foi identificada a xantona (Figura 22). Já com o uso de persulfato ativado com ferro, só foi possível identificar a antraquinona. No entanto quando se utilizou persulfato ativado em meio alcalino, além da identificação da antraquinona proveniente do antraceno, foi possível identificar o xanteno (Figura 23), após 24 horas de tratamento. Por outro lado, não foi identificado nenhum intermediário proveniente do fenantreno utilizando permanganato, persulfato e peróxido de hidrogênio como oxidante de acordo com os parâmetros adotados neste presente estudo. No entanto Beltran e colaboradores (1998) identificaram o 9-hidroxifenantreno como intermediário proveniente do fenantreno após a degradação de $80 \%$ dos HPA, utilizando o processo de Fenton em água contaminada. $^{103}$

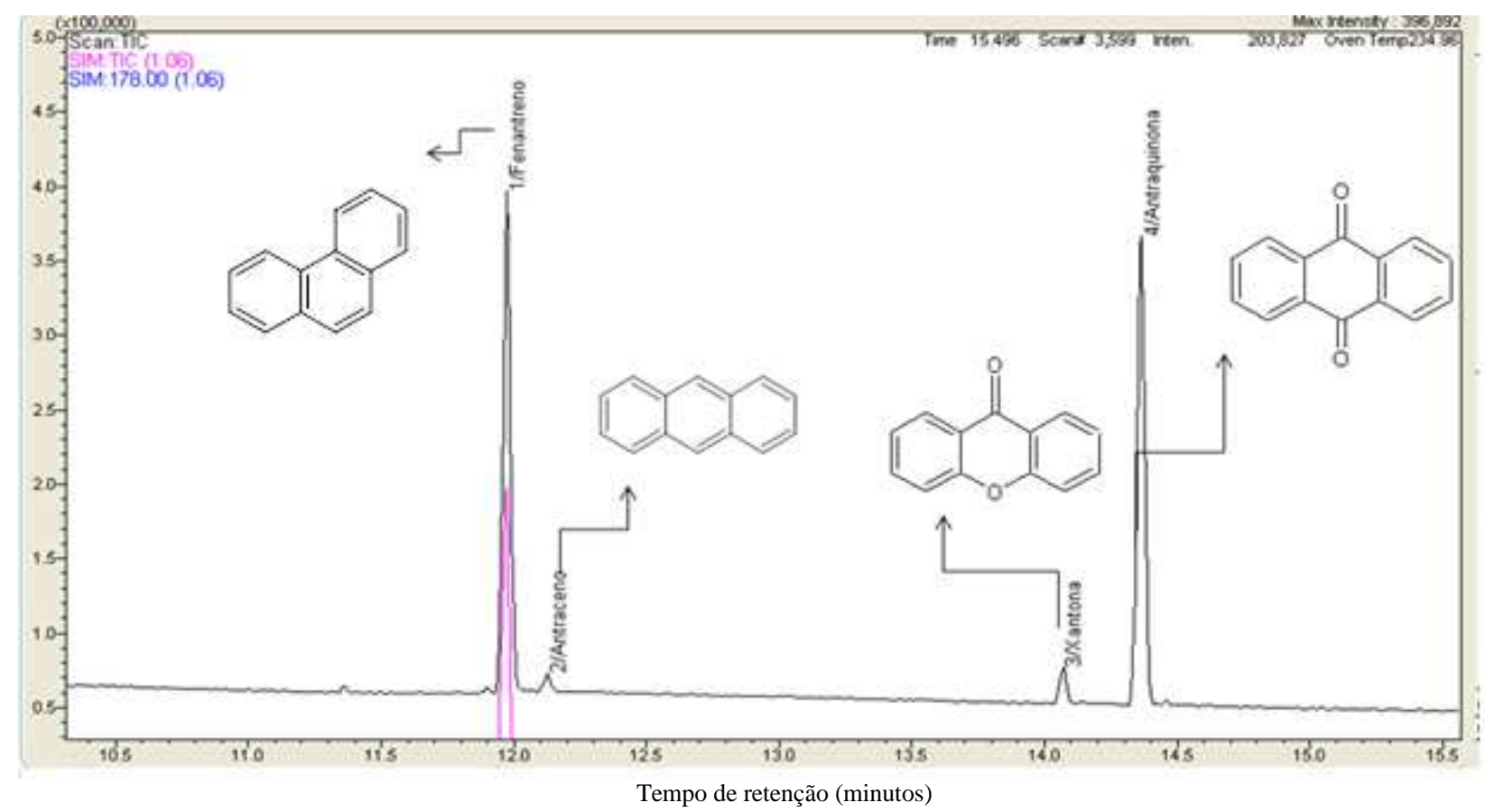

Figura 22- Cromatograma dos contaminantes fenantreno, antraceno residual e da formação dos intermediários antraquinona e xantona presentes na areia padrão, após 24 horas de tratamento utilizando o oxidante permanganato na proporção de 1:22 (contaminante:oxidante). 


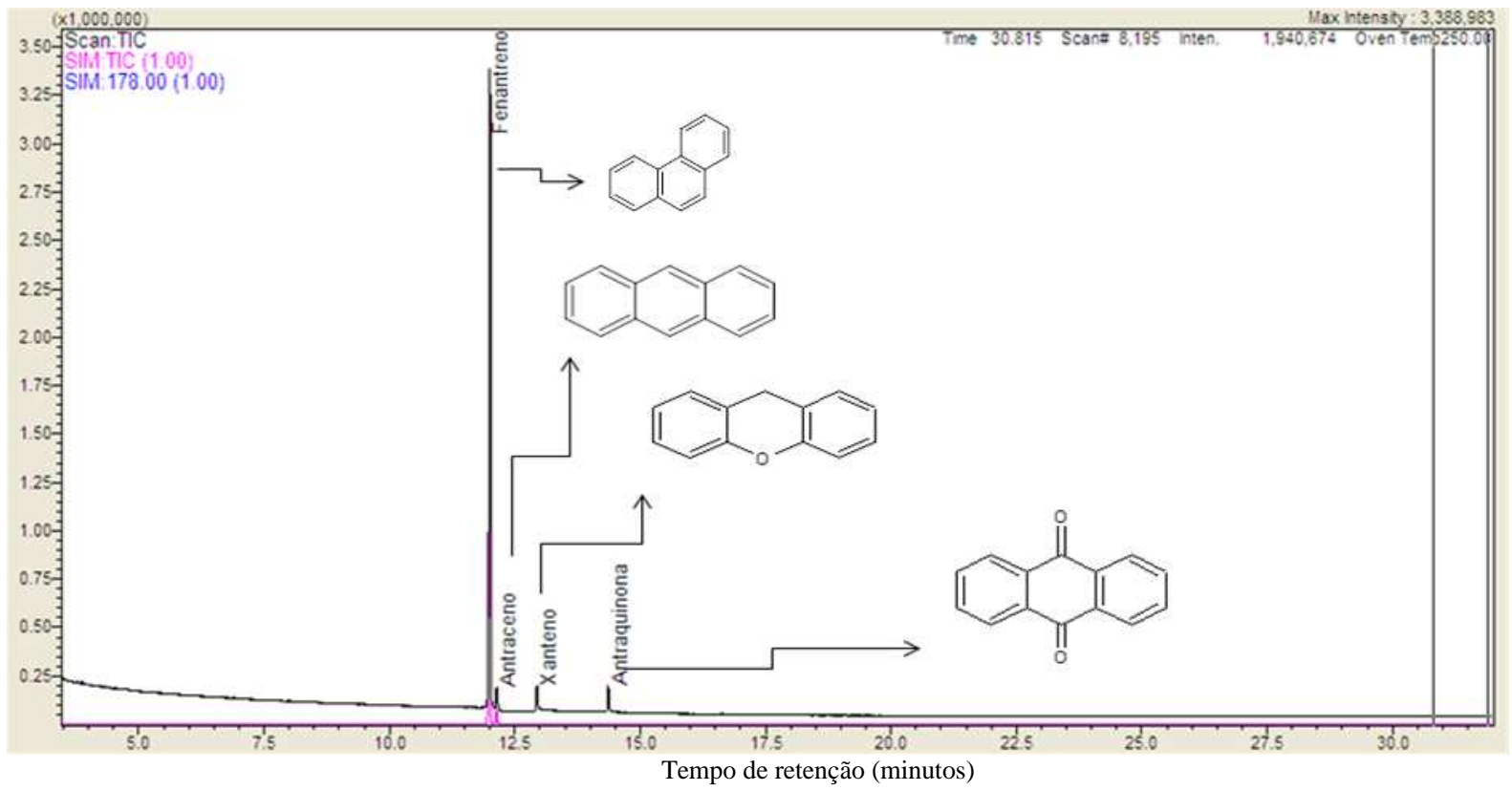

Figura 23- Cromatograma dos contaminantes fenantreno e antraceno residual e da formação dos intermediários antraquinona e xanteno presentes na areia padrão, após 24 horas de tratamento utilizando oxidante persulfato em meio alcalino na proporção de 1:33 (contaminante:oxidante).

Em um estudo realizado por Ferrarese e colaboradores (2008), foi verificado que os percentuais de remoção de HPA utilizando diferentes oxidantes não são proporcionais em relação ao percentual de carbono orgânico total (COT) residual que permanece na matriz após o tratamento, indicando que não houve mineralização completa dos contaminantes. ${ }^{52}$

A formação dos intermediários provenientes dos contaminantes, como HPA, depende não somente do oxidante utilizado, mas do tempo de tratamento, da forma de ativação, e da matriz que se encontra o contaminante.

\subsubsection{Mecanismo de formação dos intermediários provenientes do antraceno}

O radical sulfato, como o radical hidroxila são fortes oxidantes e pode oxidar os contaminantes, entre eles os HPA, por três mecanismos: abstração de hidrogênio, por quebra de ligações $\pi$ e transferência direta de elétrons. 
Só foi possível identificar os intermediários oriundos do antraceno, entre eles o intermediário majoritário: a antraquinona. O fenantreno é menos reativo, em relação ao antraceno, devido ao impedimento estérico nas posições mais reativas dificultando a atuação dos radicais na degradação. O possível mecanismo de degradação do antraceno e formação da antraquinona por meio de ataque eletrofílico do radical hidroxila e sulfato estão esquematizados nas Figuras 24 e 25. Os produtos da reação entre os radicais e os contaminantes geram cátion radical orgânico que pode reagir tanto com a água e com outras espécies, ocasionado a decomposição. ${ }^{53,104,105}$<smiles>c1ccc2cc3ccccc3cc2c1</smiles><smiles>O</smiles><smiles>O=C1c2ccccc2C(=O)c2ccccc21</smiles><smiles>c1ccc2c(c1)Cc1ccccc1C2</smiles><smiles>O</smiles><smiles>C=CC</smiles><smiles>C</smiles><smiles>O[C@H]1c2ccccc2[C@H](O)c2ccccc21</smiles>

Figura 24 -Formação da antraquinona a partir do antraceno na presença do radical hidroxila de acordo com o mecanismo proposto por PAUL e SHARON. ${ }^{106}$

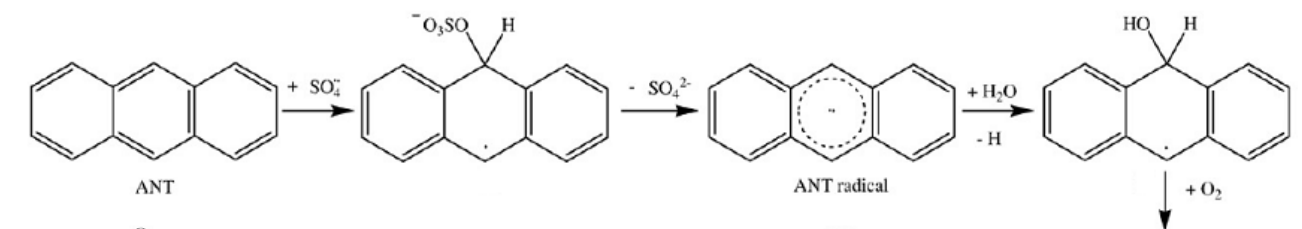

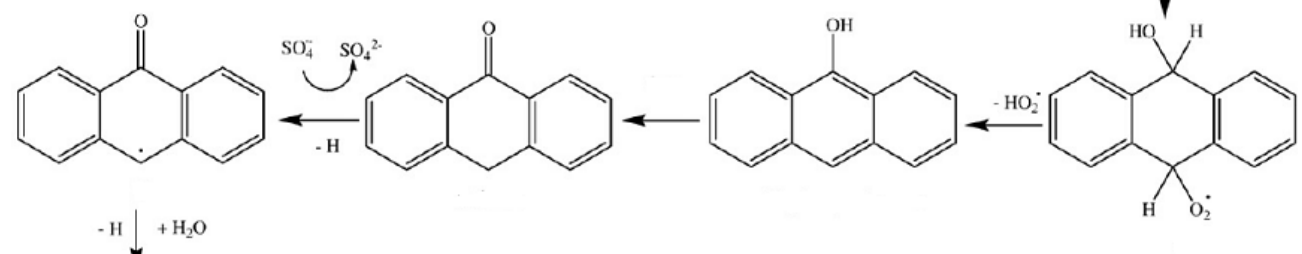<smiles>O=C1c2ccccc2C(O)c2ccccc21</smiles><smiles>CC(C)C(O)c1ccc2c(c1)C(=O)c1ccccc1C2=O</smiles>

Figura 25- Formação da antraquinona a partir do antraceno na presença do radical sulfato, mecanismo proposto por WANG e colaboradores. ${ }^{105}$ 


\subsection{Teor de ferro nos solos}

Foi quantificado o teor de ferro nas amostras de solo A, B, e C para poder avaliar se a presença do ferro nos solos interferiria na atuação dos oxidantes. A digestão e a quantificação do ferro presente nos solos foram realizadas baseadas nos métodos 3051 e 6010 da EPA. Foram adicionados $100 \mathrm{mg}$ da amostra de solo em $3 \mathrm{~mL}$ de $\mathrm{HNO}_{3}$ e $1 \mathrm{~mL}$ de $\mathrm{HCl}$ para se fazer a digestão em micro-ondas. Este método adotado não é uma técnica de digestão total dos metais. O ferro presente em amostras refratárias como quartzo e silicato, presentes no solo, não foram dissolvidos. No entanto este ferro possivelmente ligado ao silicato e quartzo estão excluídos de serem transportados para o meio aquoso, logo possivelmente não interferiram na eficiência dos processos oxidativos. Foi utilizado o Espectrômetro Ótico de Emissão Atômica por Plasma Acoplado Indutivamente (ICP-AES Radial), fabricante Spectro-Modelo ArcosSOP para realizar a quantificação. O comprimento de onda utilizado para a leitura do ferro foi de 259,941 nm. Os dados obtidos estão descritos na Tabela 9. ${ }^{107,108}$

Tabela 9 Teor de ferro presente nos solos arenosos A, B e C.

\section{Teor de Ferro}

\section{Amostra}

\begin{tabular}{ccc} 
& $\mathbf{m g ~ k \mathbf { ~ g } ^ { - 1 }}$ & $\mathbf{C . V}$ \\
\hline Solo A & 1231 & 123 \\
Solo B & 1143 & 107 \\
Solo C & 16 & 0,8 \\
\hline
\end{tabular}

CV: Coeficiente de Variação 


\subsection{O uso do persulfato de sódio ativado com ferro em diferentes matrizes}

Após avaliar o uso dos diferentes oxidantes utilizando a mesma matriz (areia padrão), foi escolhido o uso do persulfato ativado com ferro na proporção molar de 1:100 (contaminante:oxidante) aplicados em diferentes matrizes. Foi escolhida a maior dosagem de oxidante, pois nos solos arenosos havia a presença de matéria orgânica e minerais, o que poderia comprometer a eficiência da degradação dos contaminantes.

Foi aplicado persulfato ativado com ferro na areia padrão, nos solos A, B e C sendo avaliados a degradação dos contaminantes em diferentes matrizes,após 24 horas de tratamento (Figura 26).

Utilizando persulfato como oxidante, após 24 horas de tratamento, a degradação do fenantreno foi maior na areia padrão em relação aos solos B e C, sendo 55, 45 e 11 \% para areia padrão, solo B e solo C, respectivamente. No solo A, a degradação dos contaminantes foi mais eficiente, apesar de apresentar maior teor de argila e silte na sua composição comparado com os demais solos estudados, que poderia ocasionar sorção dos contaminantes.

O uso do persulfato possibilitou a degradação de quase $100 \%$ do antraceno enquanto ao utilizar o peróxido de hidrogênio como oxidante na mesma matriz (Solo A) houve a degradação de $62 \%$ do antraceno, como apresentado anteriormente no item 4.4. O oxidante persulfato é mais persistente que o peróxido de hidrogênio o que pode ter favorecido a degradação. 


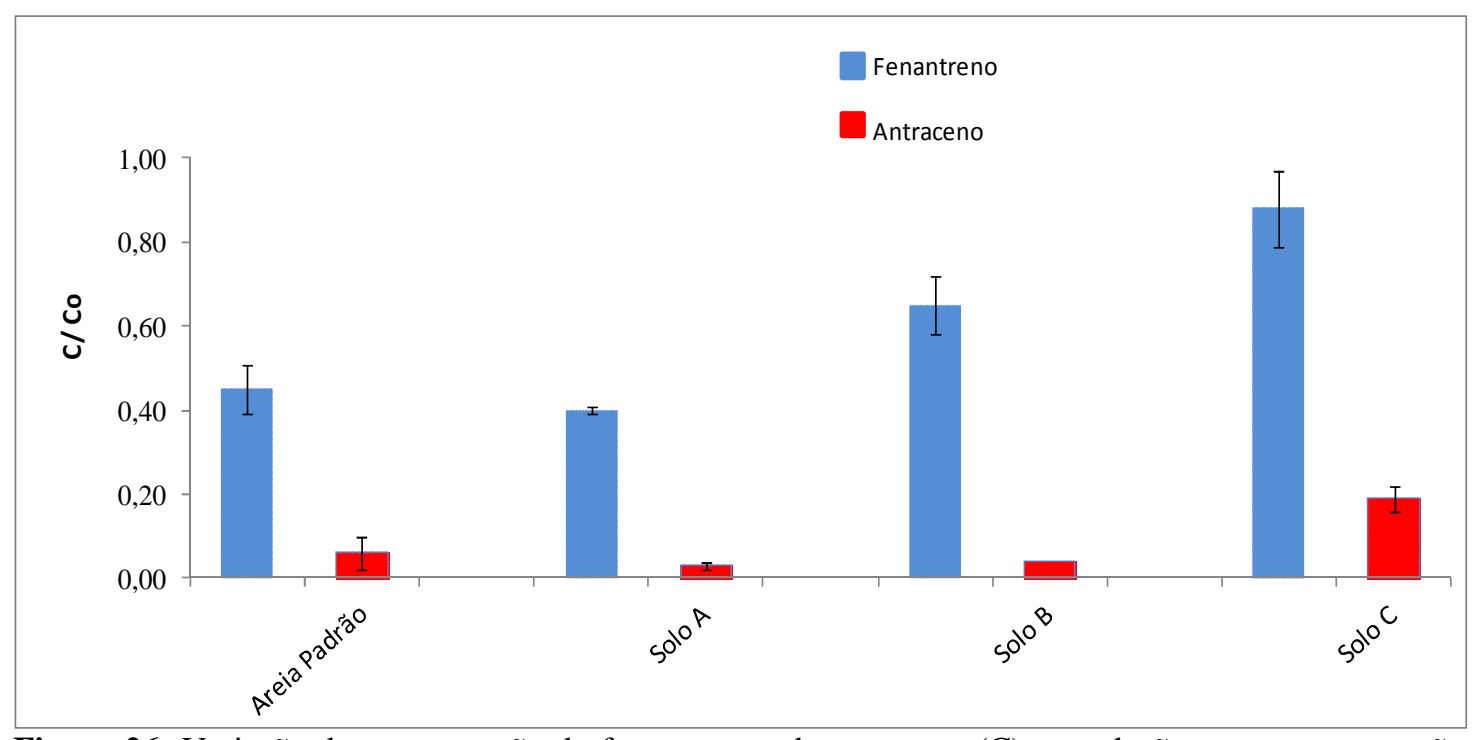

Figura 26- Variação da concentração do fenantreno e do antraceno (C) em relação a sua concentração inicial (Co) após 24 horas de tratamento, utilizando persulfato ativado com ferro como oxidante em proporção molar de 1:100:8 (contaminante: oxidante: $\mathrm{Fe}^{2+}$ ) utilizando diferentes matrizes.

A baixa degradação do fenantreno no solo $\mathrm{C}$, em relação às demais matrizes, provavelmente foi afetada pela sorção dos contaminantes pelo ácido húmico, pois esse solo possuía maior teor desse ácido em relação as demais matrizes em estudo. Ainda, ácidos húmicos são insolúveis em meio ácido, e as reações se deram em pH entre 2 e 3 . Os ácidos húmicos, em relação aos ácidos fúlvicos, apresentam estrutura molecular com maior aromaticidade e maior massa molecular, o pode ter dificultado a interação entre o contaminante, o persulfato e o ferro. ${ }^{97,109}$ Além disso, quando estão em solução, os ácidos húmicos tendem a formar estruturas tipo micelas que são capazes de sequestrar moléculas hidrofóbicas como os HPA, dificultando a disponibilidade para a atuação do oxidante. O solo C foi o que apresentou menor permeabilidade da água, o que pode também ter dificultado o contato entre o contaminante e oxidante. ${ }^{110,111,112}$

Como discutido anteriormente, outro fator que pode influenciar na eficiência da degradação é a presença de ferro no solo, pois podem atuam como ativantes na geração dos radicais sulfato. Os solos A, B e C já apresentavam em sua composição 1.230; 1.143 e 16 mg $\mathrm{kg}^{-1}$ de ferro, respectivamente (Tabela 9). Foi adicionado em cada uma das matrizes, cerca de 
$550 \mathrm{mg} \mathrm{kg}{ }^{-1}$ de $\mathrm{Fe}^{2+}$ proveniente de uma solução de sulfato de ferro. Os resultados demonstraram que, mesmo os solos A e B apresentando cerca de duas vezes mais ferro que a areia padrão em sua matriz, o que favorece a formação de radicais sulfatos, não foram obtidas maiores degradações dos contaminantes nestas matrizes. A justificativa para esse comportamento é que o ferro presente nos solos $\mathrm{A}, \mathrm{B}$ e $\mathrm{C}$ poderiam estar na forma de $\mathrm{Fe}^{3+} \mathrm{ou}$ não estar disponível para reagir com os íons sulfato do oxidante, e, com isso, dificultando a geração dos radicais, desfavorecendo a degradação dos contaminantes. ${ }^{71}$ No entanto a composição mineralógica e o teor de matéria orgânica do solo também pode comprometer na degradação dos contaminantes pelos oxidantes.

Estudos anteriores, como o realizado por Yen e colaboradores (2011), verificaram que somente $43-55 \%$ de óleo diesel foi degradado após 80 dias de tratamento utilizando óxidos de ferro presentes no solo para ativar o persulfato, mesmo com concentrações de $50 \mathrm{mg} \mathrm{kg}{ }^{-1}$ de ferro. ${ }^{71,113}$ Outro estudo proposto por Ahmad e colaboradores (2010) investigou dois óxidos de ferro (goetita e hematita ) na presença de persulfato, em $\mathrm{pH}<7$, por 30 dias e verificou que menos de $15 \%$ do persulfato sofreu decomposição. ${ }^{114}$ Por outro lado em um estudo mais recente, realizado por Usman e colaboradores (2012) utilizando persulfato ativado com ferro magnetita obteve-se a degradação de 70-80\% dos HPA presentes em solo arenoso, após uma semana de tratamento. O ferro magnetita é uma mistura de íons de $\mathrm{Fe}^{2+}$ e $\mathrm{Fe}^{3+}$ o que pode ter favorecido a reação, pois os íons $\mathrm{Fe}^{2+}$ reagem diretamente com os íons sulfato gerando radicais sulfato, diferentemente da goetita e da hematita que são constituídas somente de $\mathrm{Fe}^{3+} \cdot 100,109$

Entretanto, o excesso de ferro também pode reduzir a eficiência na remoção dos contaminantes devido à competição entre o ferro em excesso e os contaminantes na interação com os radicais. Estudos demonstraram que a proporção molar entre oxidante e ferro $\left(\mathrm{Fe}^{2+}\right)$ deve ser avaliada, pois quando a quantidade de íons de ferro e oxidante é deficitária ou 
quando estão em excesso, a eficiência da reação pode ser comprometida. ${ }^{71} \mathrm{Com}$ isso, uma adição gradual de íons $\mathrm{Fe}^{2+}$ seria mais eficaz, pois segundo a literatura, o ânion persulfato persiste no solo após 5 meses do início da reação. ${ }^{3,65,71}$

Foi possível identificar a antraquinona oriunda do antraceno, após 24 horas de tratamento tanto no solo A (Figura 27) quanto no solo B e C. No entanto não foi possível quantificar o intermediário antraquinona devido a complexidade das matrizes, que resultou em valores não reprodutíveis.

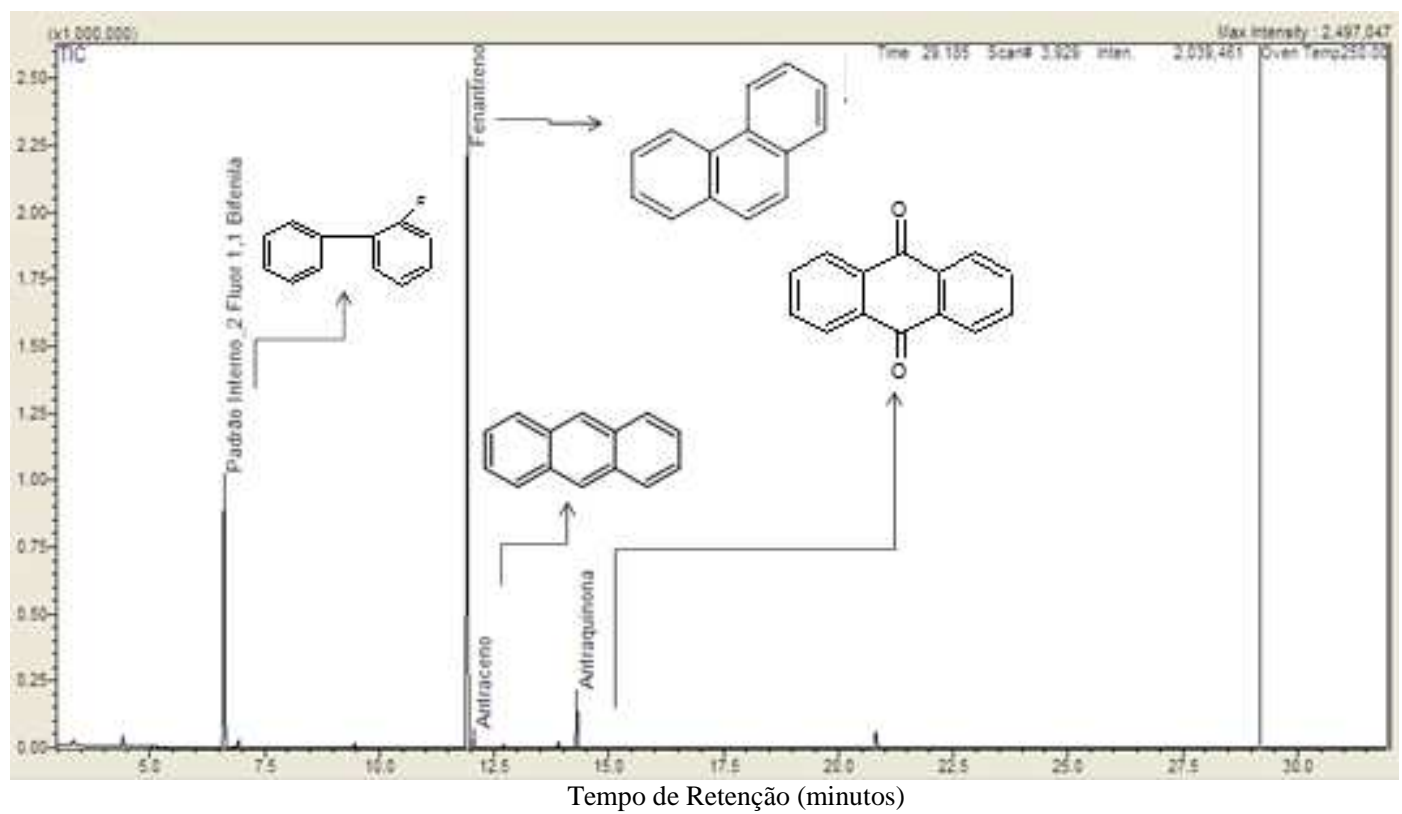

Figura 27- Cromatograma dos contaminantes fenantreno e antraceno residual e da formação do intermediário antraquinona, após 24 horas de tratamento no solo A, utilizando oxidante persulfato ativado com ferro na proporção de 1:100 (contaminante:oxidante).

O estudo comparativo da eficiência dos oxidantes em diferentes matrizes é muitas vezes complexo, mesmo avaliando somente os HPA como contaminantes e os solos arenosos como matriz. No presente trabalho, todas as matrizes avaliadas foram saturadas em água, mas sem a presença de sobrenadante, simulando um tratamento entre os poros do solo, diferente de muitos estudos na literatura que tratam os solos dispersos em água simulando um sedimento. ${ }^{52,57,100}$ Constatou-se por meio destes estudos comparativos que a concentração dos 
oxidantes em mol L ${ }^{-1}$ influencia na eficiência da decomposição dos HPA mesmo adicionando o mesmo teor de oxidante, já que a reação ocorre em meio aquoso.

Outro fator relevante é a concentração dos contaminantes, pois a degradação pode não ser a mesma para uma mistura de HPA em relação aos compostos presentes individualmente, pois deve-se considerar a solubilidade efetiva e a competição entre os contaminantes na decomposição. ${ }^{52}$ Assim como os poluentes adicionados previamente; podem ser mais facilmente oxidados que poluentes nativos, que geralmente estão mais sorvidos nas matrizes do solo. $52,56,57,100$

\subsection{Avaliação do consumo do carbono orgânico após o tratamento por meio de processos oxidativos nos solos arenosos.}

O teor de carbono orgânico, assim como das respectivas frações (ácido fúlvico, ácido húmico e humina) foram quantificados nos solos arenosos. Primeiramente foi quantificado do solo original e posteriormente foi quantificado o carbono orgânico de cada uma das frações após o uso do oxidante no solo contaminado com fenantreno e antraceno (Tabela 10).

Os solos A e B foram coletados na mesma região, com uma distância horizontal de cerca de $150 \mathrm{~m}$, porém em profundidades diferentes, de $14-50 \mathrm{~cm}$ para o solo A e de $50-80$ cm para o solo B. Verificou-se que o mesmo solo, coletado em profundidades diferentes, pode apresentar alterações tanto no teor de carbono orgânico como na distribuição das frações das substâncias húmicas, sendo necessária uma prévia avaliação em aplicações in situ do oxidante. Embora haja diferença entre as substâncias húmicas de diferentes fontes, algumas propriedades gerais consideram suas origens similares, facilitando os estudos comparativos entre os mesmos tipos de solos, mas que apresentam diferentes proporções das frações das substâncias húmicas. ${ }^{34}$

De acordo com a técnica adotada neste presente trabalho para quantificar o carbono orgânico do solo e considerando que se trata de uma matriz heterogênea, é possível afirmar 
que não houve mineralização do carbono proveniente da matéria orgânica natural dos solos arenosos após o uso dos oxidantes persulfato e peróxido de hidrogênio (Tabela 10). Neste presente estudo não foi possível avaliar se houve alteração na estrutura das substâncias húmicas, mesmo mantendo quase que inalterável a quantidade de carbono orgânico após o uso do oxidante. Por outro lado, se observou que nos solos A e B houve o aumento na concentração de carbono nas frações de ácidos húmicos e fúlvicos após a oxidação e o decaimento na concentração de carbono na fração humina . Isso pode ter sido ocasionado pela a decomposição da estrutura humina que é mais complexa, em ácido húmico e ácido fúlvico, respectivamente. Como também, a presença de compostos orgânicos (os HPA) pode ter modificado a solubilidade das frações das substâncias húmicas em água.

TABELA 10 - Avaliação do teor de carbono, após 24 horas de tratamento, nas frações das substâncias húmicas em solo arenosos contaminados com fenantreno e antraceno que sofreram processo oxidativo.

\begin{tabular}{|c|c|c|c|c|}
\hline Amostra & Atributo & Solo Original & $\begin{array}{c}\text { Solo com } \mathrm{HPA} \mathrm{Na} \mathrm{Na}_{2} \mathrm{~S}_{2} \mathrm{O}_{8} \text { ativado } \\
\operatorname{com~\mathrm {Fe}^{2+}}\end{array}$ & $\begin{array}{c}\mathrm{H}_{2} \mathrm{O}_{2} \text { ativado } \\
\text { com } \mathrm{Fe}^{2+}\end{array}$ \\
\hline & & $\mathrm{g} \mathrm{kg}^{-1}$ & $\mathrm{~g} \mathrm{~kg}^{-1}$ & $\mathrm{~g} \mathrm{~kg}^{-1}$ \\
\hline \multirow{4}{*}{ Solo A } & C-org & 27,2 & 27,8 & 28,4 \\
\hline & $\mathrm{C}-\mathrm{AF}$ & 3,7 & 4,0 & 4,0 \\
\hline & $\mathrm{C}-\mathrm{AH}$ & 4,8 & 5,0 & 5,0 \\
\hline & C-Hum & 7,8 & 6,2 & 6,3 \\
\hline \multirow{4}{*}{ Solo B } & C-org & 16 & 12,1 & \\
\hline & $\mathrm{C}-\mathrm{AF}$ & 4,5 & 4,8 & \\
\hline & $\mathrm{C}-\mathrm{AH}$ & 4,4 & 6,0 & \\
\hline & C-Hum & 3,9 & 2,1 & \\
\hline \multirow{4}{*}{ Solo C } & C-org & 31,2 & 29,4 & \\
\hline & $\mathrm{C}-\mathrm{AF}$ & 1,2 & 1,1 & \\
\hline & $\mathrm{C}-\mathrm{AH}$ & 18,5 & 18,5 & \\
\hline & C-Hum & 2,8 & 3,0 & \\
\hline
\end{tabular}

C-org- Carbono Orgânico Total; C-AF- Carbono- Ácido Fúlvico, C-AH- Carbono- Ácido Húmico, C-HUMCarbono -Humina

Neste presente trabalho foi aplicado cerca de $50 \mathrm{~g} \mathrm{~L}^{-1}$ de persulfato em três diferentes solos e não houve o consumo de carbono orgânico, após 24 horas de tratamento. Em contrapartida, Kanwaters (2010), em seu estudo, observou a redução da matéria orgânica 
natural do solo em cinco dos setes sedimentos estudados quando aplicado dosagens de $20 \mathrm{~g} \mathrm{~L}^{-1}$ de persulfato, após cem dias de tratamento. ${ }^{115}$ Sun e colaboradores (2007) observaram mudanças na composição das frações das substâncias húmicas após o uso das reações de Fenton, e ainda o consumo de cerca de $22 \%$ do carbono da matéria orgânica. ${ }^{116}$

A conservação do teor de carbono após a oxidação química é favorável, pois pode impedir a lixiviação dos contaminantes residuais presentes no solo após a oxidação, exigir menor dosagem de oxidante, além de não alterar a fertilidade do solo.

Para avaliar a eficiência da degradação dos HPA do presente trabalho em relação com aos trabalhos encontrados na literatura seriam necessários uma avaliação da matriz solo, da concentração do oxidante e do contaminante e o tempo de contato do contaminante com a matriz, visto que tais parâmetros podem influenciar tanto no tratamento quanto na extração dos contaminantes. Ainda, é preciso considerar que contaminantes podem ser mineralizados em água, necessitem de altas dosagens de oxidante e longo tempo de tratamento quando aplicadas em sistema água/ solo. Além disso, é essencial avaliar o consumo do oxidante por espécies redutoras (matéria orgânica e compostos inorgânicos) presentes no solo. Há outros fatores dos quais são adotados durante o ensaio, como a presença de sobrenadante no tratamento do solo, agitação do meio reacional, origem do ferro (nativo ou adicionado), a proporção molar entre oxidante:ferro e o tempo de tratamento que devem ser avaliados ao se comparar a eficiência de degradação dos contaminantes. Apesar desta diversidade de variáveis, este presente estudo dos HPA em solos arenosos em escala bancada pode contribuir para estudos posteriores in situ, visto que é por meio deste conhecimento prévio do solo contaminado como as características mineralógicas, a quantidade de ferro e quantidade de matéria orgânica que é possível avaliar qual é o oxidante mais adequado para mineralizar o contaminante presente na matriz em escala real. 


\section{CONCLUSÃO}

Para avaliar a eficiência do tratamento por meio do uso de processos oxidativos, é preciso considerar primeiramente, a eficiência da extração dos contaminantes em cada uma das matrizes que estão presentes. A presença de umidade no solo e a sorção dos contaminantes na matriz podem gerar valores superestimados na eficiência de degradação dos oxidantes sob os contaminantes.

Em nenhum dos tratamentos adotados neste trabalho, utilizando os diferentes oxidantes (permanganato, peróxido de hidrogênio e persulfato), foi possível identificar os intermediários provenientes do contaminante fenantreno. Por outro lado foi observada a formação da antraquinona oriundo do antraceno a partir do uso de diferentes oxidantes. A antraquinona formada é mais biodegradável que o contaminante antraceno presente inicialmente.

O mais adequado seria utilizar somente o ferro já presente no solo para ativação dos oxidantes. Entretanto, a geração dos radicais pode ser comprometida pela disponibilidade, estado de oxidação do ferro.

Não houve alterações significativas nas frações das substâncias húmicas presentes nos solos arenosos analisados, após o uso do processo de oxidação com persulfato e peróxido de hidrogênio, tornando o seu uso bastante favorável em tratamentos de solo. O uso destes oxidantes pode além de mineralizar os contaminantes sem gerar resíduos, ainda conserva o teor de carbono após a oxidação química. Desta forma impede a lixiviação dos contaminantes residuais presentes no solo após a oxidação, exigindo menor dosagem de oxidante, não alterarando a fertilidade do solo.

Não foi possível avaliar se houve alteração na estrutura química das substâncias húmicas após o uso dos processos oxidativos. No entanto, verificou-se que pode ter ocorrido 
uma possível alteração nas estruturas devido ao declínio de carbono proveniente da humina e aumento na quantidade de carbono na fração do ácido húmico após a oxidação.

A variação na concentração dos oxidantes, assim como dos contaminantes e tempo de contaminação no solo; pode alterar na eficiência da degradação dos contaminantes, além de dificultar a comparação entre diferentes estudos realizados.

Por outro lado por meio dos estudos preliminares em escala bancada é possível avaliar qual é oxidante mais adequado para se aplicar em determinada matriz contaminada para um posterior estudo em escala real. 


\section{REFERÊNCIAS BIBLIOGRÁFICAS}

1 COMPANHIA AMBIENTAL DO ESTADO DE SÃO PAULO -CETESB Qualidade do solo Disponível em <http://www.cetesb.sp.gov.br/solo/Informa\%C3\%A7\%C3\%B5esB\%C3\%A1sicas/5-Polui\%C3\%A7\%C3\%A3o> Acesso: 04/07/2013.

2 WEBER, R., GAUS, C., TYSKLIND, M., JOHNSTON, P., FORTER, M., HOLLERT H., HEINISCH E.,HOLOUBEK I., LLOYD-S., M., MASUNAGA S., MOCCARELLI P., SANTILLO D., SEIKE N.,SYMONS, R., MACHADO TORRES, J.P., VERTA M., VARBELOW G., VIJGEN, J., WATSON A.,COSTNER P., WOELZ J., WYCISK P., ZENNEGG M., Dioxin- and POP-contaminated sites-contemporary and future relevance and challenges, Environmental Science and Pollution Research. v.15 ,p.363-393,2008.

3 ITRC (the Interstate Technology \& Reguklatory Council), Technical and Regulatory Guidance for in Situ Chemical Oxidation, $2^{\text {nd }}$ ed.,2005.

4 ATSDR (US Agency for Toxic Substances and Disease Registry). Toxicological profile for polyaromatic hydrocarbons, US. Departament of Health and Human services, Atlanta, 2005.

5 TIBURTIUS, E. R. L. Remediação de solos e águas contaminadas por compostos orgânicos voláteis (BTX), utilizando processos Fenton e lavagens com biosurfactantes.Tese de Doutorado, Universidade Federal do Paraná,(2008).

6 EEA- EUROPEAN ENVIRONMENT AGENCY. Progress in management of contaminated sites (CSI015),2007

7 COMPANHIA AMBIENTAL DO ESTADO DE SÃO PAULO -CETESB. Relação de áreas contaminadas e reabilitadas no Estado de São Paulo 2011. Disponível em <http://www.cetesb.sp.gov.br/userfiles/file/areas-contaminadas/2011/texto-explicativo.pdf> Acesso em : 15/07/2012.

8 COMPANHIA AMBIENTAL DO ESTADO DE SÃO PAULO -CETESB. Relação de áreas contaminadas e reabilitadas no Estado de São Paulo 2012. Disponível em http://www.cetesb.sp.gov.br/areas-contaminadas/relacoes-de-areas-contaminadas/15publicacoes Acesso: 14/06/2013 
9 HIGARASHI,M.M. Processos oxidativos avançados aplicados à remediação de solos brasileiros contaminados com pesticidas. 1999. Tese (Doutorado) Universidade Estadual de Campinas, Instituto de Química, Campinas.

10 KHAN, F. I.; HUSAIN, T.; HEJAZI, R. An overview and analysis of site remediation technologies. Journal of Environmental Management, v. 71, n. 2, p. 95-122, 2004.

11 CETESB - COMPANHIA DE TECNOLOGIA DE SANEAMENTO AMBIENTAL. Manual de gerenciamento de areas contaminadas. 2ed. São Paulo: CETESB, 2001.

12 JOHNSEN, A.R. Principles of microbial PAH- degradation in soil , Environemntal Pollution, Oxford, v.133, n.1, p. 71-84, 2005.

13 LEE,L.S.,RAO,P.S.C.,OKUDA,I. Equilibrium Partitioning of Polycyclic AromaticHydrocarbons From Coal-Tar Into Water. Environmental Science \&Technnolgy, v.26 p.2110-2115,1992.

14 SEMPLE, K. T., REID, B. J.,FERMOR, T. R.,Review: Impact of composting strategies on the treatment of soils contaminated with organic pollutants. Environmental. Pollution,v. 112 p.269-283,2001.

15 WILD, S.R., JONES, K.C. Polynuclear Aromatic Hydrocarbons in the United Kingdom environment: a preliminary source inventory and budget. Environmental Pollution,v. 88, p.91-108, 1995.

16 WILCKE W, AMELUNG W, KRAUSS M, MARTIUS C, BANDEIRA A AND GARCIA MVB. Polycyclic aromatic hydrocarbon (PAH) patterns in climatically different ecological zones of Brazil. Organic Geochemistry v.34, p.1405-1417, 2003.

17 MOTELAY,M.A., OLLIVON, D., GARBAN, B., TEIL MJ,BLANCHARD M., CHEVREUIL, M. Distributionand spatial trends of PAHs and PCBs in soils in the Seine River basin, France. Chemosphere v. 55,p. 555-565, 2004.

18 MIELKE HW, WANG G, GONZALES CR, POWELL ET,LE B AND QUACH VN. PAHs and metals in the soils of inner-city and suburban New Orleans, Louisiana, USA. Environmental Toxicology and Pharmacology v.18,p. 243-247. 2004.

19 BOUROTTE, C.,FORTI,M.C.,LUCAS,Y.,MELFI,A.J. Comparison of polycyclic aromatic hydrocarbon (PAH) concentrations in urban and natural forest soils in the atlantic forest (São Paulo State) Anais da Academia Brasileira de Ciências v.81,p.127-136, 2009. 
20 JUHASZ, A.L., and NAIDU,R. Bioremediation of high molecular weight polycyclic aromatic hydrocarbons: a review of the microbial degradation of benzo[a]pyrene.

International. Biodeterioration \& Biodegradation v.45, p. 57-88, 2000.

21 U.S. Environmental Protection Agency, 1990. "Subsurface Contamination Reference Guide" EPA/540/2-90/011.

22 WILD, S. R., M. L. BERROW, AND K. C. JONES. 'The Persistence of Polynuclear Aromatic-Hydrocarbons (Pahs) in Sewage-Sludge Amended Agricultural Soils',

Environmental Pollution v. 72, n. 2, p. 141-157, 1991.

23 CERNIGLIA,C.E.,HEITKAMP,M.A. Microbial degradation of polycyclic aromatic hydrocarbons in the aquatic environment. In Metabolism of Polycyclic Aromatic Hydrocarbons in the Aquatic Environment.ed.U.Varanasi,CRC Press,Boca Raton,Florida.1988.

24 GUERIN, W.F., BOYD, S.A.Differential bioavailability of soil-sorbed naphthalene to two bacterial species Applied Environmental Microbiology, v.58,n. 4, 1142-1152, 1992.

25 COMPANHIA DE TECNOLOGIA DE SANEAMENTO AMBIENTAL- CETESB Valores Orientadores para solo e águas subterrâneas no Estado de São Paulo. Disponível em <http://www.cetesb.sp.gov.br/solo/relatorios/tabela_valores_2005.pdf> Acesso: 02/07/2013.

26 CONSELHO NACIONAL DO MEIO AMBIENTE RESOLUÇÃO - CONAMA n ${ }^{\circ} 420$ 2009 Disponível em < http://www.mma.gov.br/port/conama/legiabre.cfm?codlegi=620> Acesso : 02/07/2013

27 TAN, K.H. Environmental soil science. 2.ed. Nova York, Marcel Dekker, 2000. 480p.

28 ASSOCIAÇÃO BRASILEIRA DE NORMAS TÉCNICAS-ABNT. Rochas e solos: terminologia, NBR 6502/95. Rio de Janeiro: 1995.18p.

29 EMPRESA BRASILEIRA DE PESQUISA AGROPECUÁRIA - EMBRAPA. Sistema Brasileiro de classificação de solos. 2.ed. Rio de Janeiro, Embrapa Solos, 2006. 306p.

30 AHANGAR, A.G. Sorption of PAHs in the soil environment with emphasis on the role of soil organic matter: a review. World Applied Sciences Journal v.7, p.759-765,2010. 
31 JACKSON, M.L. Determinaciones de Materia Orgánica en los Suelos. In - Analisis Químico de Suelos. Ediciones Omega, Barcelona, ,p.282-310,1964.

32 BIANCHI,S.R.,MIYAZAMA,M.,OLIVEIRA,E.L.,PAVAN,M.A.Relationship between the mass of organic matter and carbon in soil.Brazilian Archives of Biology and Technology v.52, n.2, 2008.

33 STEVENSON,F.J. Humus Chemistry: genesis, composition, reactions. New York: John Wiley, 1994.512p.

34 PETRUZZELLI, L., CELI, L., CIGNETTI, A.,MARSAN AJMONE, F. Influence of soil organic matter on the leaching of polycyclic aromatic hydrocarbons in soil. Journal of Environmental Science and Health, Part B,v. 37,n 3, p.187-199, 2002.

35 KONONOVA,M.M. Materia orgánica del suelo: su naturaleza, propiedades y metodos de investigación. Barcelona: Oikos-tau,3 1982,365p.

36 MC BRIDE, M.B., Environmental Chemistry of soils. Oxford UNIVERSITY Press, New York.1994,406p.

37 SCHULTEN,H.R.,SCHNITZER,M. A state of the art structure concept for humic substances. Naturwissenschaften. v.80,p.29-30,1993.

38 Grupo de Pesquisa Caracterização do Solo para Fins de Manejo Específico(CSME) Jaboticabal SP Disponível em:

$<$ http://www.google.com/url?sa=t\&rct=j\&q=\&esrc=s\&source=web\&cd=1\&ved=0CCMQFjA A\&url=http $\% 3 \mathrm{~A} \% 2 \mathrm{~F} \% 2 \mathrm{Fwww}$.acervodigital.unesp.br\%2Fbitstream\%2F123456789\%2F4043 4\%2F19\%2F9_Oxidos_de_Ferro_Indicadores_Ambientais.ppsx\&ei=YDNOUOjAIYKs9ATu 2oCIDA\&usg=AFQjCNHCEfFpRD6RZzpHpPbeJLBzMhVBIQ>Acesso em 10 de julhode 2013.

39 RITCHIE, J.D., PERDUE, E.M., Proton-binding study of standard and reference fulvic acids, humic acids and natural organic matter. Geochim. Cosmochim. Acta 67, 85-96, 2003.

40 AMELLAL, N., PORTAL, J. M.; BERTHELIN, J. Effect of soil structure on the bioavailability of polycyclic aromatic hydrocarbons within aggregates of a contaminated soil.Applied Geochemistry, v. 16, n. 14, p. 1611-1619, 2001. 
41 SILVA, MENDONÇA I.R., E.S. Matéria orgânica do solo. In: NOVAIS, R.F.; ALVAREZ V., V.H.; BARROS, N.F.; FONTES, R.L.F.; CANTARUTTI, R.B. \& NEVES, J.C.L.

Fertilidade do solo. Viçosa, MG, Sociedade Brasileira de Ciência do Solo, 2007. p.275-374.

42 ALNAIZY,R., AKGERMAN, A. Advanced oxidation of phenolic compounds Advances in Environmental Research., v. 4, p.233-244,2000.

43 HULING,S.G., PIVETZ, B.E US EPA (US Environmental Protection Agency), In situ Chemical Oxidation-Engineering Issue (EPA/600/R-06/072)2006.

44 WATTS, R and TEEL, A. "treatment of contaminated soil of contaminated soils and groundwater using ISCO". Practice Periodical of Hazardous, Toxic, and Radioactive Waste v.10,p.2-9, 2006.

45 SIRGUEY, C., SILVA, P.T., SCHWARTZ C., AND SIMONNOT ,M. O. 'Impact of Chemical Oxidation on Soil Quality', Chemosphere v. 72, n. 2, p.282-289, 2008.

46 MESSIAS, R.A. Estudos de adsorção/dessorção e biodegradação de simazina e 2,4-D incorporados em turfa e poliuretana. São Garios: 1998. Dissertação (Mestrado) Instituto de Química de São Carlos, Universidade de São Paulo 1998.

47 JONSSON,S.;PERSSON,Y.,FRANKKI,S.,BAVEL,B.V.,LUNDSTEDT,S. HANGLUND,P., TYSKLIND,M. Degradation of polycyclic aromatic hydrocarbons (PAH) in contaminated soils by Fenton's reagent: A multivariate evaluation of the importance of soil characteristics and PAH properties, Journal of Hazardous Materials,v.149,p. 86-96, 2007.

48 URYNOWICZ,M.A. In situ chemical oxidation with permanganate: Assessing the competitive interactions between target and not target compounds. Soil \& Sediment Contamination an International Journal v.17,p. 53-62, 2008.

49 SUTHERSAN,S.S.; "Natural and Enhanced remediation Systems" CRC Press,2001.

50 MESQUITA, A.C. Uso das Técnicas de Oxidação Química e Biodegradação na Remoção de Alguns Compostos Orgânicos Recalcitrantes. Tese de Doutorado. Engenharia Civil. COPPE. Universidade do Rio de Janeiro. Rio de Janeiro - RJ, 2004.

51 BROWN, G.S.,BARTON,L.L., THOMSOM,B.M. Permanganate oxidation of 
sorbed polycyclic aromatic hydrocarbons, Waste Management. p.737-740,2003.

52 FERRARESE, E.; ANDREOTTOLA, G.; OPREA, I. A. Remediation of PAHcontaminated sediments by chemical oxidation. Journal of Hazardous Materials, v. 152, n. 1, p. 128-139, Mar 2008

53 PETRI,B.G.; WATTS, R.J. "Fundamentals of ISCO using Hydrogen Peroxide" In: SIERGRIST, R.L., CRIMI, M. SIMPKIN, T.J. (Ed) “In Situ Chemical Oxidation for Groundwater Remediation"2011, p33-88.

54 KANEL, S. R., B. NEPPOLIAN, H. Y. JUNG, AND H. CHOI. 'Comparative Removal of Polycyclic Aromatic Hydrocarbons Using Iron Oxide and Hydrogen Peroxide in Soil Slurries', Environmental Engineering Science v. 21, n. 6, p.741-751, 2004.

55 YAP, C. L., S. Y. GAN, and H. K. Ng. 'Fenton Based Remediation of Polycyclic Aromatic Hydrocarbons-Contaminated Soils', Chemosphere v. 83, n. 11,p.1414-1430,2011.

56 SUN, H. W., AND Q. S. YAN. 'Influence of Pyrene Combination State in Soils on Its Treatment Efficiency by Fenton Oxidation', Journal of Environmental Management v. 88, n. 3, p.556-563, 2008.

57 FLOTRON, V., C. DELTEIL, Y. PADELLEC, AND V. CAMEL. 'Removal of Sorbed Polycyclic Aromatic Hydrocarbons from Soil, Sludge and Sediment Samples Using the Fenton's Reagent Process', Chemosphere v. 59, n. 10, 2005.

58 NETA,P.,MADHAVAN,V.,ZEMEL,H.,and FESSENDEN,R.W.Rate constants and mechanism of reaction of $\mathrm{SO}_{4}{ }^{-}$with aromatic compounds. Journal of the American Chemical Society, 163-164,1977.

59 NORMAN, R. O. C., P. M. STOREY, AND P. R. WEST. 'Electron Spin Resonance Studies .25. Reactions of Sulphate Radical Anion with Organic Compounds', Journal of the Chemical Society B-Physical Organic, n. 6, 1087, 1970.

60 OCAMPA, A.M. Persulfate activation by organic compounds. Tese de Doutorado. Engenharia Civil. Universidade do Estado de Washington EUA, 2009. 
61 PETRI,B.G.; WATTS, R.J. "Fundamentals of ISCO Using Persulfate” In: SIERGRIST, R.L., CRIMI, M. SIMPKIN, T.J. (Ed) “In Situ Chemical Oxidation for Groundwater Remediation"2011 p141-191.

62 BROWN,R.A and ROBISON, D., Response to naturally occurring organic material: permanganate versus persulfate, in: proceedings of the Fourth International Conference of remediation of chlorinated and recalcitrant compounds, 2004.

63 KOLTHOFF, I. M., AND I. K. MILLER. 'The Chemistry of Persulfate .1. The Kinetics and Mechanism of the Decomposition of the Persulfate Ion in Aqueous Medium', Journal of the American Chemical Society v. 73, n. 7, 1951.

64 KILLIAN, P. F., C. J. BRUELL, C. J. LIANG, AND M. C. MARLEY. 'Iron (II) Activated Persulfate Oxidation of MGP Contaminated Soil', Soil \& Sediment Contamination Vol. 16, No. 6, 523-537, 2007.

65 LIANG, C. J., C. J. BRUELL, M. C. MARLEY, AND K. L. SPERRY. 'Persulfate Oxidation for in Situ Remediation of TCE. II. Activated by Chelated Ferrous Ion', Chemosphere v.55, n. 9,p. 1225-1233, 2004.

66 BLOCK, P.A., BROWN, R.A., ROBISON D. Novel Activation Technologies for Sodium Persulfate in Situ Chemical Oxidation”. Proceedings of the Fourth International Conference on the Remediation of Chlorinated and Recalcitrant Compounds, Monterey Califórnia,2004.

67 TSITONAKI,A.,PETRI,B.,CRIMI,M.,MOSBAEK,H.,SIEGRIST,R.L.,BJERG,P.L. In situ chemical oxidationof contaminated soil and groundwater using persulfate: Review, Critical Reviews in Environmental Science and Technology v.40 n.1,2010.

68 BENNEDSEN, L. R., J. MUFF, AND E. G. SOGAARD E.G. 'Influence of Chloride and Carbonates on the Reactivity of Activated Persulfate', Chemosphere v. 86, n. 11,p. 10921097, 2012.

69 ANIPSITAKIS, G. P.; DIONYSIOU, D. D. Radical generation by the interaction of transition metals with common oxidants. Environmental Science \& Technology, v. 38, n. 13, p. 3705-3712, 2004.

70 CRIMI, M. L.; TAYLOR, J. Experimental evaluation of catalyzed hydrogen peroxide and sodium persulfate for destruction of BTEX contaminants. Soil \& Sediment Contamination, v. 16, n. 1, p. 29-45, 2007. 
71 YEN, C. H., K. F. CHEN, C. M. KAO, S. H. LIANG, AND T. Y. CHEN. 'Application of Persulfate to Remediate Petroleum Hydrocarbon-Contaminated Soil: Feasibility and Comparison with Common Oxidants', Journal of Hazardous Materials p.2097-2102,2011.

72 NADIM F., HUANG K., DAHMANI A. Remediation of Soil and Ground Water Contaminated with PAH Using Heat and Fe(II)-EDTA Catalyzed Persulfate Oxidation. Water, Air, and Soil Pollution,p.227-232,2006.

73 USMAN, M., P. FAURE, C. RUBY, AND K. HANNA. 'Application of MagnetiteActivated Persulfate Oxidation for the Degradation of Pahs in Contaminated Soils',

Chemosphere v. 87, n. 3, 2012.

74 FONTANA,A.; PEREIRA,M.G.Anjos,L.H.C.;Benites,V.M. Quantificação e utilização das frações húmicas como característica diferencial em horizontes diagnósticos de solos. Revista Brasileirade Ciência de Solo, v.34,p.1241-1257. 2010.

75 USEPA - United States Environmental Protection Agency. USEPA SW 846 Method 3545 Pressurized Fluid Extraction (2007).

76 USEPA - United States Environmental Protection Agency. USEPA SW 846 Method 8270B - Semivolatile organic compounds by gas chromatography/ mass spectrometry (GC/MS) (2007).

77 Standard Method $4500 \mathrm{KMnO}$. Disponível em <.http://www.water800.com/jcff/waw/waw16.pdf > Acesso em 10 de julho de 2013.

78 Empresa Brasileira de Pesquisa Agropecuária -EMBRAPA. Manual de métodos de análise do solo. Embrapa Solos. Rio de Janeiro.2011, 225 p.

79 BENITES, V. M.; MADARI, B.; MACHADO, P. L. O. A. Extração e fracionamento quantitativo de substâncias húmicas do solo: um procedimento simplificado de baixo custo. Rio de Janeiro: Embrapa Solos 2003.13 p.

80 YEOMANS, J.C. \& BREMNER, J.M. A rapid and precise method for routine determination of organic carbon in soil. Communications ins soil science and plant analysis., v. 19,p.1467-1476, 1988.

81 LAU.E.V.,GAN,S.,NG,H.K. Extraction Techniques for polycyclic aromatic hydrocarbons in soils. International Journal of Analytical Chemistryp v.2010,p.9 , 2010 
82 BERSET, J. D., M. EJEM, R. HOLZER, AND P. LISCHER. 'Comparison of Different Drying, Extraction and Detection Techniques for the Determination of Priority Polycyclic Aromatic Hydrocarbons in Background Contaminated Soil Samples', Analytica Chemical Acta v.383, n. 3, p.263-275, 1999.

83 ENELL A, REICHENBERG F, WARFVINGE P, EWALD, G. A column method for determination of leaching of polycyclic aromatic hydrocarbons from aged contaminated soils. Chemosphere v.54,p.707-715,2004.

84 RICHTER, B.E. Extraction of hidrocarbon contamination from soils using accelerated solvent extraction. Journal of Chromatography A, v.874,p. 217-224,2000.

85 RICHTER, B. E., B. A. JONES, J. L. EZZELL, N. L. PORTER, N. AVDALOVIC, AND C. POHL. 'Accelerated Solvent Extraction: A Technique for Sample Preparation', Analytical Chemistry v. 68, n. 6, p.1033-1039, 1996.

86 SAIM,N.A.,DEAN,J.R.,ABDULLAH,M.P.,ZAKARIA,Z.Extraction of polycyclic aromatic hydrocarbons from contaminated soil using Soxhlet extraction, pressurized and atmospheric microwave-assisted extraction, supercritical fluid extraction and accelerated solvent extraction, Journal of Chromatography A,v.719, p.361-366 1997.

87 USEPA - United States Environmental Protection Agency. USEPA SW 846 Method 3500Organic Extraction and sample preparation - (2007).

88 MURPHY,E.M., ZACHARA,J.M.,SMITH,S.C., Influence of mineral bound humic substances on the sorption of hydrophobic organic compounds. Environmental Science \& Tecnology, v.24, p.1507-1516,1990.

89 KARICKHOFF,S.W. Semiempirical estimation of sorption of hidrophobic pollutants on natural sediments and soil. Chemosphere v.10,p.833-846,1981.

90 GUTMAN,I.,STANKOVIC,S. Why phenanthrene more stable than anthracene?, Macedonian Journal of Chemistry and Chemical Engineering, v. 26, n. 2, p. 111$114,2007$.

91 TANG, W.Z.HUANG,C.P. 2,4 -dichlorophenol oxidation kinetics by Fenton reagent. Environmental Technology1 v.7,p.1371-1377,1996. 
92GEORGIA,A.,SCHIERZ,A.,TROMMLER,U.,HORWITZ,C.P.,COLLINS,T.J.,KOPINKE, F.D., Humic acid modified Fenton reagent for enhancement of the working $\mathrm{pH}$ range, Applied Catalysis B; Environmental 72(2007) 26-36.

93 LINDSEY, M. E., AND M. A. TARR. 'Inhibition of Hydroxyl Radical Reaction with Aromatics by Dissolved Natural Organic Matter', Environmental Science \& Technology v.34, n 3, p.444-449, 2000.

94 WATTS, R. J., P. C., STANTON, J.,HOWSAWKENG, AND A. L. TEEL. 'Mineralization of a Sorbed Polycyclic Aromatic Hydrocarbon in Two Soils Using Catalyzed Hydrogen Peroxide', Water Research Vol. 36, nº 17, 2002.

95 BOGAN, B. W., AND V. TRBOVIC. 'Effect of Sequestration on PAH Degradability with Fenton's Reagent: Roles of Total Organic Carbon, Humin, and Soil Porosity', Journal of Hazardous Materials v. 100, p. 1-3, 2003.

96 FURMAN, O. S., A. L. TEEL, M. AHMAD, M. C. MERKER, AND R. J. WATTS. 'Effect of Basicity on Persulfate Reactivity', Journal of Environmental Engineering-Asce v. 137, n. 4, p.241-247, 2011.

97 FORSEY,S.P, 2004. In situ chemical oxidation of creosote/ coal tar residuals: experimental and numerical investigation. PhDthesis, University of Waterloo Canadá.

98 TSITONAKI, A., SMETS, B.F., BJERG, P.J.The effects of heat-activated persulfate oxidation on soil microorganisms. Water Research .v.42, p.1013-1022, 2008.

99 USMAN, M., P. FAURE, C. RUBY, AND K. HANNA. 'Application of MagnetiteActivated Persulfate Oxidation for the Degradation of Pahs in Contaminated Soils', Chemosphere v. 87, n. 3, 2012.

100 NETA,P.,MADHAVAN,V.,ZEMEL,H.,and FESSENDEN,R.W.Rate constants and mechanism of reaction of $\mathrm{SO}_{4}{ }^{-}$with aromatic compounds. Journal of the American Chemical Society,p.163-164,1977.

101 LEE, B. D., HOSOMI, M.,MURAKAMI, A. Fenton oxidation with ethanol to degrade anthracene into biodegradable 9,10-anthraquinon: A pretreatment method for anthracenecontaminated soil. Water Science and Technology, v. 38, n. 7, 1998. 
102 LEE, B.D., HOSOMI, M.,. A hybrid Fenton oxidation-microbial treatment for soil highly contaminated with benz(a)anthracene. Chemosphere 43, 1127-1132 2001a.

103 BELTRAN, F. J., M. GONZALEZ, F. J. RIVAS, AND P. ALVAREZ. 'Fenton Reagent Advanced Oxidation of Polynuclear Aromatic Hydrocarbons in Water', Water Air and Soil Pollution Vol. 105, nº. 3-4, 685-700, 1998.

104 ANANTHULA, R.,YAMADA,T.,TAYLOR,P.H. Kinetics of OH Radical reaction with phenanthrene: new absolute rate measurements and comparison with other PAH. International Journal of Chemical Kinetics ,2007

105 WANG D.,YIFAN, L.,YANG,M.HAN,M.,Decomposition of polycyclic aromatic hydrocarbons in atmospheric aqueous droplets throughsulfate anion radicals: An experimental and theoretical study. Science of the total environment 393 64-71,2008.

106 B. Pal, M. Sharon, Photodegradation of polyaromatic hydrocarbons over thin film of $\mathrm{TiO} 2$ nanoparticles; a study of intermediate photoproducts, Journal of Molecular Catalysis. A: Chemical. V.160,453-460,2000.

107 USEPA - United States Environmental Protection Agency. USEPA SW 846 Method 3051 A - Microwave assited acid digestion of sediment sludges, soils and oils (2007).

108 USEPA - United States Environmental Protection Agency. USEPA SW 846 Method 6020- Inductively coupled plasma mass spectrometry (2007).

109 CHIN, Y. P., G. R. AIKEN, AND K. M. DANIELSEN. 'Binding of Pyrene to Aquatic and Commercial Humic Substances: The Role of Molecular Weight and Aromaticity', Environmental Science \& Technology Vol. 31, No. 6, 1630-1635, 1997.

110 SCHULTEN, H. R., AND P. LEINWEBER. 'Characterization of Humic and Soil Particles by Analytical Pyrolysis and Computer Modeling', Journal of Analytical and Applied Pyrolysis Vol. 38, 1-53, 1996.

111 LINDSEY, M. E., AND M. A. TARR 'Inhibition of Hydroxyl Radical Reaction with Aromatics by Dissolved Natural Organic Matter', Environmental Science \& Technology Vol. 34, No. 3, 444-449, 2000.

112 GARA, P. M. D., BOSIO,G.N. MONICA C. GONZALEZ,M.C.; AND MARTIRE,D.R. 'Kinetics of the Sulfate Radical-Mediated Photor-Oxidation of Humic Substances', International Journal of Chemical Kinetics Vol. 40, $\mathrm{n}^{\circ} .1,2008$. 
113 WATTS,R.J. .Enhanced Reactant-Contaminant Contact through the Use of Persulfate In Situ ChemicalOxidation (ISCO). SERDP Project ER-1489, 2011290 p.

114 AHMAD,M.TEEL,A.L.,WATTS R.J. "Persulfate activation by subsurface mineral" Journal of Contaminant Hydrology vol 115, 2010.

115 KANWARTEJ, S. "Persulfate persistence and treayability of gasoline compounds, $\mathrm{Ph} \mathrm{D}$. thesis, University of Waterloo, ON, Canada, 171 pp, 2010.

116 SUN, H.W, AND YAN,Q.S. Influence of Fenton Oxidation on Soil Organic Matter and Its Sorption and Desorption of Pyrene, Journal of Hazardous Materials Vol. 144, No. 1-2, 2007. 